Tetrahedron report 1171

\title{
Recent advances in the asymmetric catalytic synthesis of chiral 3-hydroxy and 3-aminooxindoles and derivatives: Medicinally relevant compounds
}

\author{
Pedro Brandão ${ }^{\mathrm{a}, \mathrm{b}, * *}$, Anthony J. Burke ${ }^{\mathrm{b}, \mathrm{c}, *}$ \\ ${ }^{\text {a }}$ CQC and Department of Chemistry, University of Coimbra, Rua Larga, 3004-535 Coimbra, Portugal \\ ${ }^{\mathrm{b}}$ Centro de Química de Évora, Institute for Research and Advanced Studies, University of Évora, Rua Romão Ramalho, 7000 Évora, Portugal \\ ${ }^{c}$ Department of Chemistry, School of Science and Technology, University of Évora, Rua Romão Ramalho, 7000 Évora, Portugal
}

\section{A R T I C L E I N F O}

\section{Article history:}

Received 29 March 2018

Received in revised form

1 June 2018

Accepted 5 June 2018

Available online 11 June 2018

\section{Keywords:}

3-Hydroxyoxindole

3-Aminooxindole

Asymmetric catalysis

Organocatalysis

\begin{abstract}
A B S T R A C $T$
Several oxindole derivatives, of natural or synthetic origin, have been identified as medicinally appealing compounds, with a plethora of bioactivities reported. Chiral 3-hydroxy and 3-aminooxindole scaffolds have captured the attention of several research groups, due to their importance in drug discovery. In this review, we systematically address the wide variety of asymmetric catalytic methodologies employed in the preparation of these relevant chiral scaffolds, present in many biologically active compounds and/or natural products. Special focus will be given to the nature of the catalyst used.
\end{abstract}

(c) 2018 Elsevier Ltd. All rights reserved.

\section{Contents}

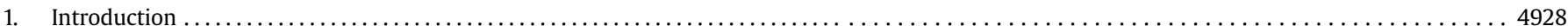

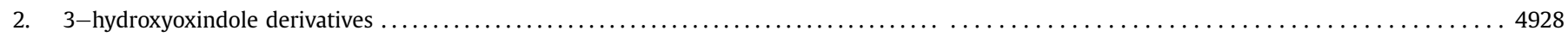

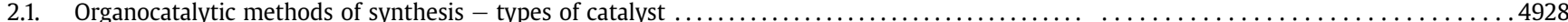

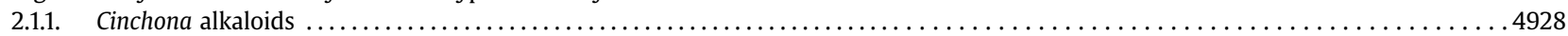

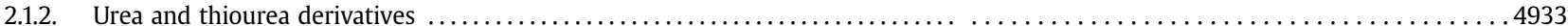

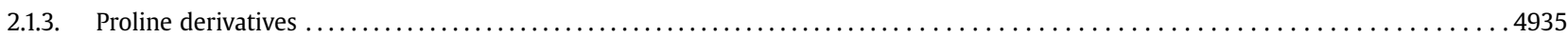

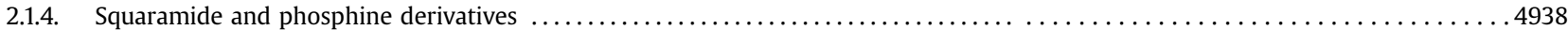

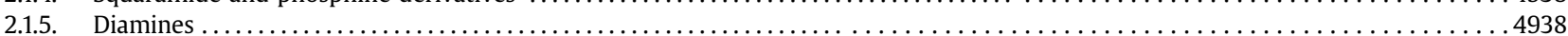

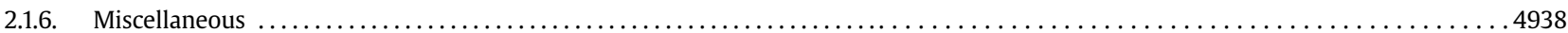

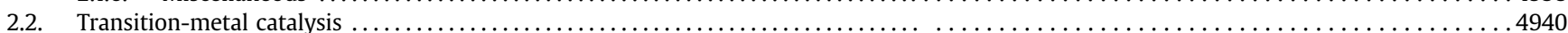

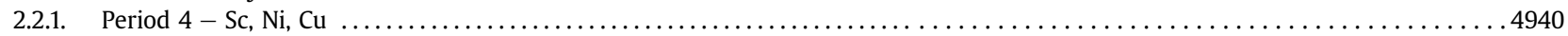

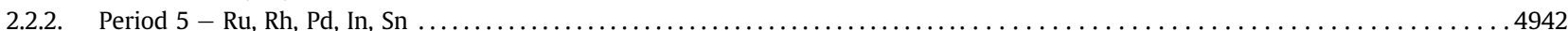

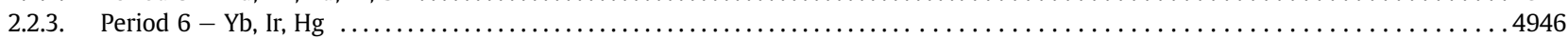

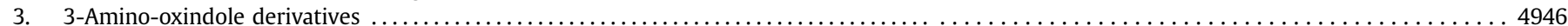

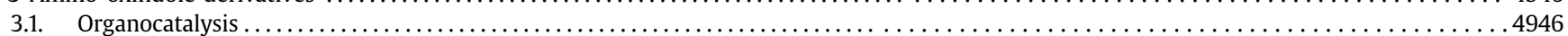

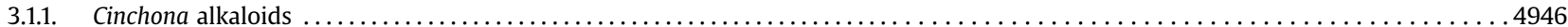

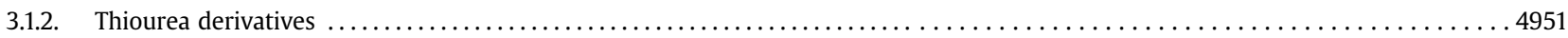

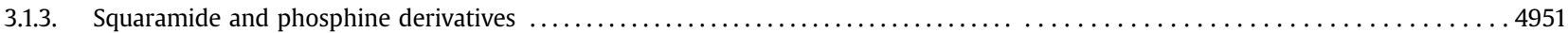

\footnotetext{
* Corresponding author. Centro de Química de Évora, Institute for Research and Advanced Studies, University of Évora, Rua Romão Ramalho, 7000 Évora, Portugal.

** Corresponding author. CQC and Department of Chemistry, University of Coimbra, Rua Larga, 3004-535 Coimbra, Portugal.

E-mail address: ajb@uevora.pt (A.J. Burke).
} 


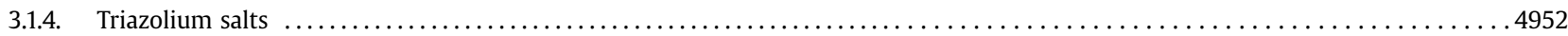

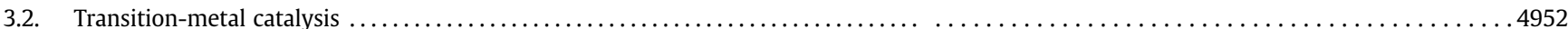

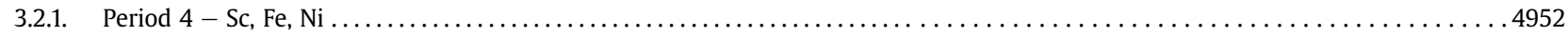

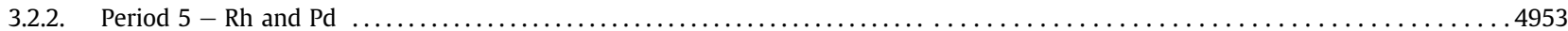

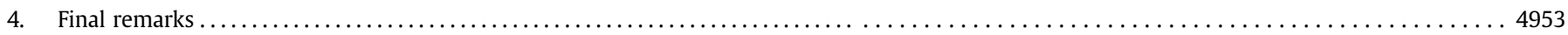

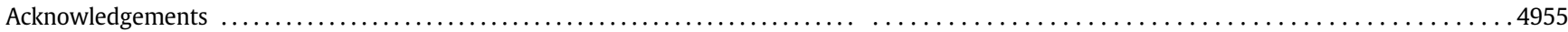

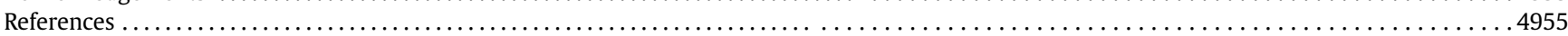

\section{Introduction}

The oxindole scaffold (chemically named 1,3-dihydro-2Hindole-2-one) is a valuable motif in several fields of Chemistry, but particularly in Organic Chemistry and Medicinal Chemistry, since it is present in a wide variety of natural products and synthetic compounds that present interesting bioactivities [1]. The presence of stereocenters can be crucial for the bioactivity, pharmacokinetic profile and even environmental impact of molecules with interesting medicinal applications [2-5].

From the synthetic point of view, the preparation of chiral bioactive compounds, from new molecular entities to the total synthesis of known natural products, can be quite challenging to organic chemists. Enantiomeric separation of racemic mixtures or kinetic resolution many times is not desired nor profitable and thus asymmetric synthesis became the focus for many research groups involved in organic synthesis and medicinal chemistry [6,7]. Asymmetric catalytic methods, namely those based on the use of chiral organocatalysts or chiral metal-based complexes to prepare molecules in the enantiomerically pure form has become a recurrent topic in the scientific literature [8-10]. In the current literature, we found reports of 3-hydroxy-oxindoles showing a plethora of potential medicinal applications, including anti-tumor [11-13], monoamine oxidase inhibition [14], anti-HIV [15], antioxidant [16,17] and antimicrobial activities [17]. Some of these reactions were conducted using green synthetic methods, but without any chiral catalysts. However, further studies are required to determine the impact of the configuration of its stereogenic center on the bioactivity of these molecules.

Due to the relevance of the oxindole scaffold in Medicinal Chemistry and the bioactivity presented by several chiral 3,3disubstituted-oxindole derivatives, several recent review publications have appeared in the literature, that range from the bioactivity of chiral spirooxindole compounds $[18,19]$ to the asymmetric catalytic preparation of chiral 3,3-disubstituted-oxindole derivatives [20-24]. Indolin-2,3-dione, commonly known as isatin, is quite often used as starting material for such synthetic modifications [25-29]. Natural and synthetic spirooxindoles are of major interest in the fields of Organic and Medicinal Chemistry due to their wide range of biological applications [30-36]. However, there is very little focus on this family of oxindoles in this review, particularly as their asymmetric catalytic synthesis was recently comprehensively reviewed [37].

In this review, attention will be given to the current state of the art of the asymmetric synthesis of 3-hydroxy and 3-aminooxindole derivatives. Since there are several reviews published on the type of reaction for the synthesis of these compounds [38-41], we decided to organize this review according to the type of catalyst used. Furthermore, in this review we explore the synthesis of 3-hydroxy and 3-aminooxindole derivatives that have or exhibit potential medicinal properties and that have appeared in the literature over the last 10 years.

\section{3-hydroxyoxindole derivatives}

Nature has been the source of biologically active compounds for millenia, many of them bearing one or more stereocenters. Among these, some chiral 3-hydroxy-oxindole derivatives surfaced as relevant molecules in the field of Medicinal Chemistry (Fig. 1). TMC95A, isolated from the ascomycete fungus Apiospora montagnei, presented 20S proteasome inhibition activity [42,43]. Another natural product, 3-hydroxy- $N$-methylwelwitindolinone $\mathrm{C}$ isothiocyanate, identified in marine cyanobacteria, belongs to a family of alkaloids with a broad spectrum of biological activities, including antifungal, insecticidal, and antitumor, due to its ability to inhibit multidrug resistance targets and tubulin polymerization [44-46]. Maremycins are a group of compounds isolated from Streptomyces sp. bearing the 3-substituted-3-hydroxy-2-oxindole structural motif. Maremycins B and C present slight cytotoxicity towards some tumor cell lines [47]. The total synthesis of this group of compounds and their derivatives remains a very interesting challenge for organic and medicinal chemists, as we will see later on in this review.

In the case of maremycins, although the total syntheses of these compounds have been described in the literature, in most cases a diastereoselective protocol was investigated with no asymmetric catalysis. An exception is the synthesis of maremycin A reported by Bergonzini and Melchiore. Using a 3-hydroxy-oxindole scaffold enantioenriched spirooxindoles were prepared using a chiral organocatalyst and further reaction steps led to the desired natural product, as shown in Scheme 1 [48].

\subsection{Organocatalytic methods of synthesis - types of catalyst}

\subsubsection{Cinchona alkaloids}

Cinchona alkaloids are natural products that have been widely studied as asymmetric organocatalysts, as reviewed in the literature [49-52].

One example, reported by Sano et al., consisted of the use of this type of catalyst for the asymmetric hydroxylation of oxindoles. Using oxygen as a benign and environmentally friendly oxidant, they prepared a library of 3-hydroxyoxindole derivatives in high yields and enantioselectivities using a cinchonidine-based chiralphase transfer catalyst ( $\mathrm{C} 1$ - Scheme 2) in the presence of a base $(\mathrm{KOH})$ [53]. Liao et al. applied a different hydroxylating agent (aromatic oximes) for the production of enantioenriched 3,3disubstituted oxindoles in the presence of $\mathrm{K}_{2} \mathrm{CO}_{3}$ and the cinchona alkaloid derivative C2 (Scheme 2) under mild conditions [54].

Chauhan et al. prepared a library of 3-indole-3hydroxyoxindoles using a highly enantioselective Friedel-Craftstype addition of indole to isatin, in the presence of catalyst C3 Scheme 3 a) [55]. A similar library was prepared using the same type of reaction with a slightly higher catalyst loading $(20 \mathrm{~mol} \%$ compared to $15 \mathrm{~mol} \%$ in the previous) and in a different solvent (1,4-dioxane instead of THF) [56] (catalyst C4 - (Scheme 3 b)). Kaur 
<smiles>C/C=C\NC(=O)[C@H](NC(=O)C(CC(N)=O)NC(=O)[C@H](Cc1ccc(O)c(-c2cccc3c2NC(=O)[C@]3(O)C(O)[C@H](O)NC(=O)C(=O)[C@H](C)CC)c1)NC(=O)C(=O)N[C@@H](C)CC)C(=O)N[C@@H](C)CC</smiles>

TMC-95A<smiles>C=C[C@]1(C)C(Cl)=C[C@H](C(C)(C)C)[C@]2(O)C(=O)N(C)c3cccc(c32)C1(C)[N+](=O)[O-]</smiles>

3-Hydroxy- $\mathrm{N}$-methylwelwitindolinone C isothiocyanate<smiles>[R]C1(C(C)C2NC(=O)C(CSC)NC2=O)C(=O)N(C)c2ccccc21</smiles>

Maremycin A $(\mathbf{R}=\cdots \cdots+\mathrm{OH})$ Maremycin B $(\mathrm{R}=-\mathrm{OH})$<smiles>[R][S+](C)CC1NC(=O)[C@H]([C@H](C)[C@]2(O)C(=O)N(C)c3ccccc32)NC1=O</smiles>

Maremycin $\mathrm{C}_{1}\left(\mathrm{R}=\cdots \cdot \mathrm{O}^{-}\right)$ Maremycin $C_{2}\left(R=-O^{-}\right)$<smiles>[R]C1([C@@H](C)[C@H]2NC(=O)C(=C)NC2=O)C(=O)N(C)c2ccccc21</smiles>

Maremycin $\mathbf{D}_{1}(\mathbf{R}=\cdots \cdot \mathrm{OH})$

Fig. 1. Relevant bioactive compounds bearing the chiral 3-hydroxyoxindole structural motif.
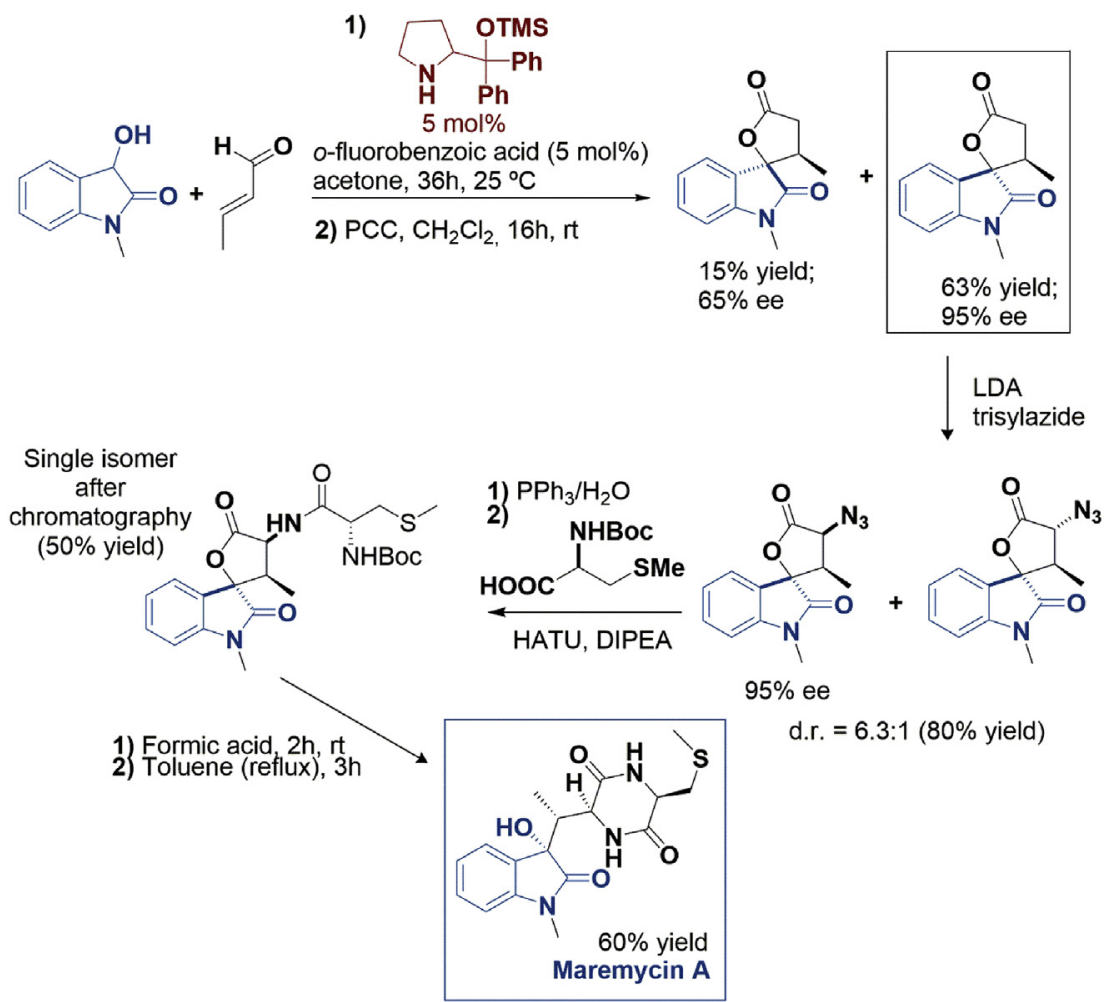

Scheme 1. Total synthesis of maremycin A via enantioselective spirooxindole formation.

et al. used catalyst C5 (10 mol\%) for the preparation of 3-aryl-3hydroxy-2-oxindoles. They reported two libraries of compounds using this cinchonidine-thiourea organocatalyst, one with the addition of 1-naphthols, the other with the addition of phenols to isatin derivatives (Scheme $3 \mathrm{c}$ ) and d)) [57,58]. The enantioselective Friedel-Crafts alkylation of isatin derivatives and 1-naphthols was also studied by Wu et al., using the organocatalyst $\mathbf{C 6}$ (Scheme 3 e)).
The authors also mentioned that the presence of a substituent with a lone pair of electrons (such as 4-MeO or $\mathrm{Cl}$ ) in the 1-naphthol moiety of the 3-(naphthalene-2-yl)-3-hydroxy-2-oxindoles, could lead to a spontaneous dehydration process, with formation of a double bond [59].

Using $N$-protected isatin derivatives as starting materials and reacting them with acrylates via a Morita-Baylis-Hillman reaction, 

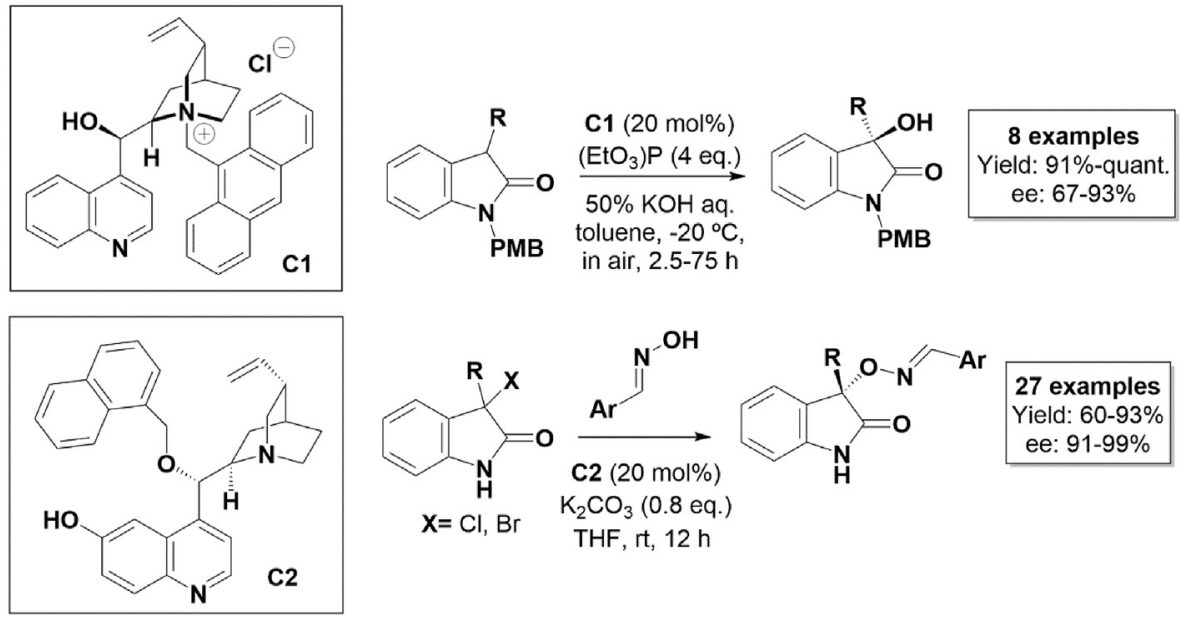

Scheme 2. Hydroxylation reactions using cinchona alkaloid-based chiral catalysts.

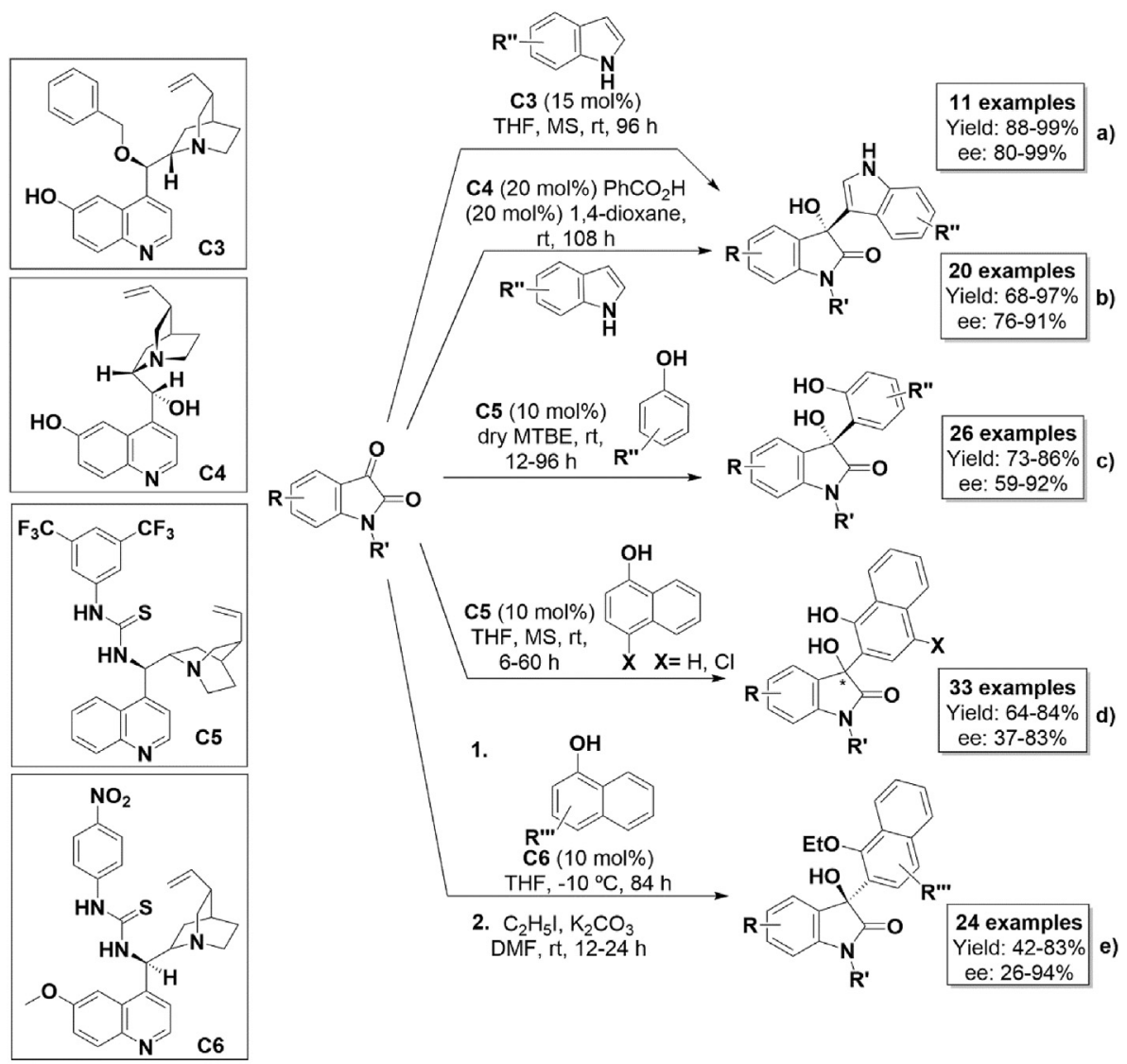

*absolute configuration not reported

Scheme 3. Friedel-Crafts reactions using cinchona alkaloid-based asymmetric catalysts.

Guan et al. synthesized a library of twenty two 3-substituted-3hydroxyoxindole derivatives using catalyst C7 (Scheme 4 a); $10 \mathrm{~mol} \%$ ), the products were obtained with moderate to excellent yields and very good enantioselectivities [60]. Similar results were achieved with the same catalyst by Zhoung et al., and their studies showed that the $\mathrm{C6}^{\prime}-\mathrm{OH}$ group participates in an intramolecular proton relay process, hence facilitating the proton transfer step of the catalytic process (Scheme $4 \mathrm{~b}$ ) [61]. The same catalyst was employed in the reaction between isatin derivatives (and $\mathrm{N}$-protected isatin derivatives) with acrolein as the nucleophile with excellent results (Scheme $4 \mathrm{c}$ ) [62]. In another example, the same catalyst C7 ( $\beta$-isocupreidine) was employed in the asymmetric reaction between $N$-protected isatin derivatives and maleimides with very good results (Scheme $4 \mathrm{~d}$ ) [63].

In order to expand the scaffold diversity of this type of compound, a similar approach was reported recently, applying the same 


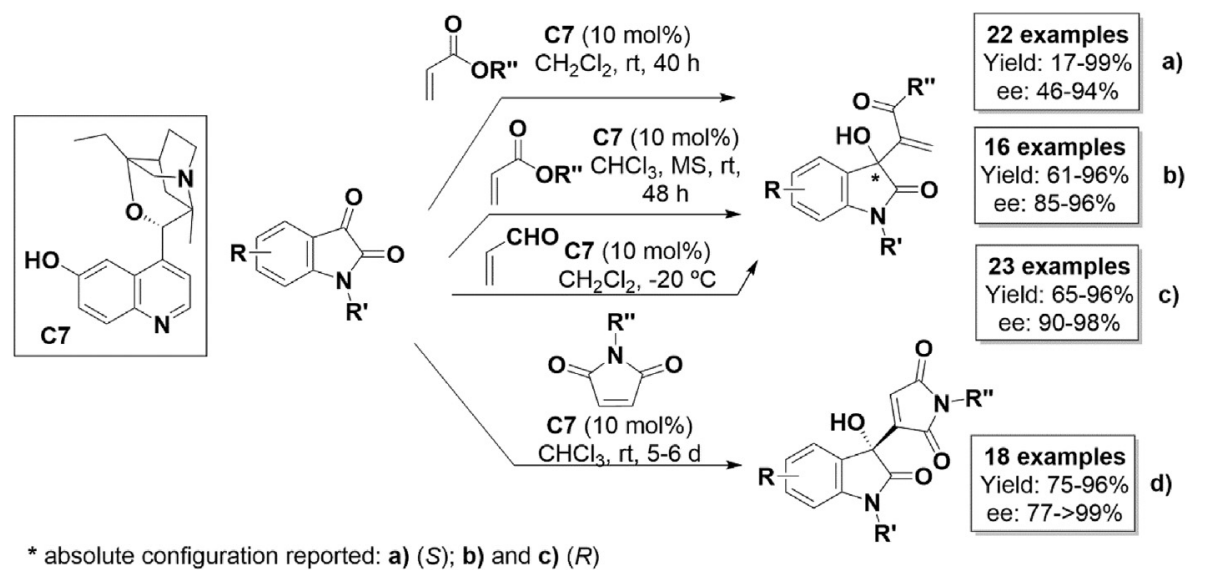

Scheme 4. Morita-Baylis-Hillman reactions using a cinchona alkaloid-based asymmetric catalyst.

organocatalyst, and using 7-azaisatin derivatives as the starting material (Scheme 5) [64]. It was found that 7-azaisatins showed better reactivity as electrophiles than the analogous isatins, affording the corresponding 3-hydroxy-7-aza-2-oxindole derivatives in moderate to good yields and good enantioselectivities [64].

The enantioselective aldol reaction is a powerful method for the introduction of $\mathrm{C}-\mathrm{C}$ bonds for the synthesis of enantiopure compounds. A quinidine-thiourea catalyst (C8 - Scheme 6 a) $-10 \mathrm{~mol}$ \%) was used to prepare 3-alkyl-3-hydroxyoxindole derivatives in very good to excellent yields and enantioselectivities [65]. Similarly, a cinchonidine-based urea catalyst (C9 - Scheme 6 b) $20 \mathrm{~mol} \%$ ) was applied with the objective of reacting isatin with several unactivated ketones, resulting in the formation of 3substituted-3-hydroxyoxindole derivatives (24 examples) in high yields and enantioselectivities [66]. In another example, the same kind of reaction was explored, this time in the preparation of 3- $(2 \mathrm{H}-$ chromen-2-one)-3-hydroxyoxindole derivatives, using isatin and 3-acetyl-2H-chromen-2-ones as starting materials and a quinidineurea bifunctional catalyst (C10 - Scheme 6 c)) [67]. Aldol adducts were also synthesized in moderate to good yields and enantioselectivities using isatin derivatives and $\alpha, \beta$-unsaturated ketones as starting materials, in the presence of the quinidine-thiourea organocatalyst C8 and its epimer C11 (Scheme 6 d)) [68].

The organocatalyst $\mathbf{c 8}$ (Scheme 6) was also applied in the decarboxylative aldol addition of trifluoromethyl $\boldsymbol{\alpha}$-fluorinated gem-diols to $\mathrm{N}$-benzyl isatin derivatives, with the desired products being obtained in almost quantitative yields and high enantioselectivities, showing the versatility of this organocatalyst in the synthesis of chiral fluorinated molecules (Scheme 7) [69].

In another example, a regioselective-reversed asymmetric aldol reaction was reported, using a cinchonidine-thiourea bifunctional organocatalyst (C5 - Scheme 8 a)). The aldol adducts were prepared from the reaction between isatin derivatives and 1,3- dicarbonyl compounds, in moderate to high yields and enantioselectivities [70]. The same catalyst was applied in the decarboxylative addition of $\beta$-ketoacids to $N$-protected isatin derivatives with very good yields and enantioselectivities (Scheme 8 b)) [71].

The catalyst 9-amino-(9-deoxy)-epi-cinchonidine and its pseudo-enantiomer (10 mol\%; catalysts C12 and C13 - Scheme 9) were applied in the asymmetric direct aldol reaction of isatin derivatives with pyruvic aldehyde dimethyl acetal, using trichloroacetic acid (TCA) as additive, providing both enantiomers of the 3hydroxy-3-substituted-oxindole. It was catalyst C12 that afforded the $R$-enantiomer, while the $S$-enantiomer was obtained using catalyst C13, with very good to excellent yields and enantiomeric purities [72].

A different approach was used by Hara et al., using a squaramide-quinine catalyst (C14 - Scheme 10) to promote a decarboxylative aldol reaction of isatin with malonic acid halfthioesters. Both high yields and high enantioselectivities were achieved, although the enantioselectivity was highly dependent on the catalyst load and on the starting material substitution pattern [73].

Cinchona alkaloids were also tested to perform enantioselective phospho-aldol reactions between diphenyl phosphites and $\mathrm{N}$ alkylated isatin derivatives. The best results were achieved using quinine as the organocatalyst (C15 - Scheme 11) and the final 3hydroxy disubstituted products were obtained in good to excellent yields and low to moderate enantioselectivities. The reaction was complete in one hour when $20 \mathrm{~mol} \%$ of catalyst was used [74].

The nitroaldol reaction, also known as the Henry reaction, involves the use of nitroalkanes (e.g. nitromethane). Li et al. [75]. used this reaction with isatin derivatives in the presence of catalyst $\mathbf{C 3}$ (10 mol\%), a library of 3-hydroxy-3-nitromethyloxindole derivatives was obtained, with the $\mathrm{C}^{\prime}$ - $\mathrm{OH}$ group and the quinuclidine scaffold of the catalyst playing a major role in the asymmetric induction of the reaction (Scheme 12 a)). That same year, another

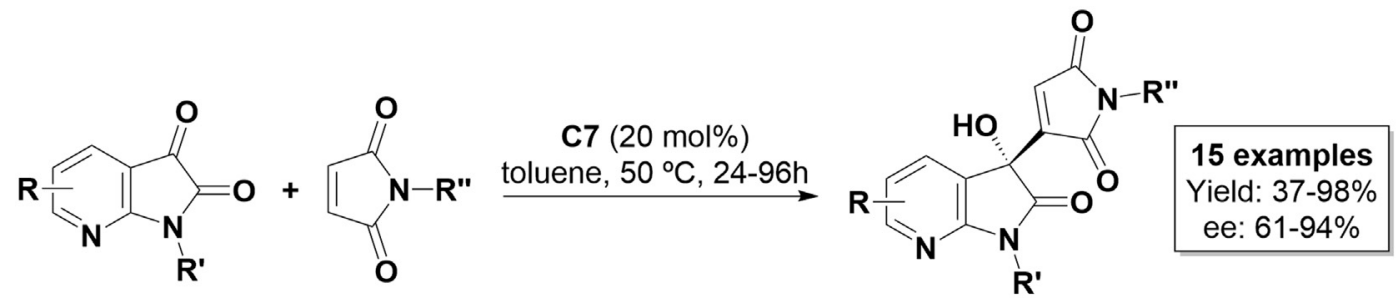

Scheme 5. Morita-Baylis-Hillman reaction using 7-azaisatins as substrates and a cinchona alkaloid-based asymmetric catalyst. 

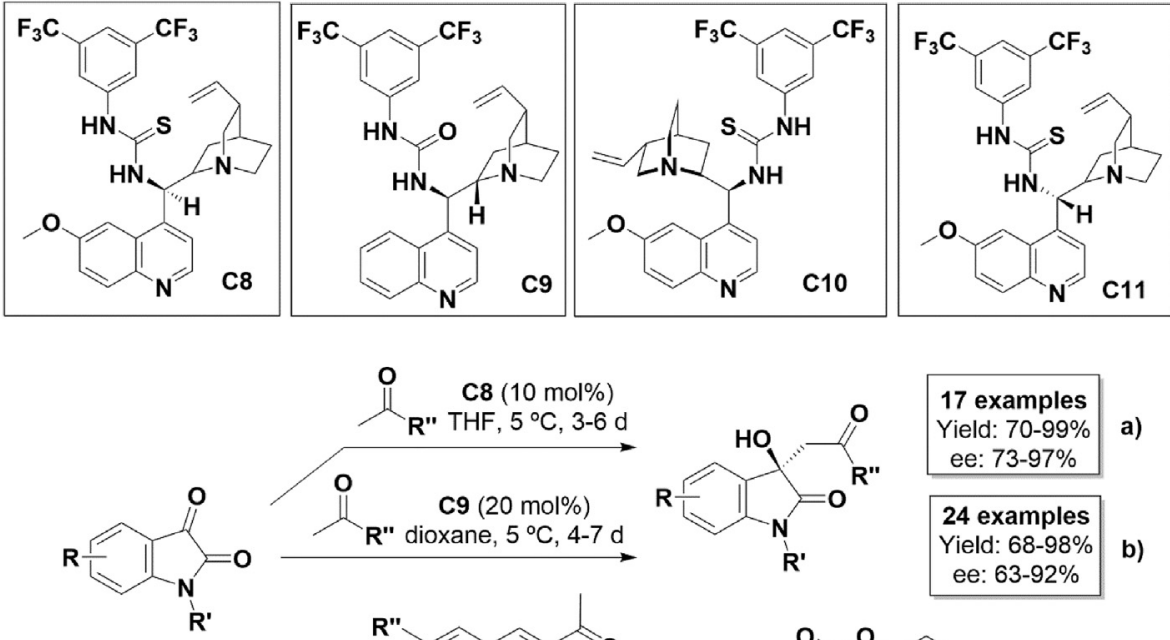

R" THF, $5^{\circ} \mathrm{C}, 3-6 \mathrm{~d}$

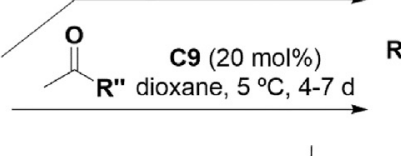

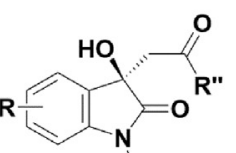

17 examples Yield: $70-99 \%$ a) ee: $73-97 \%$

24 examples Yield: $68-98 \%$ b) R" '́' ee: $63-92 \%$

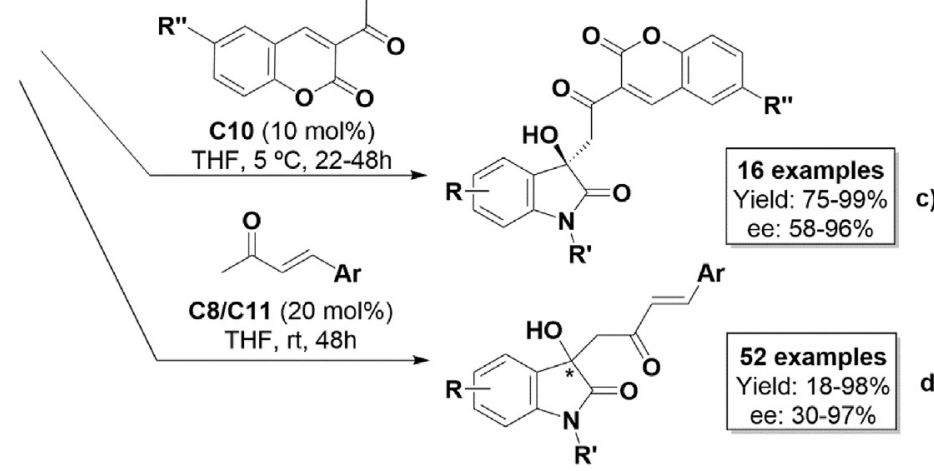

* absolute configuration reported: $(R)$ when using catalyst $\mathbf{C} 8$ and $(S)$ for catalyst $\mathbf{C} 11$

Scheme 6. Aldol reactions using isatin as substrates and cinchona alkaloid-based asymmetric catalysts.

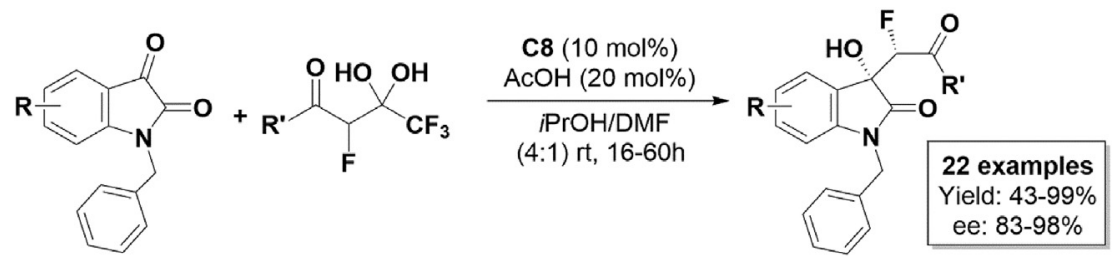

Scheme 7. Aldol addition of trifluoromethyl $\alpha$-fluorinated gem-diols to $N$-benzyl isatins.<smiles>[R]C(=O)CC(C)=O</smiles>

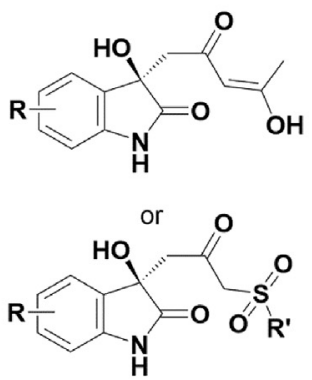

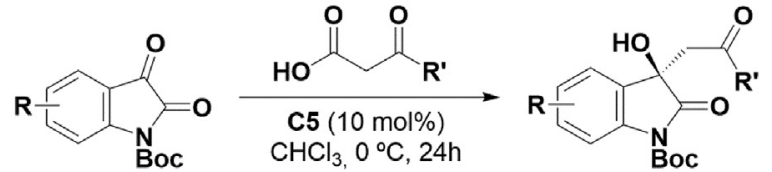




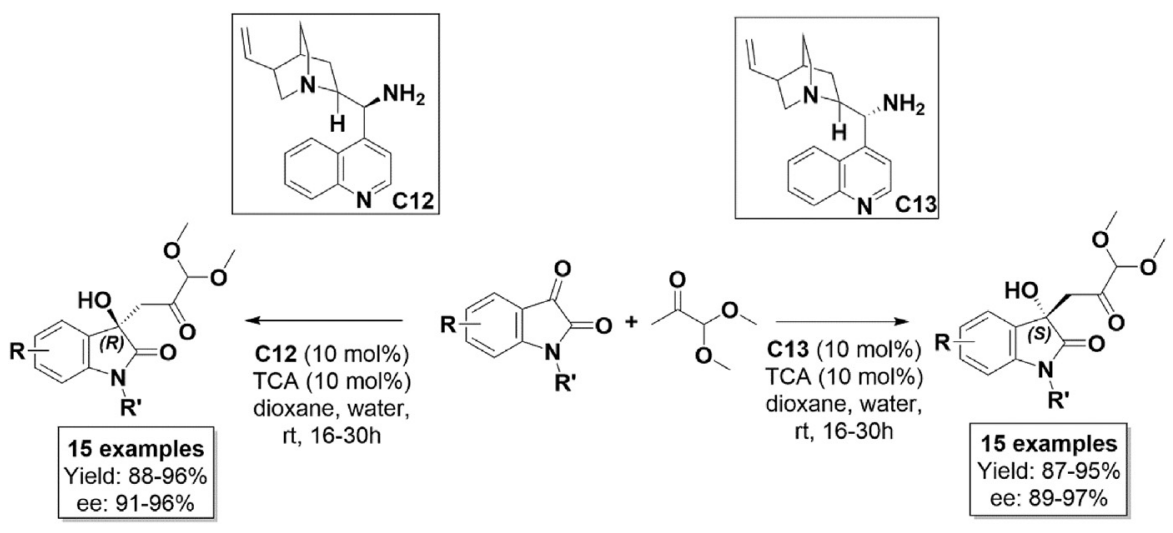

Scheme 9. Direct aldol reaction of pyruvic aldehyde dimethyl acetal with isatin derivatives.

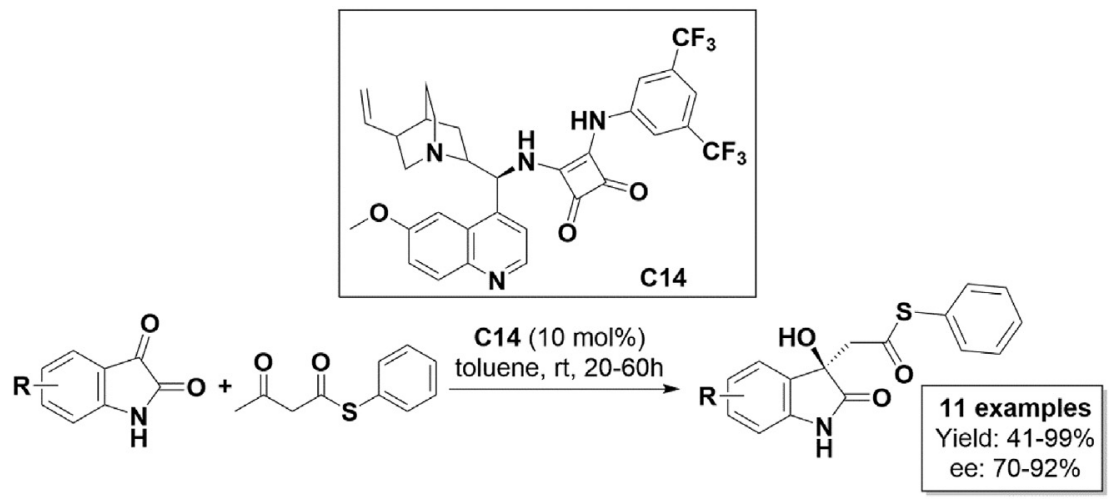

Scheme 10. Decarboxylative aldol reaction of isatin with malonic acid half-thioesters.

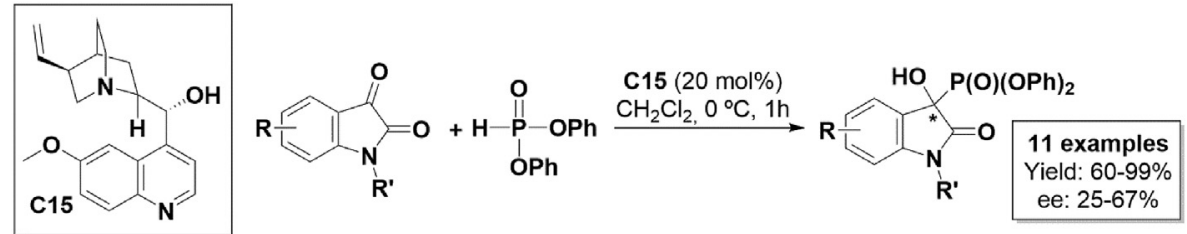

* absolute configuration not reported.

Scheme 11. Phospho-aldol reaction of isatin derivatives with diphenyl phosphites.

group reported the study of the Henry reaction using the same type of reactants, however they applied a different catalyst (the biscinchona alkaloid C16 - Scheme 12 b)). The use of a bis-cinchona alkaloid as the organocatalyst allowed not only a reduction of the catalyst loading (to $4 \mathrm{~mol} \%$, which can be considered a low catalyst load in the field of organocatalysis where $20 \mathrm{~mol} \%$ loading is generally the norm)), but also a remarkable reduction of the reaction time (from 4 to 5 days to $<14 \mathrm{~h}$ ) [76]. Another quinidine-based organocatalyst (C17 - Scheme 12 c)) was also reported for the nitroaldol reaction with isatin derivatives [77].

Recently, an example of the asymmetric organocatalytic Wittig $[2,3]$-rearrangement of oxindoles was reported. Using organocatalyst C14 (20 mol\%), 3-cinnamyloxyoxindole derivatives were converted to 3-substituted-3-hydroxyoxindoles in very high yields and enantioselectivities. Despite the low diastereoselectivity of the reaction, the isomers could be separated by chromatography, allowing their isolation and characterization (Scheme 13) [78].

\subsubsection{Urea and thiourea derivatives}

In the examples previously mentioned, several of the organocatalysts were based on bifunctional cinchona alkaloid-(thio)urea structures (catalysts C5, C6 and C8-C11).

However, instead of cinchona alkaloids, other amines can be combined with the (thio)urea scaffold to develop efficient organocatalysts, as can be found in several review publications [79-82]. This family of catalysts has been employed in the synthesis of chiral 3-hydroxy-oxindole derivatives.

In one example, reported by Retini et al., the reduced form of isatin dioxindole and dioxindole derivatives were converted to 3substituted-3-hydroxy-oxindoles through a 1,3-addition to nitroalkenes. On using catalyst $\mathbf{C 1 8}(20 \mathrm{~mol} \%)$ the desired products (14 examples) were obtained with moderate to very good yields and enantiomeric excesses (Scheme 14) [83].

This family of catalysts has also been useful in different aldol reactions. Thiourea functionalized organocatalysts $\mathbf{C 1 9}$ (Scheme 15 a)) promoted a highly efficient enantioselective direct vinylogous 

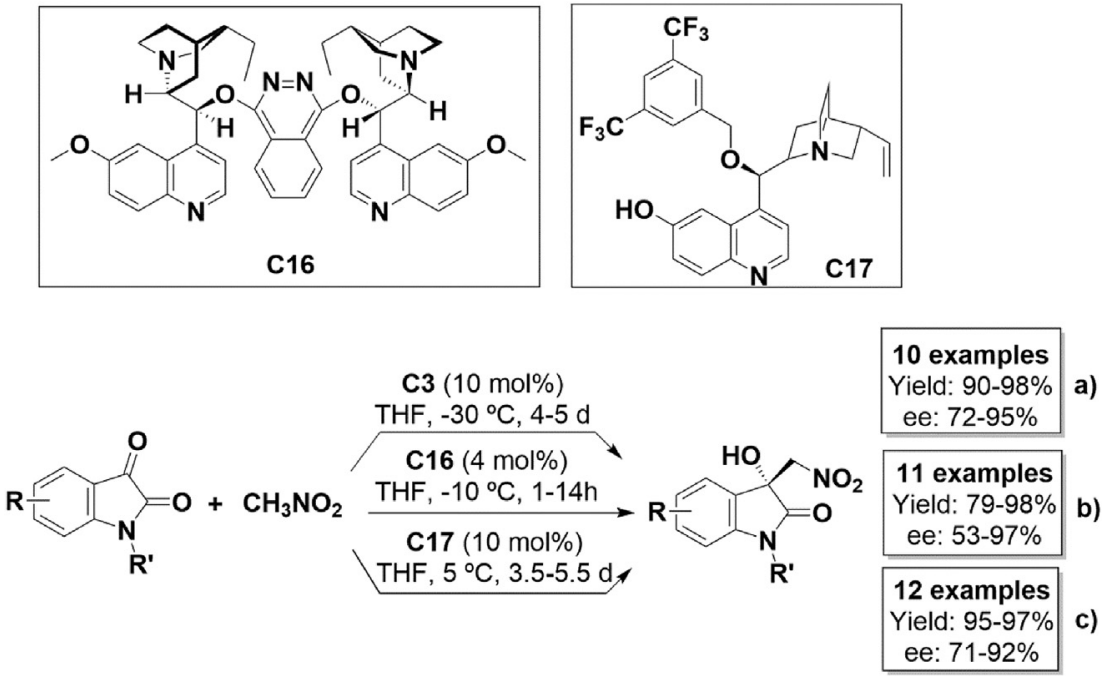

Scheme 12. Asymmetric Henry reaction of isatin derivatives with nitromethane.

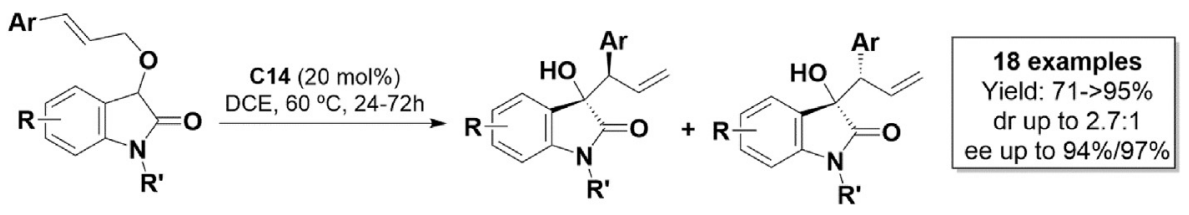

Scheme 13. Enantioselective organocatalytic [2,3]-rearrangement of oxindoles.

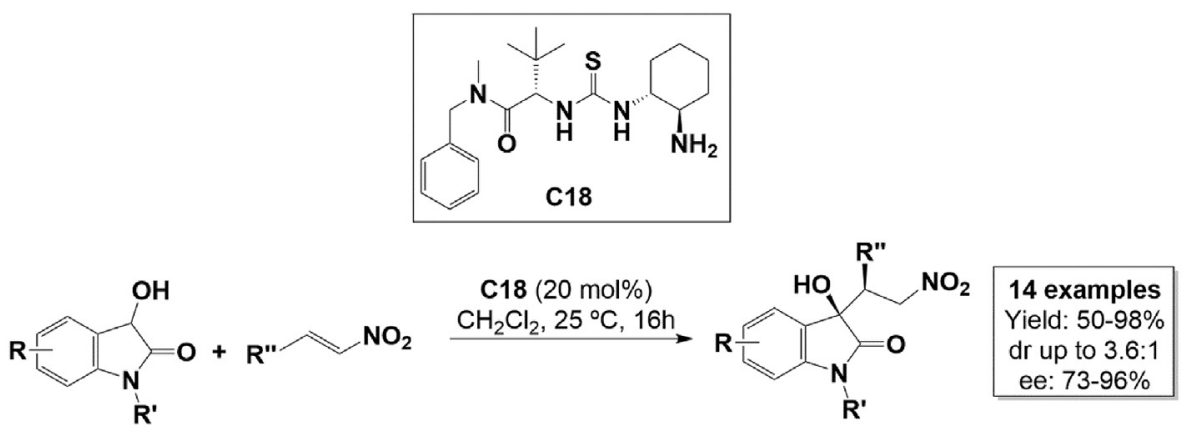

Scheme 14. 1,4-addition of dioxindole derivatives to nitroalkenes.
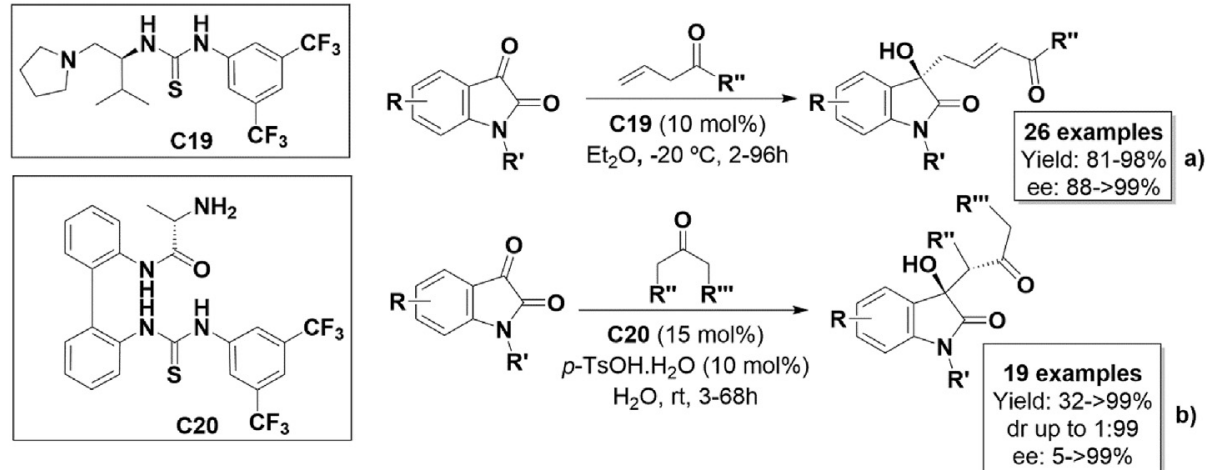

Scheme 15. Aldol reactions of isatin derivatives with ketones using thiourea-based organocatalysts. 
aldol reaction involving isatin derivatives and allyl ketones [84]. Zhao et al. reported the development of axially unfixed biaryl-(thio) urea bifunctional catalysts to allow aldol reactions to be performed using water as solvent, and therefore it is an interesting green and safe approach. The best results were achieved with catalyst C20 (Scheme 15 b) - $15 \mathrm{~mol} \%$ ) and the resulting 3-alkyl-3-hydroxyoxindole derivatives were delivered, with various chemical yields and enantioselectivities [85].

Organocatalyst C21 (Scheme $16-10 \mathrm{~mol} \%$ ) gave moderate to good yields and stereocontrol in the synthesis of chiral 3-hydroxy3-substituted-oxindole derivatives via an asymmetric Mannich reaction between 3-hydroxy-oxindoles and amidosulfones, creating 2 vicinal stereocenters [86].

Binaphthyl-based catalysts have become a versatile tool in asymmetric catalysis over the past decades, with their axial chirality playing a major role on reaction stereocontrol $[87,88]$. For this reason, the study of bifunctional binaphthyl-(thio)urea organocatalysts appeared as a challenging field for several research groups. Two examples of binaphthyl-bis(thio)urea catalysts in the asymmetric synthesis of 3-hydroxy-oxindole derivatives have been reported. Catalyst C22 (Scheme 17 a)) was studied for a MoritaBaylis-Hillman reaction between $\alpha, \beta$-unsaturated $\gamma$-butyrolactam and isatin derivatives. However, even in the presence of high catalyst loading $(100 \mathrm{~mol} \%)$ and in the presence of DABCO $(1,4-$ diazabicyclo[2.2.2]octane), the enantioselectivity values were moderate (up to $78 \%$ ee) [89]. Better stereocontrol was achieved with catalyst $\mathbf{C 2 3}$ (Scheme $17 \mathbf{b}$ )) in the reaction of isatin derivatives and formaldehyde $\mathrm{N}$-tert-butyl hydrazine, with the resulting chiral 3-hydroxy-3-substituted-oxindole derivatives presenting enantioselectivities of up to $99 \%$ ee with good to excellent yields [90].

\subsubsection{Proline derivatives}

Proline, a chiral amino acid, was shown to be an efficient catalyst in several types of reactions, with the advantages that it is inexpensive and easily available in both enantiomeric forms. Several publications can be found testifying to the versatility of prolinederivatives as asymmetric organocatalysts [91-95].

The proline stereocenter in position 2 of the pyrrolidine heterocycle inspired the creation of new asymmetric catalysts. One example was the use of (S)-pyrrolidine tetrazole C24 (Scheme 18 a) - $15 \mathrm{~mol} \%$ ), in the asymmetric crossed-aldol reaction of aldehydes with isatin derivatives. Using water and $\mathrm{H}_{3} \mathrm{PO}_{4}$ as additives, chiral 3-substituted-3-hydroxy-oxindole derivatives (12 examples) bearing two vicinal stereogenic centers were prepared with moderate to good yields and enantioselectivities [96]. A 4hydroxydiarylprolinol catalyst C25 (Scheme 18 b) - $20 \mathrm{~mol} \%$ ), could promote the aldol reaction of acetaldehyde with different isatin derivatives to achieve a library of 3-substituted-3-hydroxyoxindole derivatives, with no need for additives, and in moderate to high yields and good enantioselectivities. Two of the products prepared were further used to synthesize four different natural products with interesting biological activities: $(R)$ - convolutamydines B and E (Scheme 19), (-)-donaxaridine and $(R)$ chimonamidine [97].

Convolutamydine A which is isolated from the marine bryozoan species Amathia convolute, is another very interesting scaffold in Medicinal Chemistry. It presents a wide range of biological activities, including antitumor (HL-60 human pro-myelocytic leukemia cells), antinociceptive and anti-inflammatory properties. Several groups already reported the asymmetric synthesis of both enantiomers of this molecule, using different organocatalysts, as summarized in Scheme 20 [98-101].

Several convolutamydine A synthetic derivatives described in the literature have demonstrated antinociceptive activity in animal models. The synthetic methods were not enantioselective so the results reported are only for racemic mixtures. Nevertheless, these findings have shown that these compounds are active after oral administration and that they can act in different pain mechanisms and pathways, showing their potential use as drug candidates in pain treatment [102,103].

$(R)$-convolutamydine A and seven derivatives were synthesized by Hara et al. using a recyclable catalyst. Briefly, catalyst C28 (Scheme 21 a)) was entrapped in Montmorillonite by an ionexchange reaction. The asymmetric reactions not only could provide the desired chiral 3-substituted-3-hydroxy-oxindoles from the reaction between isatin derivatives and acetone (or acetaldehyde) in high yields and stereocontrol, but also could be recycled without significant changes in the reaction outcome [104]. The same type of reaction between isatin derivatives and acetone was explored by Pearson et al. with moderate yields and moderate to good enantiomeric excesses, but this time using an $N$-prolinylanthranilamide pseudopeptide C29 as organocatalysts (Scheme $21 \mathbf{b}$ ) - $10 \mathrm{~mol} \%$ ) [105].

An enantioselective vinylogous aldol reaction of isatin derivatives with $\alpha$-branched enals was promoted using catalyst C30 (Scheme $22-10 \mathrm{~mol} \%$ ) with the additive 2,6-bis(trifluoromethyl) benzoic acid. The chiral 3-( $\alpha$-branched- $\alpha, \beta$-unsaturated-aldehyde)3-hydroxy-oxindole derivatives were obtained with moderate to good yields and stereoselectivity [106].

The aldol reaction between isatin derivatives and 2,2-dimethyl1,3-dioxan-5-one was studied using the pseudopeptide organocatalyst C31 (Scheme 23) with the additive $\mathrm{H}_{3} \mathrm{PO}_{4}$, in moderate yields and moderate to good enantiomeric excesses. One of the obtained products achieved could be applied for the synthesis of TMC-95A (Fig. 1) [107], a relevant biologically active compound with reversible proteasome inhibition activity, and therefore studied for its potential clinical application as an anticancer agent [108,109].

The bifunctional proline-thiourea organocatalysts $\mathbf{C 3 2}$ (Scheme 24) catalyzed an asymmetric decarboxylative cyanomethylation of isatin derivatives with cyanoacetic acid, with a catalyst loading of just $5 \mathrm{~mol} \%$. The chiral 3-cyanomethylene-3-hydroxy-oxindole derivatives resultant from the reaction presented overall good enantioselectivities, with moderate yields [110].

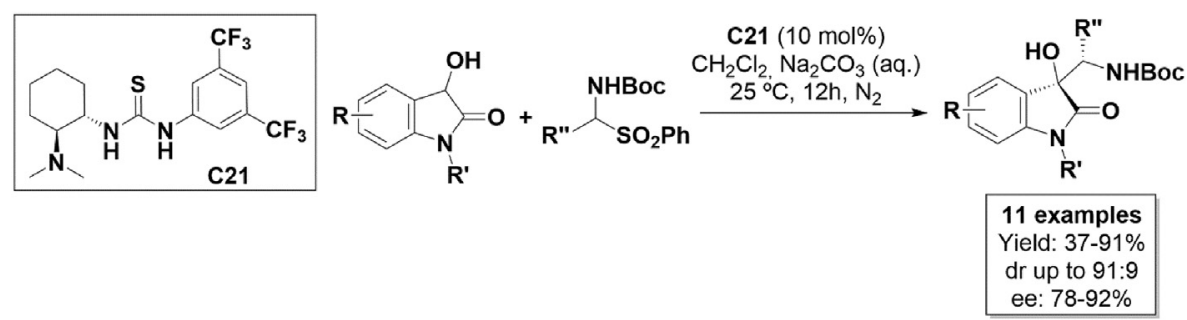

Scheme 16. Asymmetric Mannich reaction of 3-hydroxyoxindole derivatives with amidosulfones. 

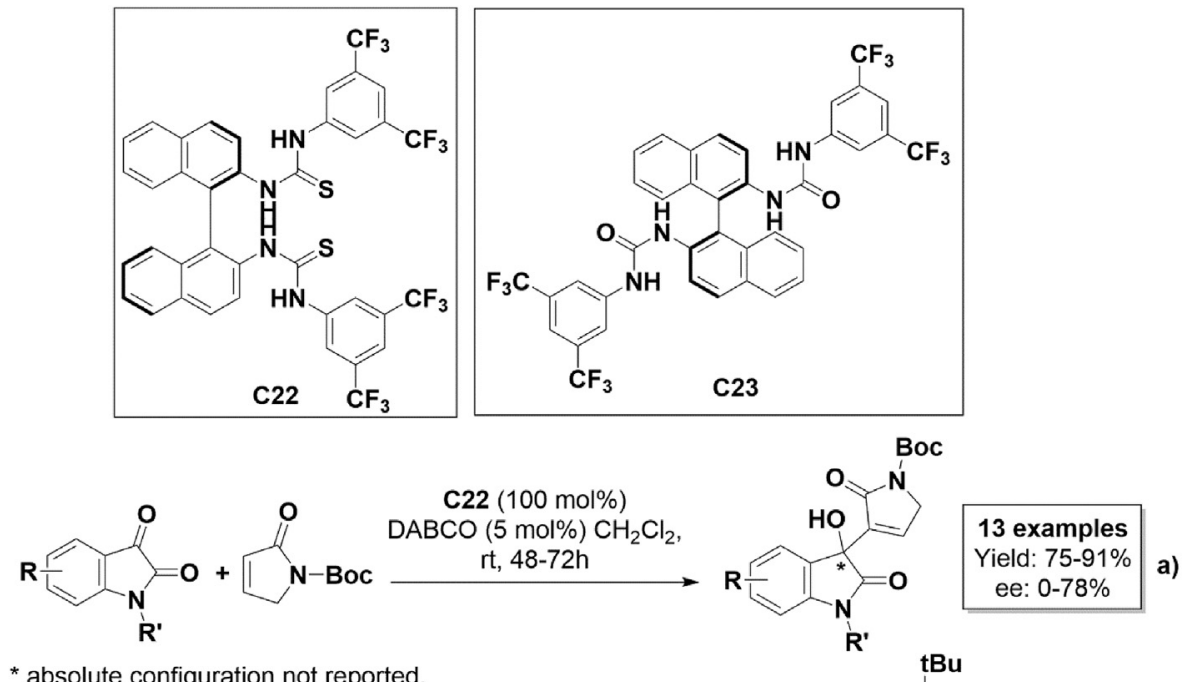

* absolute configuration not reported.

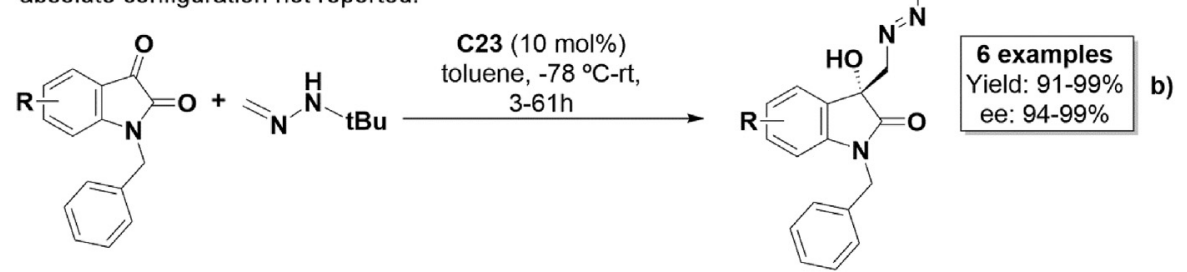

Scheme 17. Use of bi-naphthyl-bis(thio)urea organocatalysts for the synthesis of chiral 3-hydroxy-3-substituted oxindole derivatives.
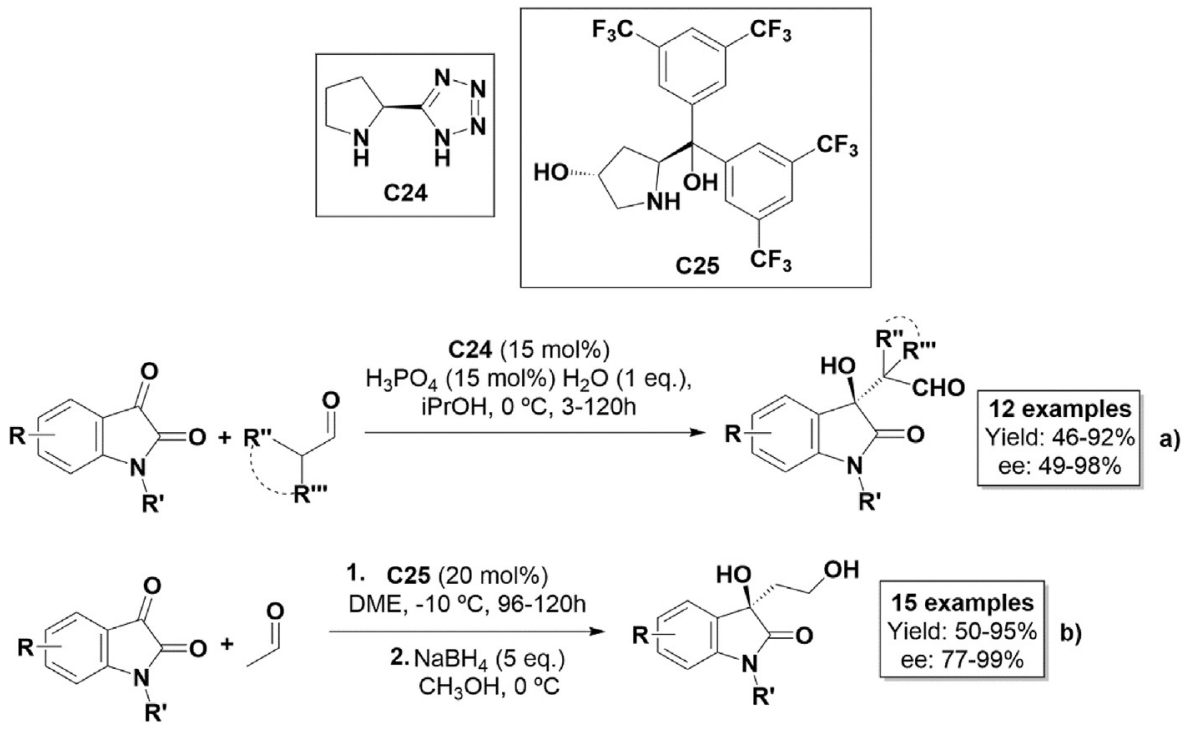

Scheme 18. Asymmetric aldol reaction of isatin derivatives with aldehydes using proline-inspired organocatalysts.

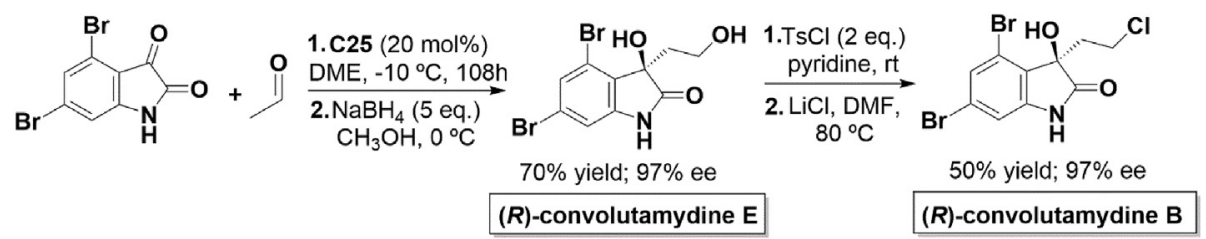

Scheme 19. Synthesis of chiral natural products $(R)$-convolutamydine E and B. 

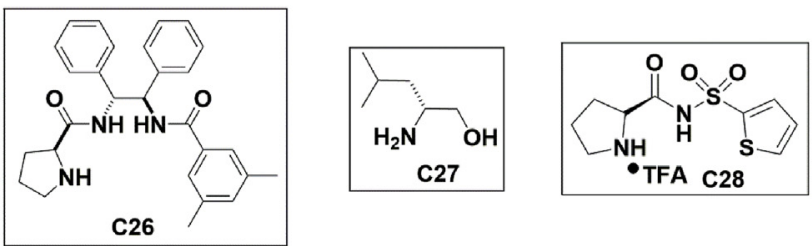

C26 (20 mol\%)

$\mathrm{AcOH}(40 \mathrm{~mol} \%)$
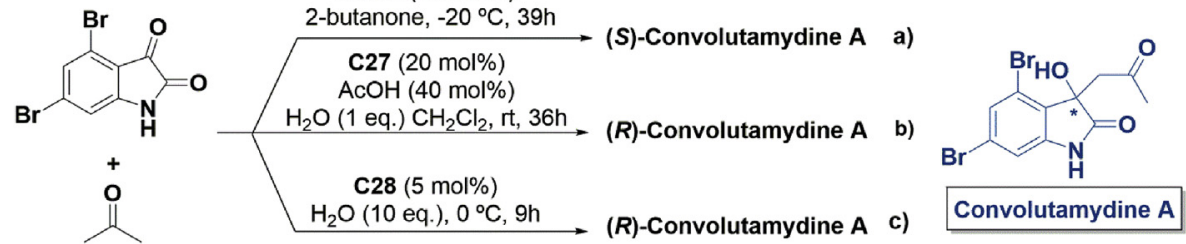

Scheme 20. Asymmetric catalytic synthesis of Convolutamydine A.

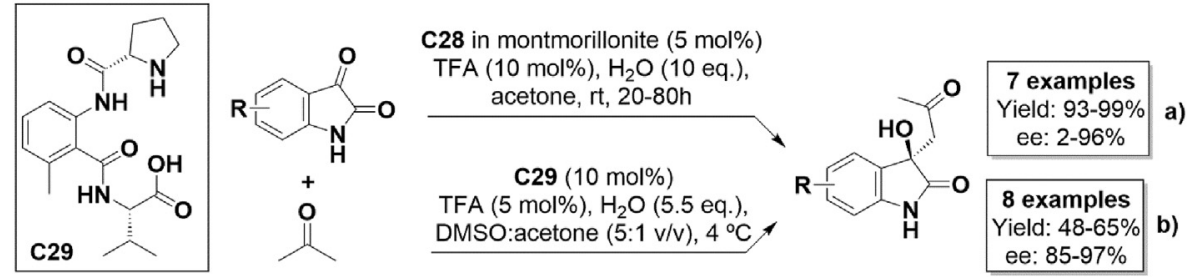

Scheme 21. Asymmetric organocatalytic aldol reaction of isatin derivatives with acetone.

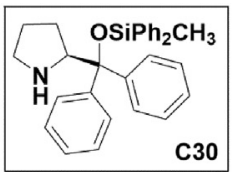

C30

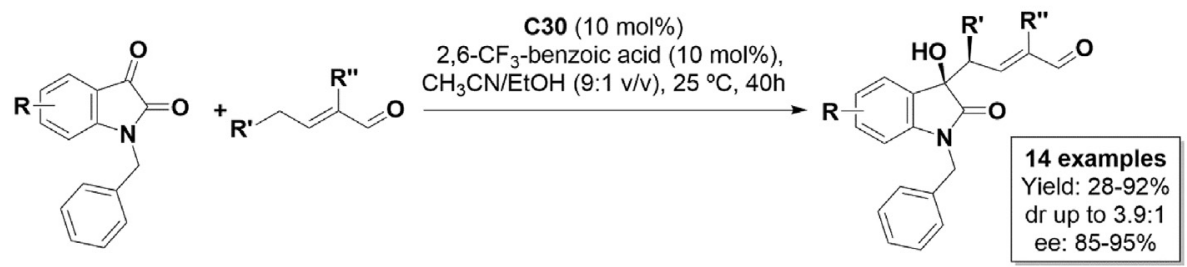

Scheme 22. Asymmetric vinylogous aldolization using organocatalyst C30.
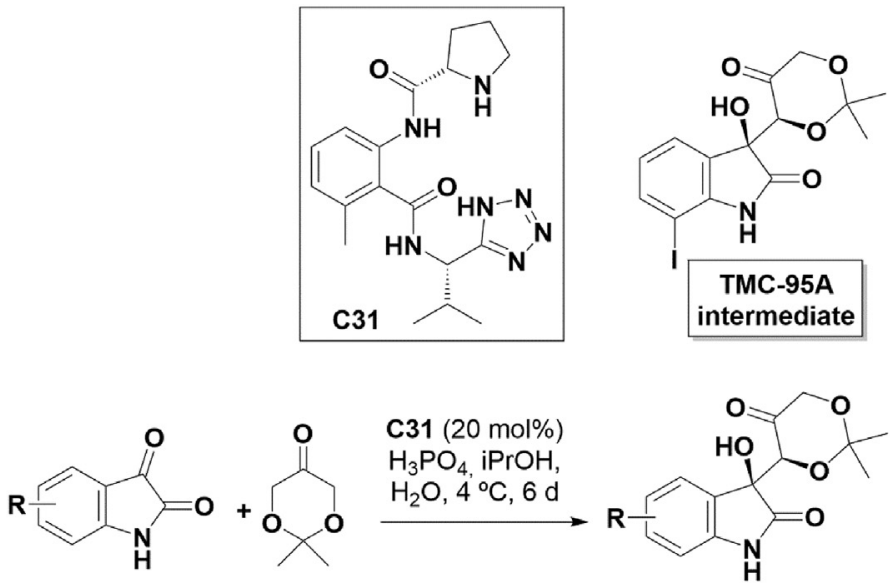


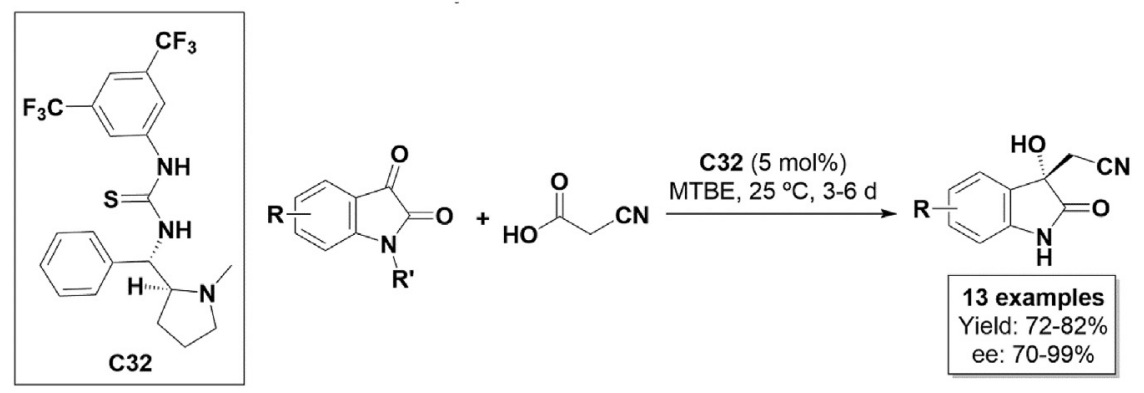

Scheme 24. Enantioselective decarboxylative cyanomethylation using a bifunctional thiourea-proline based organocatalyst.

\subsubsection{Squaramide and phosphine derivatives}

Squaramides, four-membered rings derived from squaric acid, have significant interest in catalysis due to their ability to form up to four hydrogen bonds. The addition of this moiety to chiral scaffolds is a highly desirable way to build new asymmetric catalysts. Catalyst C14 (Scheme 10) is a good example, in which the squaramide ring was combined with a cinchona alkaloid, to achieve a more efficient stereocontrol. The properties of squaramide-based catalysts have already been explored in several publications [111-114].

Phosphines bearing chiral skeletons are well established ligands for asymmetric catalysis [115-117]. Qian et al. developed an effective catalyst combining these two scaffolds (catalyst C33 - Scheme 25 a)). Catalyst C33 (2 mol\%) could effectively catalyze a MoritaBaylis-Hillman enantioselective synthesis of 3-hydroxy-3substituted-oxindole derivatives, using isatins as electrophiles. The products were obtained in good to excellent yields and enantioselectivities [118]. The same type of reaction with catalyst C34 (Scheme 25 b) - $5 \mathrm{~mol} \%$ ) was studied by Dong et al., and gave similar results [119]. These two examples illustrate the efficiency of squaramide-phosphine organocatalysts, namely as regards the low catalyst loading compared to other organocatalysts.

As shown for catalysts $\mathbf{C 2 2}$ and $\mathbf{C 2 3}$ (Scheme 17), the incorporation of axial chirality in organocatalysts, by using a binaphthyl moiety, can improve considerably the enantioselectivity of an asymmetric process. Catalyst C35 (Scheme 26) shows that a binaphthyl-squaramide catalyst can create high levels of stereocontrol at very low catalyst loading ( $1 \mathrm{~mol} \%$ ) and are more effective than the corresponding binaphthyl-thiourea or cinchona alkaloidthiourea organocatalysts. In fact, catalyst C35 produced a library of 19 chiral 3-hydroxy-3-phenacyloxindoles via decarboxylative aldol addition of $\beta$-ketoacids to isatins with overall good yields
[120].

\subsubsection{Diamines}

The presence of amine groups is crucial for many catalytic processes, as already reported in this work (e.g., with the cinchona alkaloids). For this reason, the use of small-molecule chiral amines has become an interesting research topic, both as bona fide catalysts and as ligands.

Raj et al. reported the synthesis of chiral 3-cycloalkanone-3hydroxy-oxindole derivatives, using a primary-tertiary diamine C36 (Scheme 27) with trifluoroacetic acid (TFA). Isatin derivatives reacted with cyclohexanone in water medium and provided good to excellent enantioselectivities and overall good yields. Among the products of the reaction, compound (S)-3-hydroxy-3-((R)-2oxocyclohexyl)indolin-2-one is very interesting, since it presents potential biological activity as an anticonvulsant agent, since it acts as an antagonist for the biological process that lead to maximal electroshock seizures (anti-MES) [121,122].

Liu et al. performed aldol reactions between isatin derivatives and different ketones using 1,2-diaminohexane catalyst C37 (Scheme 28 a) - $20 \mathrm{~mol} \%$ ) and hexanedioic acid (HDA) as cocatalyst, with the best results being achieved with cyclic ketones (up to 99\% ee and 90\% yield) [123]. A remarkably environmentally benign procedure for "in water" aldol reaction of isatins with cyclohexanone and acetone was developed by Kumar et al. The simple primary-tertiary diamine $\mathbf{C 3 8}$ (Scheme $28 \mathbf{b}$ )) proved to be efficient at $1 \mathrm{~mol} \%$ catalyst loading, using 2,4-dinitrophenol (DNP) as additive to achieve chiral 3-hydroxy-3-substituted oxindole derivatives with good yields and enantioselectivities [124].

\subsubsection{Miscellaneous}

Carbohydrates, especially aminosugar-derivatives, surfaced over
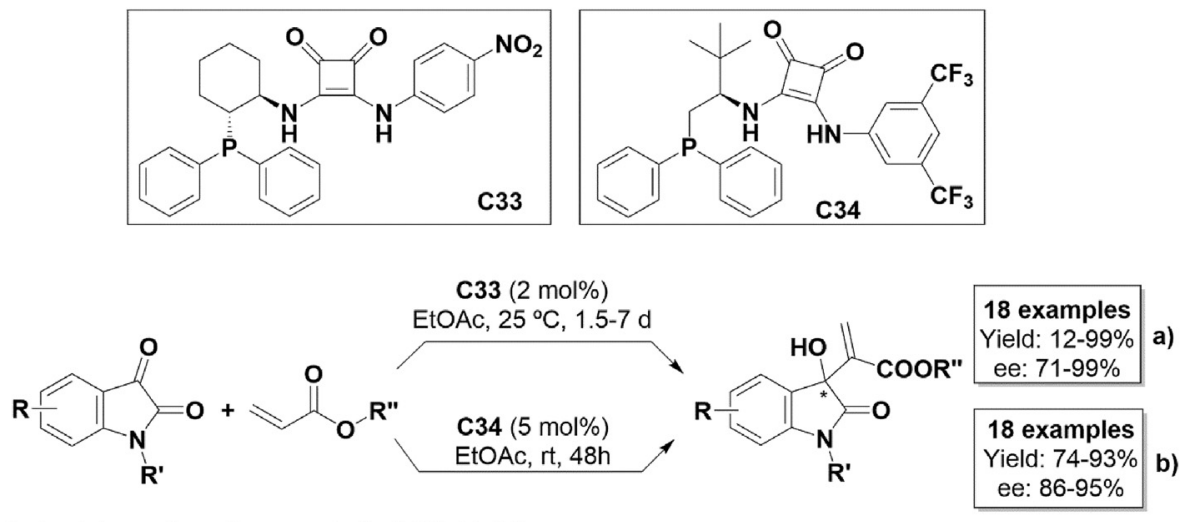

* absolute configuration reported: a) $(S)$; b) $(R)$

Scheme 25. Enantioselective Morita-Baylis-Hillman reaction using squarimide-phosphine organocatalysts. 


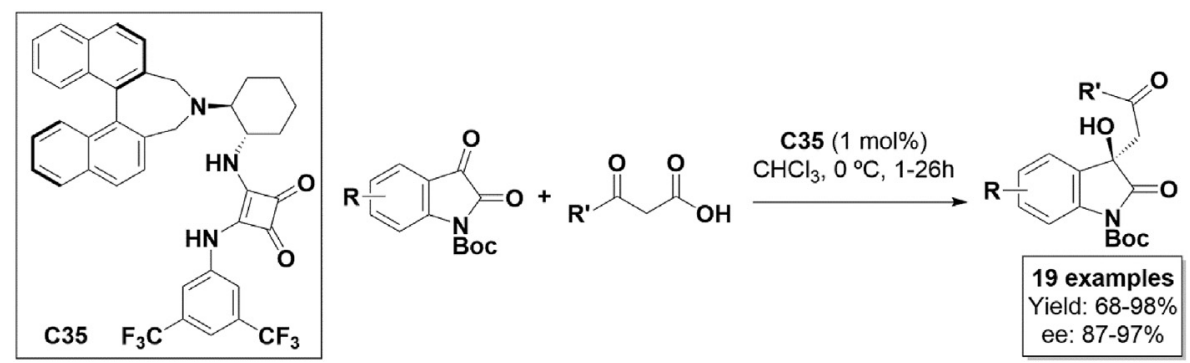

Scheme 26. Asymmetric decarboxylative aldol addition of $\beta$-ketoacids to isatin derivatives using a binaphthyl-squaramide organocatalyst.

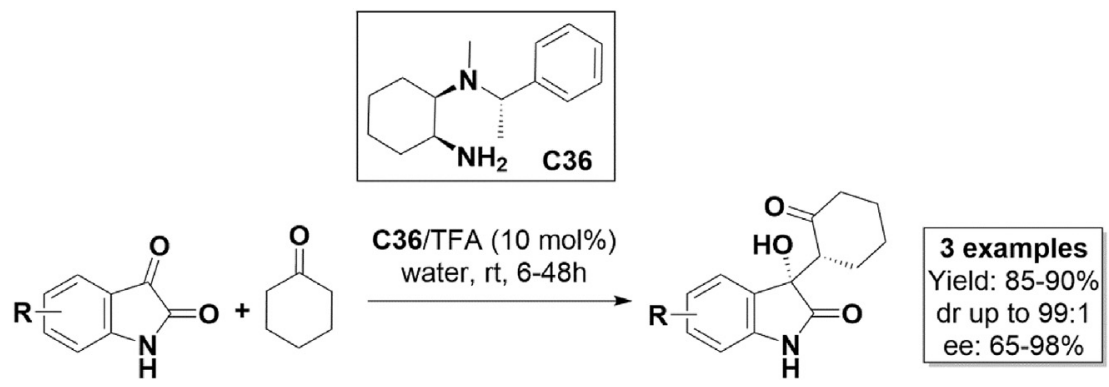

Scheme 27. Enantioselective synthesis of 3-cycloalkanone-3-hydroxy-2-oxindole derivatives.

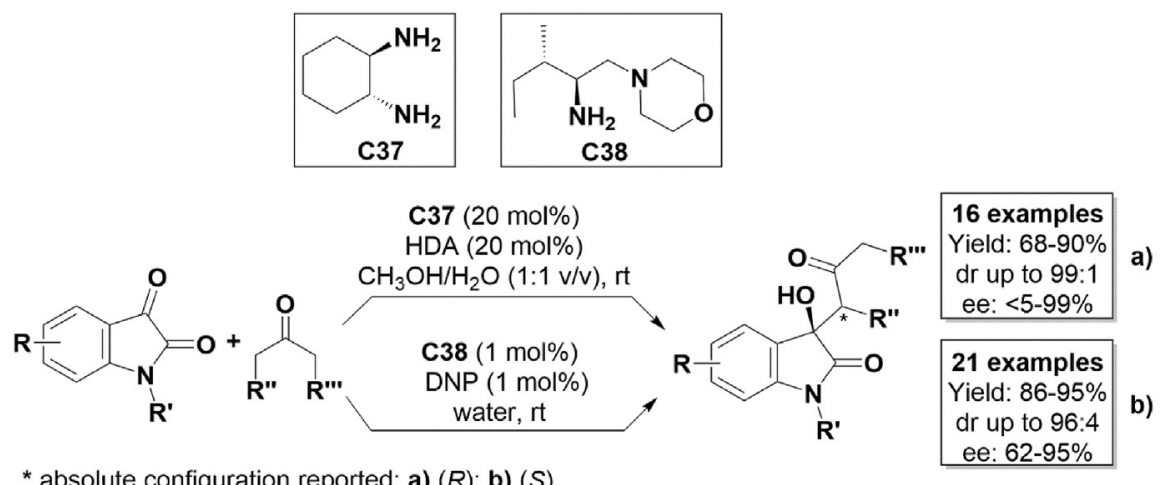

* absolute configuration reported: a) (R); b) (S).

Scheme 28. Enantioselective aldol reaction of isatin derivatives and ketones.
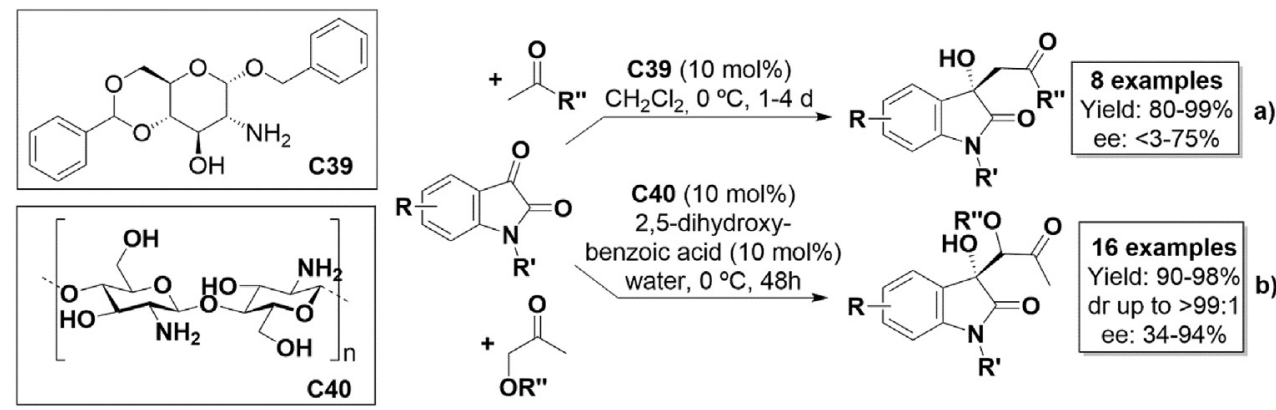

C40 (10 mol\%)

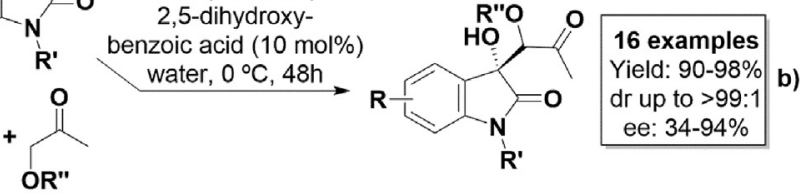

Scheme 29. Asymmetric aldol reaction using carbohydrate-derived organocatalysts.

the last decade as important tools for asymmetric catalysis, as recently reviewed in the literature [125]. Shen et al. reported an asymmetric aldol reaction between isatin derivatives and different ketones, using organocatalysts C39 (Scheme 29 a) - $10 \mathrm{~mol} \%$ ). Although the carbohydrate-derived alcohol could afford the desired 3-hydroxy-3-substituted oxindole derivatives in high yields, the stereocontrol was quite limited (up to 75\% ee) [126]. In another recent example, which was a greener approach, chitosan C40 (Scheme 29 b) - $10 \mathrm{~mol} \%$ ), in the form of aerogel, was used as the catalyst for an asymmetric aldol reaction of isatin derivatives with hydroxyacetone (or methoxyacetone). 2,5-Dihydroxybenzoic acid was used as the additive and water as solvent. The desired chiral 3- 


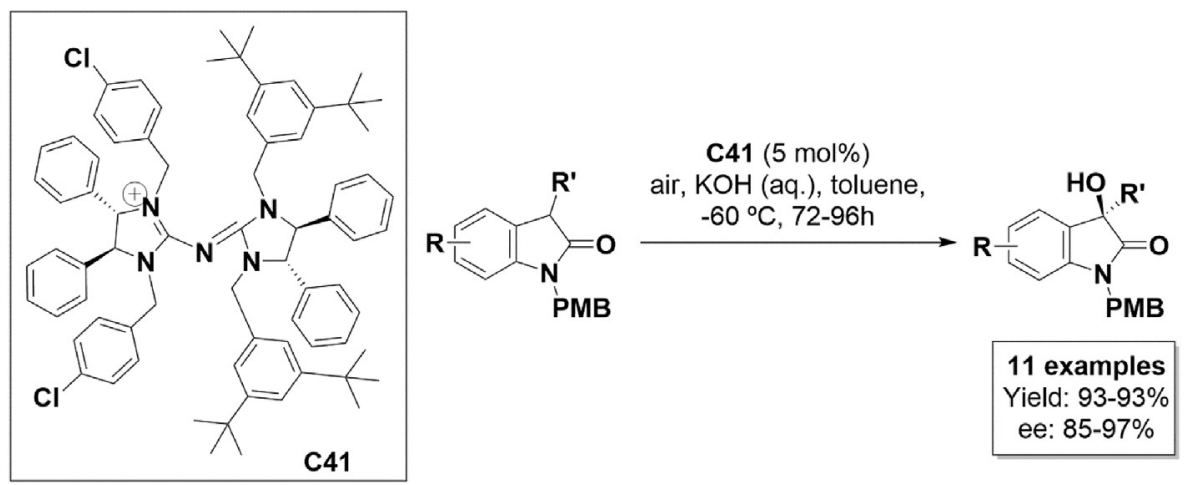

Scheme 30. $\alpha$-Hydroxylation of 3-substituted-oxindole derivatives with molecular oxygen.

hydroxy-3-substituted derivatives where obtained in good yields and chemoselectivities under these environmentally benign conditions [127].

Pentanidium-derived catalysts have also been described as valuable for asymmetric reactions, namely phase-transfer catalysis [128]. The use of this type of catalyst was reported in the successful enantioselective $\alpha$-hydroxylation of 3 -substituted-oxindoles using the inexpensive and green reagent, molecular oxygen. In fact, catalyst C41 (Scheme $30-5 \mathrm{~mol} \%$ ) afforded chiral 3-hydroxy-3substituted-oxindole derivatives with excellent enantioselectivities, via formation of the hydroperoxide oxindole followed by its kinetic resolution to the hydroxyl-derivative [129].

The use of chiral sulfonamides in asymmetric catalysis has also been reported for a range of different reactions [130-132]. Recently, the catalyst C42 (Scheme $31-20 \mathrm{~mol} \%$ ), was used to prepare 3-cycloalkanone-3-hydroxy-2-oxindole derivatives in high yields and moderate to good enantioselectivities under neat conditions at room temperature [133].

\subsection{Transition-metal catalysis}

The use of transition metals in catalysis, and particularly in asymmetric catalysis, has been explored and reviewed in several fields [134-140], including their application for the functionalization of the 3-position of the oxindole scaffold [141,142]. To systematically review this topic, the examples will be organized according to the periodic table periods.

\subsubsection{Period $4-\mathrm{Sc}, \mathrm{Ni}, \mathrm{Cu}$}

Asymmetric catalytic synthesis of substituted 3-hydroxy-oxindole derivatives using scandium (III) complexes is very desirable, since these are among the few catalytic systems that do not require the use of $N$-protected isatin derivatives. Franz's group explored this Lewis acid on different occasions. First, they promoted the monoaddition of indole and arene nucleophiles to isatins (indium (III) complexes also proved to be efficient, but scandium (III) provided higher levels of stereocontrol when different nucleophiles were tested), using $5 \mathrm{~mol} \%$ loading of the catalyst (Scheme 32 a)) [143]. Then, they further explored the enantioselective allylation of isatins (including $\mathrm{N}$-substituted isatins) using different allylsilanes, also achieving high yields and enantioselectivities (even when decreasing the catalyst loading to $0.05 \mathrm{~mol} \%$, even though the reaction time was extended under these conditions) (Scheme $32 \mathbf{b}$ )) [144]. The same group further explored an asymmetric [3+2] annulation of allylsilanes with isatins to obtain spirooxindole derivatives [145]. In all the cases, the best results were achieved using $(3 \mathrm{a} S, 8 \mathrm{a} R)$-indapybox (L1) as the chiral ligand. Indeed, oxazolinebased chiral ligands are very versatile in asymmetric catalysis with transition metals [146], as we demonstrate using further examples in this report.

The decarboxylative addition of malonic acid to different isatins was reported by Gao et al., using nickel (II) as the metal catalyst and $\mathbf{L 2}$ (Scheme 33) as the chiral ligand. The 2-(3hydroxy-2-oxoindolin-3-yl)acetic acid derivatives obtained from this reaction presented moderate to good yields and enantioselectivities [147].

In the first report on enantioselective synthesis of SM-130686, an orally active growth hormone secretagogue [148], Tomita et al. developed a different approach, since the desired product presents a trifluoromethyl substituent at C4 of the oxindole scaffold and therefore makes access to the $\mathrm{C} 3$ position of the oxindole difficult, hampering formation of the quaternary stereogenic center. For this reason, they performed a copper catalyzed $(\mathrm{Cu}(\mathrm{I}) \mathrm{F})$ enantioselective intramolecular arylation of arylboronate containing $\alpha$-ketoamides, using the chiral ligand $\mathbf{L 3}$ (Scheme 34) and this gave very satisfactory yields and stereocontrol [149]. The (S)-enantiomer is the

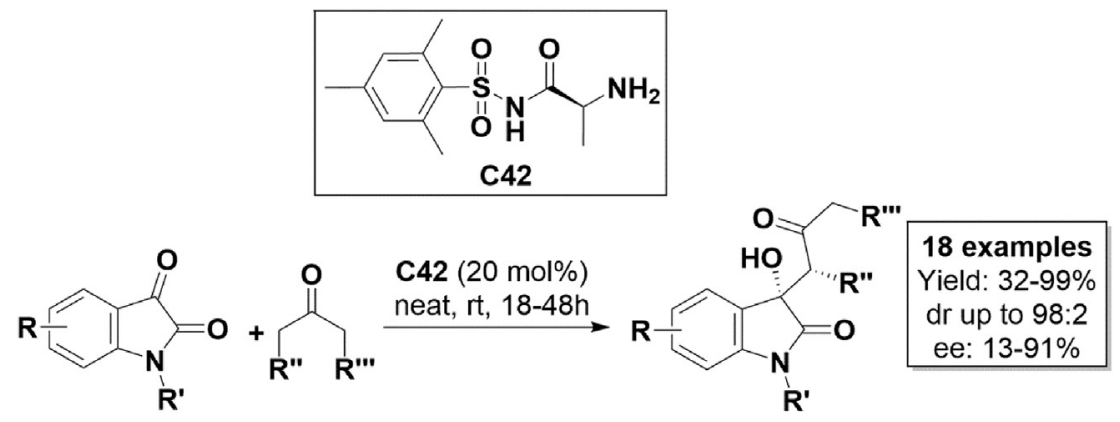

Scheme 31. Aldol reaction using an amino acid sulphonamide as organocatalyst. 

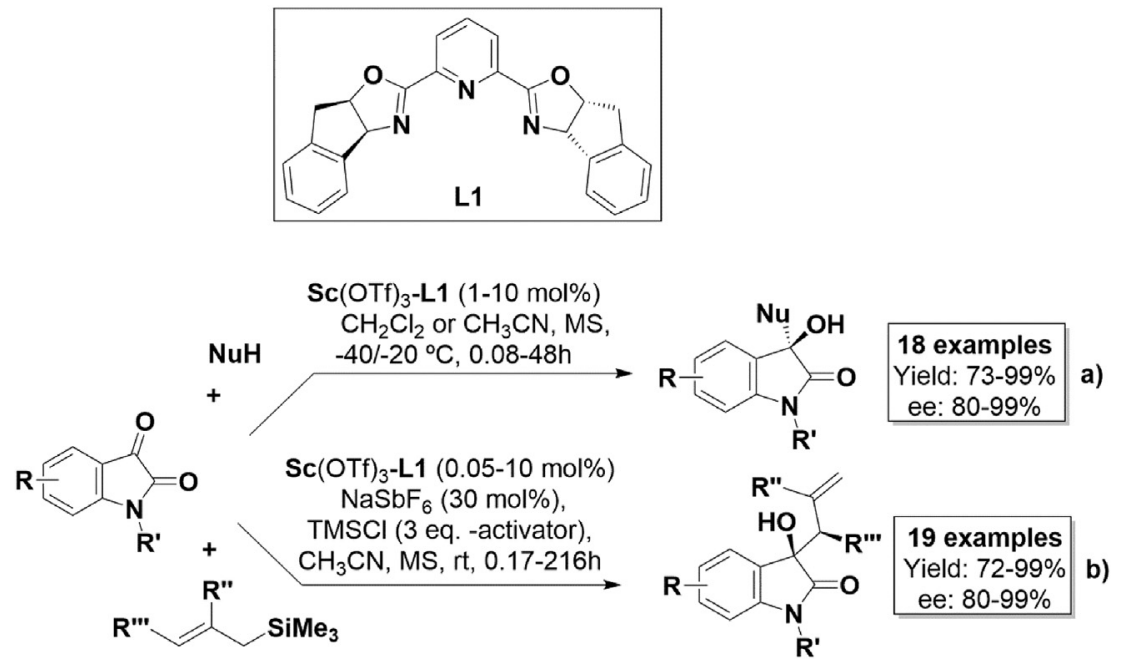

Scheme 32. Scandium-catalyzed synthesis of chiral 3-hydroxy-3-substituted oxindole derivatives.
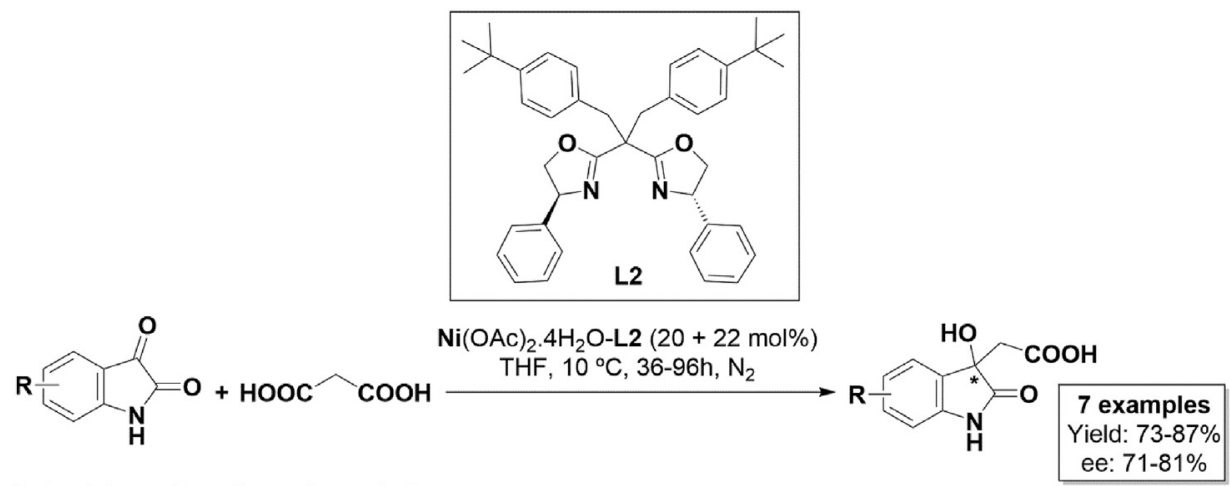

* absolute configuration not reported

Scheme 33. Nickel-catalyzed asymmetric decarboxylative addition of malonic acid and isatin derivatives.

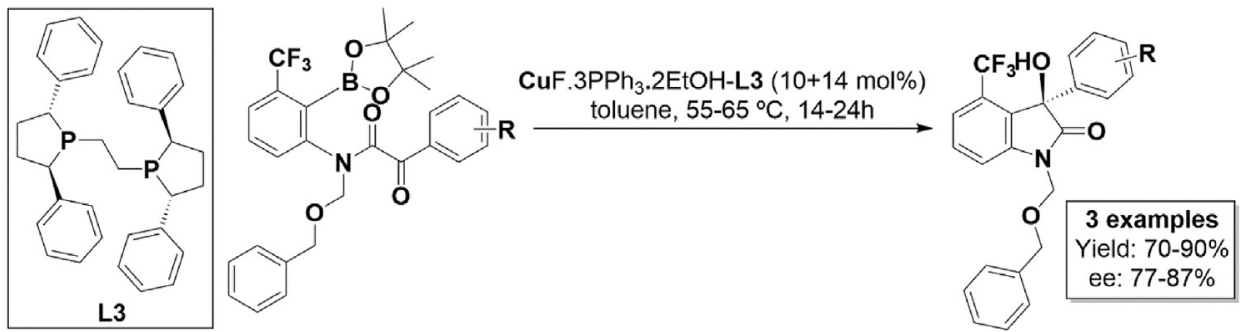

Scheme 34. Copper-catalyzed enantioselective intramolecular arylation.<smiles>COC(=O)c1ccccc1N(C(=O)C(=O)c1ccccc1Cl)c1cc(Oc2ccccc2)cc(C(F)(F)F)c1C(=O)c1ccccc1</smiles>
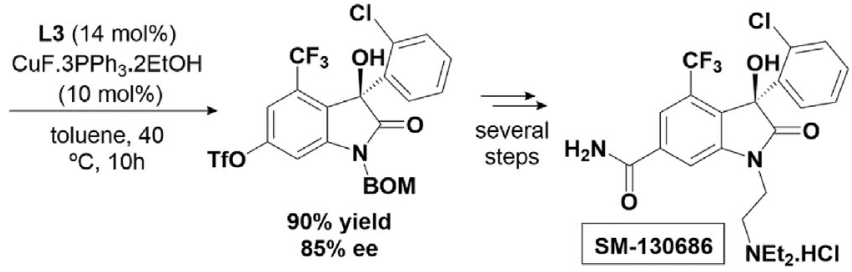

Scheme 35. Key-asymmetric synthetic step for the synthesis of bioactive SM-130686 (BOM - benzyloxymethyl group). 


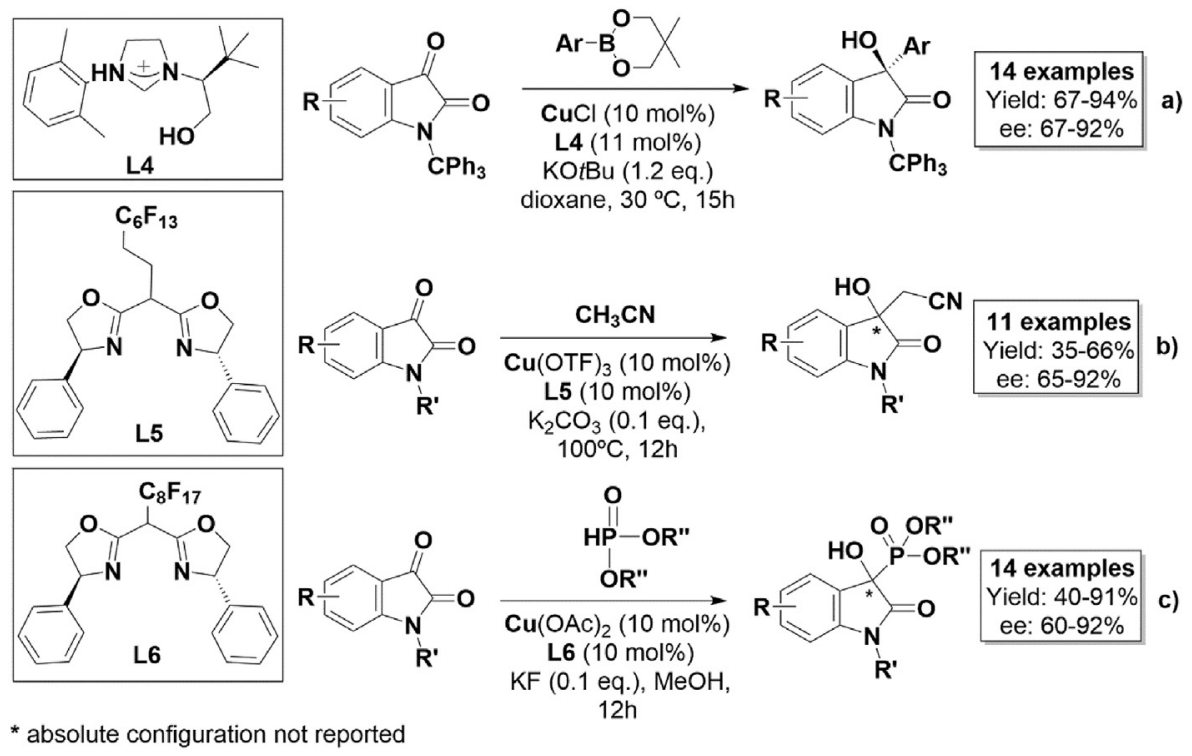

Scheme 36. Copper-catalyzed asymmetric synthesis of 3-hydroxy-oxindoles.

more biologically relevant enantiopode, and the asymmetric catalytic step, as well as the final structure of SM-130686 are shown in Scheme 35.

The synthesis of 3-aryl-3-hydroxy-oxindole derivatives has also been carried out using copper $(\mathrm{CuCl})$ and an $\mathrm{N}$-heterocyclic carbene ligand $\mathbf{L 4}$ (Scheme $36 \mathbf{a}$ )), and were formed with moderate to good yields and enantioselectivities [150].

The asymmetric addition of acetonitrile to isatin derivatives by $\mathrm{C}-\mathrm{H}$ activation was also studied using copper (II) $\left(\mathrm{Cu}(\mathrm{OTf})_{2}\right)$ and the fluorous bisoxazoline ligand $\mathbf{L 5}$ (Scheme $36 \mathbf{b}$ )), but the product was obtained in low to moderate yields although the best enantiomeric excess achieved was $92 \%$ ee [151]. The same authors applied a similar ligand $\mathbf{L 6}$ (Scheme 36 c)) with $\mathrm{Cu}(\mathrm{OAc})_{2}$, to promote an $\alpha$-hydrophosphonylation of isatin derivatives. The reaction gave moderate to good yields and enantioselectivities of the desired chiral $\alpha$-oxindole- $\alpha$-hydroxyphosphonates [152].

The Friedel-Crafts alkylation of pyrrole with isatins was studied by Li et al. for both protected and unprotected isatins. The catalyst system consisted in $\mathrm{CuBr}_{2}$, chiral ligand $\mathbf{L 7}$ (Scheme 37) and hexafluoroisopropanol (HFIP) as additive. The authors reported that the addition of HFIP allows the formation of a key hydrogen bond between the isatin $\mathrm{NH}$ and the catalyst, due to its weak Brønsted acidity. For $N$-protected isatins, a one-step reaction was carried out, and it gave excellent yields and enantioselectivities. Similar results were achieved with $\mathrm{N}$-unprotected isatins using the same chiral catalyst system, a two-step reaction pathway was identified, that consisted first of a Henry reaction, followed by a retro-Henry process [153].

The enantioselective oxygen atom transfer from an oxaziridine to different 3-aryl-oxindole derivatives was reported by Naganawa et al. [154]. The best results were achieved using $\mathrm{Cu}(\mathrm{OAc})_{2}$ and ligand L8 (Scheme 38) as the chiral catalyst, with good yields and very good enantioselectivities for the 3-aryl-3-hydroxy-oxindole derivatives obtained [154].

Recently, $\mathrm{Xu}$ et al. established a protocol for the asymmetric synthesis of 3-alkynyl-3-hydroxy-oxindole derivatives, from isatin and terminal alkynes. The catalyst was formed by $\mathrm{CuI}$ and chiral phosphine ligand L9 (Scheme 39), and the desired products were achieved in good to excellent yields and stereocontrol (up to $94 \%$ ee) [155].

\subsubsection{Period $5-R u, R h, P d, I n, S n$}

The synthesis of chiral 3-aryl-3-hydroxy-oxindoles using a ruthenium-catalyzed arylboronic acid addition to $N$-protected isatins was described by Yamamoto et al. [140]. To perform this task, the authors used a chiral $O$-linked $C_{2}$-symmetric bidentate phosphoramidite $((R, R)-\mathrm{Me}-\mathrm{BIPAM}) \mathbf{L 1 0}$ (Scheme 40$)$ as the ligand (2.2 $\mathrm{mol} \%)$ and $\mathrm{RuCl}_{2}\left(\mathrm{PPh}_{3}\right)_{3}(2 \mathrm{~mol} \%)$, in the presence of $\mathrm{KF}$. The desired products were obtained in excellent yields and good enantioselectivities [156].

Gui et al. reported the same type of addition, but this time with $\mathrm{N}$-unprotected isatin derivatives, using rhodium (I). The catalyst complex used consisted of $\left[\mathrm{Rh}\left(\mathrm{C}_{2} \mathrm{H}_{4}\right)_{2} \mathrm{Cl}_{2}\right]$ (2 mol\%) and chiral sulfoxide phosphine $\mathbf{L 1 1}$ (Scheme 41 a) - $4.8 \mathrm{~mol} \%$ ) and the final 3-

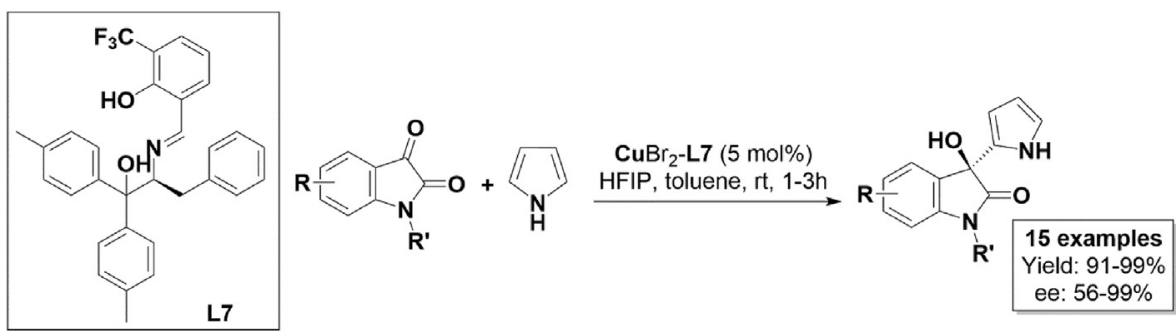

Scheme 37. Asymmetric catalytic Friedel-Crafts alkylation of pyrrole with isatins. 


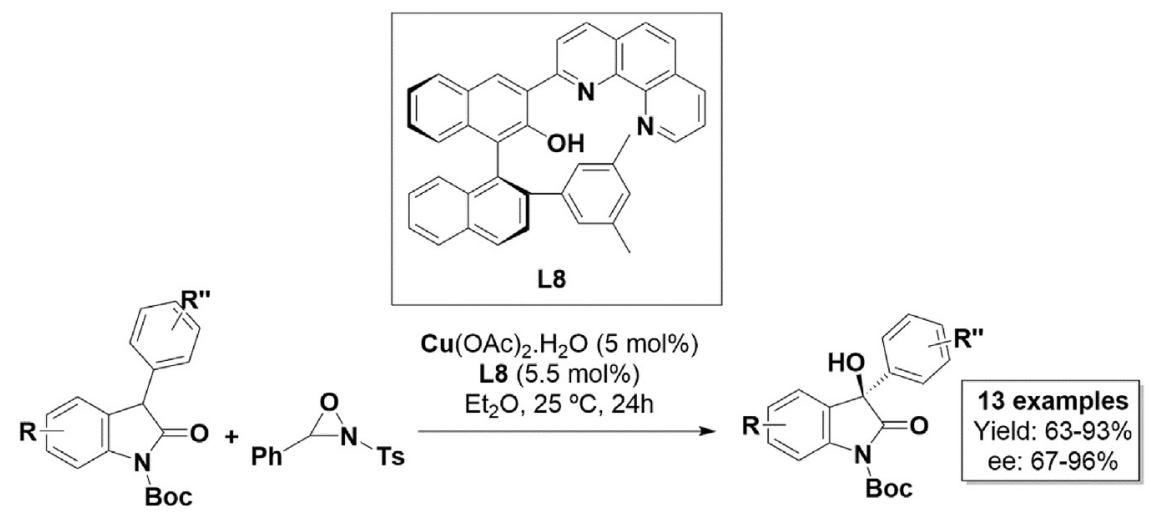

Scheme 38. Enantioselective oxygen transfer to 3-aromatic-oxindole derivatives.

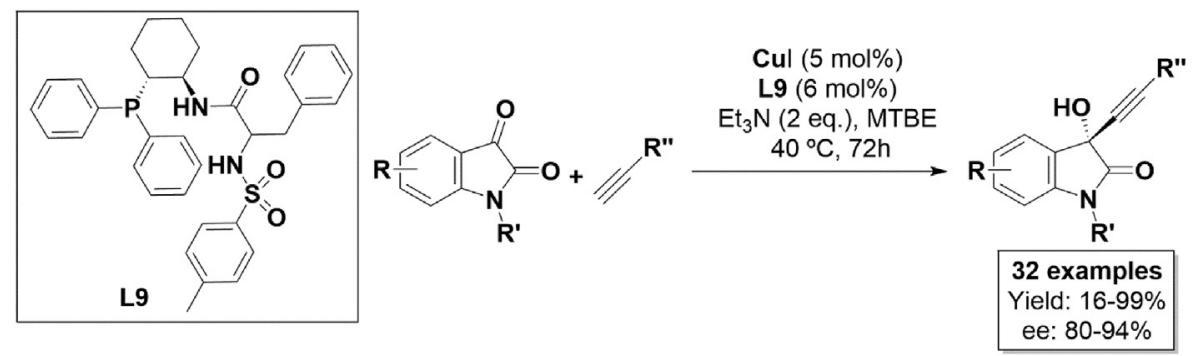

Scheme 39. Copper-catalyzed asymmetric addition of terminal alkynes to isatin derivatives.
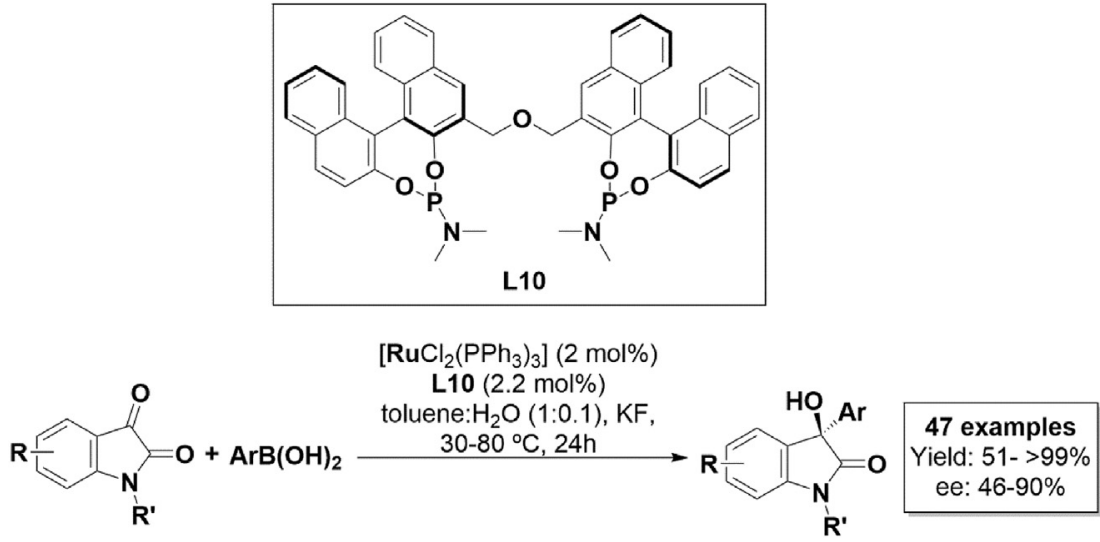

Scheme 40. Ruthenium-catalyzed asymmetric addition of arylboronic acids to isatin derivatives.

aryl-3-hydroxy-oxindole derivatives were obtained in good to excellent yields and enantioselectivities [157]. The same reaction was explored by Feng et al., using the same source of rhodium (I), although with a higher catalyst loading ( $5 \mathrm{~mol} \%$ ), and applying a chiral sulfur-alkene ligand $\mathbf{L 1 2}$ (Scheme $41 \mathbf{b}$ )). The complex was applied to $\mathrm{N}$-protected isatin derivatives only, but the results were poorer than the ones previously described [158]. It must be noted than when the introduced aryl group was a phenyl group the configuration was established to be $(R)$.

In our group, we also explored the use of rhodium (I) in asymmetric catalysis to obtain compounds with potential biological activity. The enantioselective addition of arylboronic acids to $N-1,2,3-$ triazole-isatin derivatives was reported, using $(R)$-BINAP $((R)-2,2$ bis(diphenylphosphino)-1,1-binaphthyl) as the chiral ligand (L13 - Scheme $42-6 \mathrm{~mol} \%$ ) and $\mathrm{Rh}(\mathrm{acac})\left(\mathrm{C}_{2} \mathrm{H}_{4}\right)_{2}$ (3 mol\%). The resulting $\quad \mathrm{N}$-(1,2,3-triazolemethyl)-3-hydroxy-3-aryl-oxindole derivatives where prepared with high levels of conversion and enantioselectivities up to $97 \%$ ee [159]. The configuration of the newly created quaternary center was not determined, but on the basis of similar work could be tentatively assigned the $(R)$ configuration.

We further explored this asymmetric catalytic system to obtain the two enantiomers of the hit compound $N$-benzyl-3-hydroxy-3phenyloxindole and the synthesis of a library of related compounds. Both the butyrylcholinesterase (BuChE) and acetylcholinesterase (AChE) inhibition of these compounds were screened. The best result was achieved with 1-((1-benzylpiperidin-4-yl)-methyl)3-hydroxy-3-phenylindolin-2-one (the lead compound) (Scheme 43 ). While both enantiomers were more active towards the inhibition of BuChE, the $(S)$-enantiomer proved to be more potent by nine fold $\left(\mathrm{IC}_{50}=6.19 \mu \mathrm{M}\right.$, while for the $(R)$-enantiomer value was $54 \mu \mathrm{M})[160]$. 


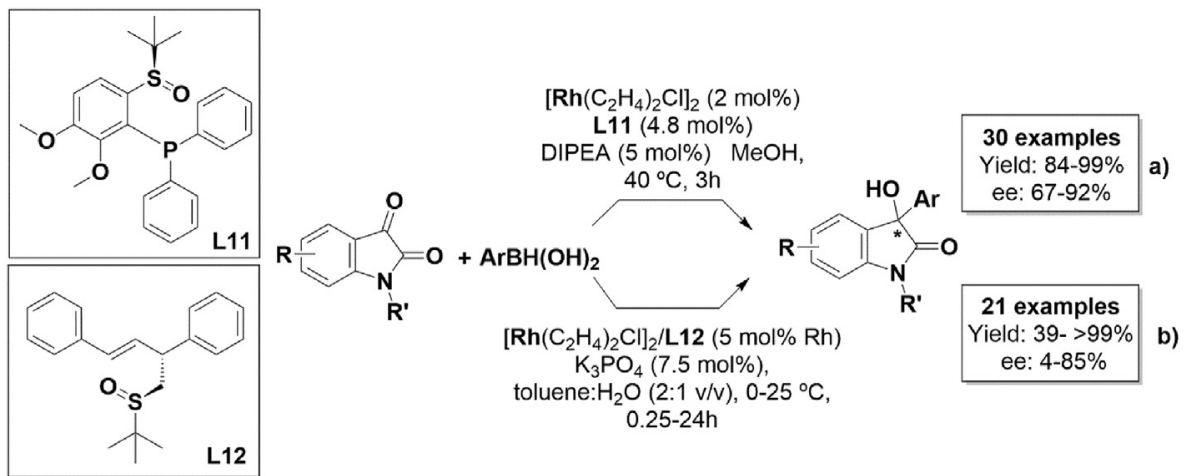

* absolute configuration reported: a) 5 examples reported as $(R)$; b) 13 examples reported as $(R)$.

Scheme 41. Rhodium-catalyzed asymmetric addition of arylboronic acids to isatin derivatives.

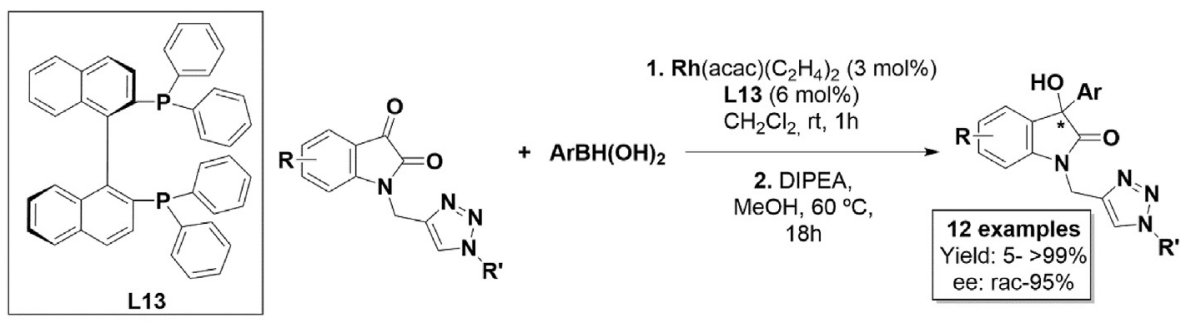

* absolute configuration not reported.

Scheme 42. Rhodium-catalyzed asymmetric addition of arylboronic acids to $N$-triazole-isatin derivatives.

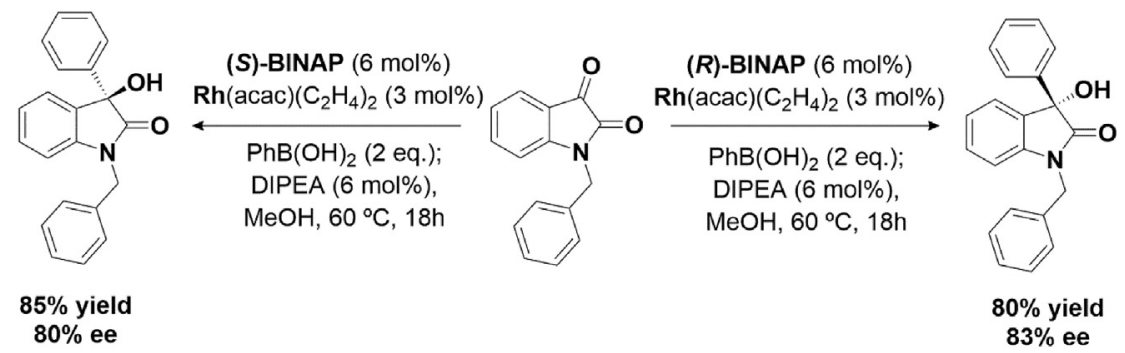

Scheme 43. Asymmetric synthesis of 3-hydroxy-3-substituted-oxindole derivatives with cholinesterase inhibition activity.

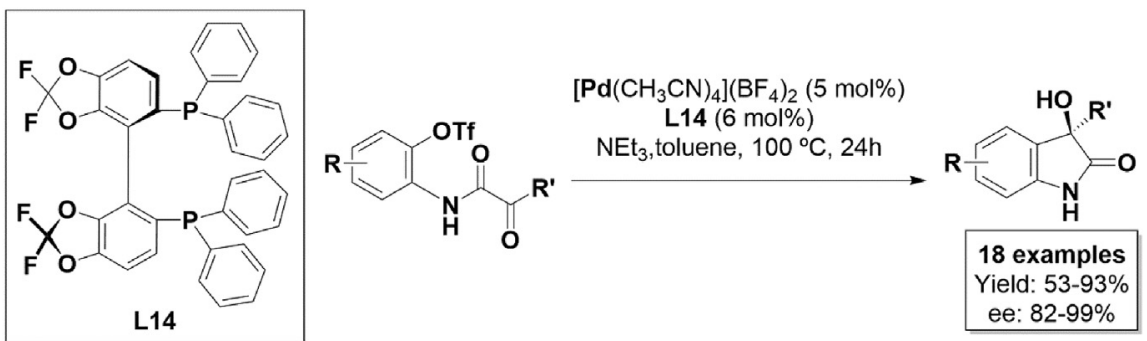

Scheme 44. Palladium-catalyzed asymmetric intramolecular arylation of $\alpha$-keto amides.

Palladium has proven to be a very useful and versatile metal catalyst in a wide variety of reactions, including asymmetric catalysis [161-164]. Among these reactions, Shibasaki et al. reported the use of palladium in an asymmetric intramolecular arylation of $\alpha$-keto amides. The catalyst $\left[\mathrm{Pd}\left(\mathrm{CH}_{3} \mathrm{CN}\right)_{4}\right]\left(\mathrm{BF}_{4}\right)_{2} /(R)-$ difluorPhos (5 mol\%/6 mol\% - chiral ligand L14 - Scheme 44) could generate chiral 3-hydroxy-2-oxindole derivatives in moderate to good yields and with very good stereocontrol (up to 95\% ee) [165].

The asymmetric allylation of isatins with allylic alcohols was reported by Qiao et al., using the catalyst $\left[\mathrm{Pd}(\mathrm{OAc})_{2}\right] /$ L15 (Scheme 45 a); $5 \mathrm{~mol} \% / 10 \mathrm{~mol} \%$ ). This ligand proved to be the best of a family of chiral spiro phosphoramidite ligands to access tertiary homoallylic alcohols 3-allyl-3-hydroxy-oxindole derivatives. Although the process resulted in very high yields, the 

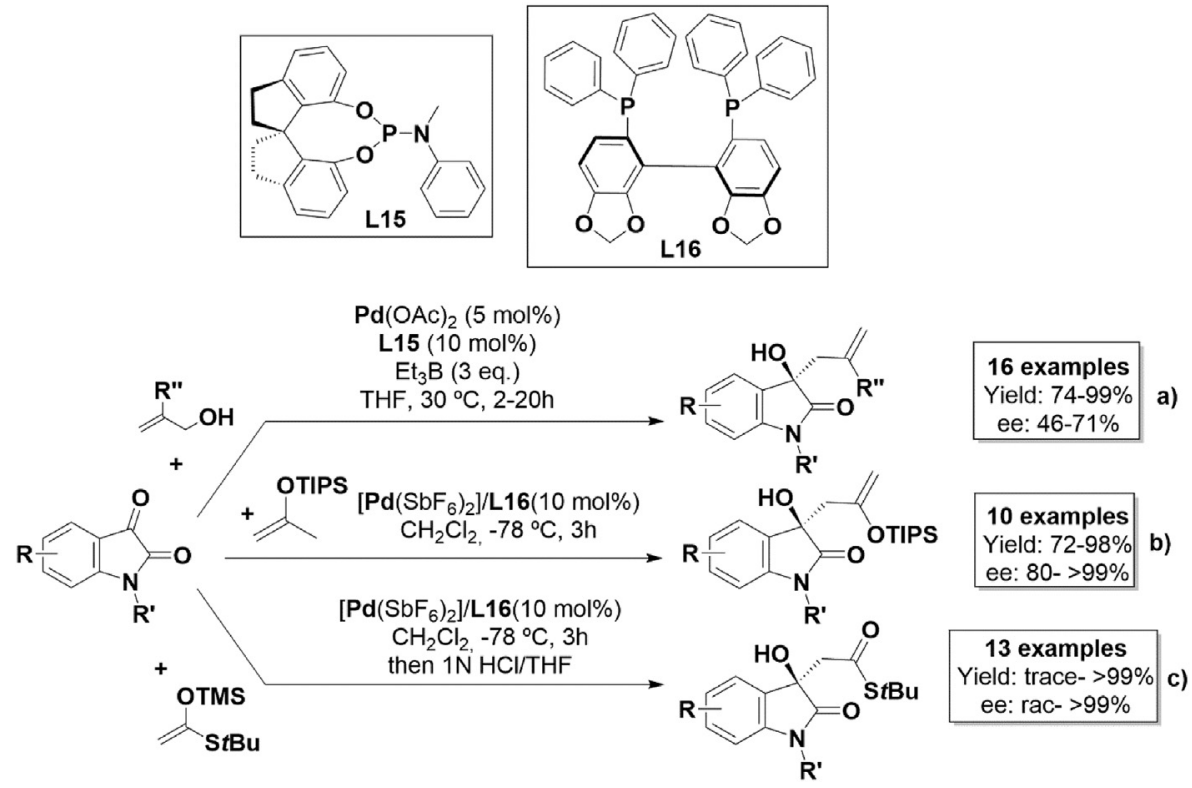

Scheme 45. Palladium-catalyzed asymmetric synthesis of 3-hydroxy-3-substituted oxindole derivatives.

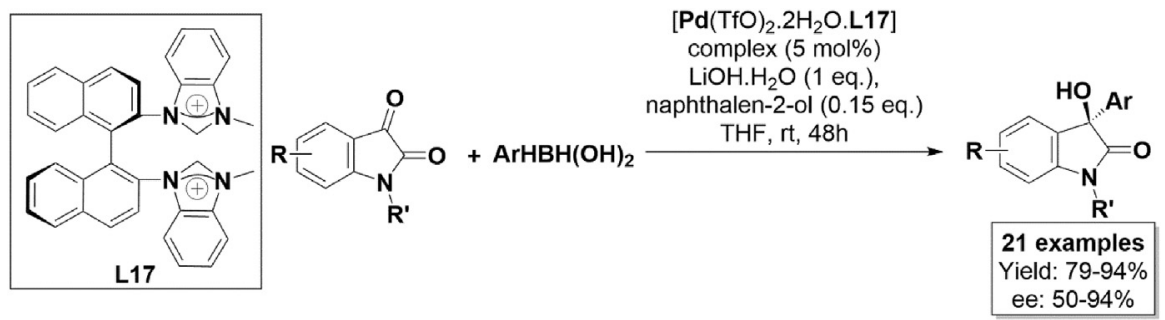

Scheme 46. Catalytic asymmetric arylation of isatin derivatives with arylboronic acids using L17.

enantioselectivities were moderate (up to $71 \%$ ee) [166]. Tertiary alcohols were also the focus of the protocol developed by Aikawa et al., who studied ene and aldol reactions of $N$-protected isatins and isopropenyloxy(triisopropyl)-silane (for the ene reaction Scheme 45 b))/isopropenyloxy(tert-butyldimethyl)-silane (aldol reaction - Scheme 45 c))/trimethylsilyl ketene thioacetal (aldol reaction), using $\left[\mathrm{Pd}\left(\mathrm{SbF}_{6}\right)_{2}\right]$ (10 $\mathrm{mol} \%$ ) and the chiral ligand $\mathbf{L 1 6}$. The chiral 3-hydroxy-3-substituted-oxindole derivatives were obtained in high yields and with remarkable enantioselectivity in some cases (>99\% ee) [167].

The addition of arylboronic acids to $N$-substituted isatins allowed the asymmetric catalytic synthesis of 3-aryl-3-hydroxyoxindole derivatives with moderate to good yields and enantioselectivities. The catalyst consisted of a $C_{2}$-symmetric cationic $N$ - heterocyclic carbene- $\mathrm{Pd}^{2+}$-diaqua complex, prepared from the chiral ligand L17 (Scheme 46) [168].

Bis(oxazoline)-based ligands were tested in an asymmetric allylation of $\mathrm{N}$-substituted-3-O-Boc-oxindoles with allyl acetates. The resulting 3-allyl-3-hydroxyoxindoles presented good enantioselectivities and diastereoselectivities (since a vicinal quaternary carbon center is formed) when prepared in the presence of the catalyst $\left[\mathrm{Pd}\left(\eta^{3}-\mathrm{C}_{3} \mathrm{H}_{5}\right) \mathrm{Cl}\right]_{2}(2.5 \mathrm{~mol} \%) / \mathbf{L 1 8}(10 \mathrm{~mol} \%)$ with $\mathrm{N}, \mathrm{O}$ - bis(trimethylsilyl)acetamide (BSA) and KOAc as additive (Scheme 47) [169].

Indium (III) is another metal that has been applied in the asymmetric synthesis of 3-hydroxy-3-substituted-oxindole derivatives. Using ligand $\mathbf{L 1}$ with $\operatorname{In}(\mathrm{OTf})_{3}(10 \mathrm{~mol} \%)$, an effective catalyst complex was obtained for the addition of pyrroles to $\mathrm{N}$ -

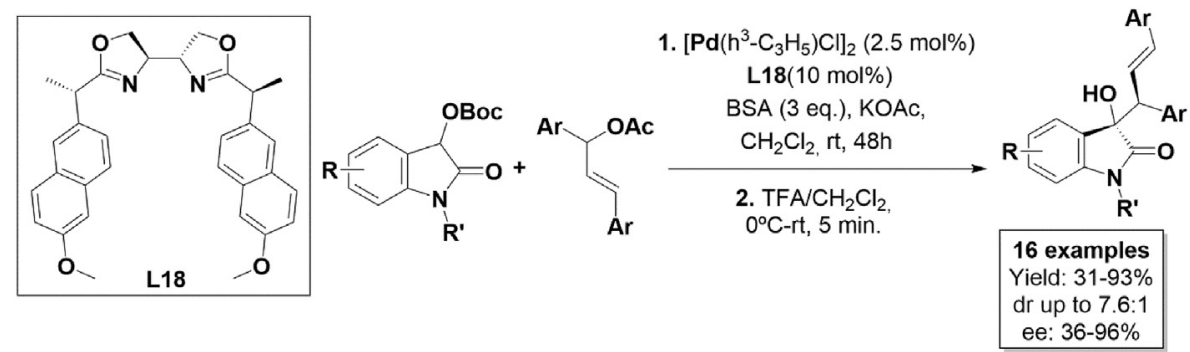

Scheme 47. Asymmetric allylation of 3-O-Boc-oxindole derivatives using palladium. 


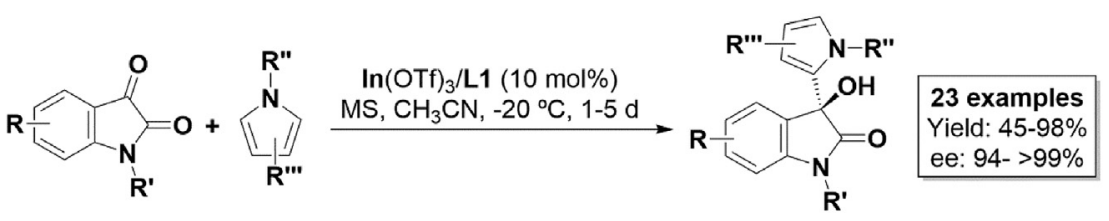

Scheme 48. Indium catalyzed asymmetric addition of pyrroles to isatin derivatives.

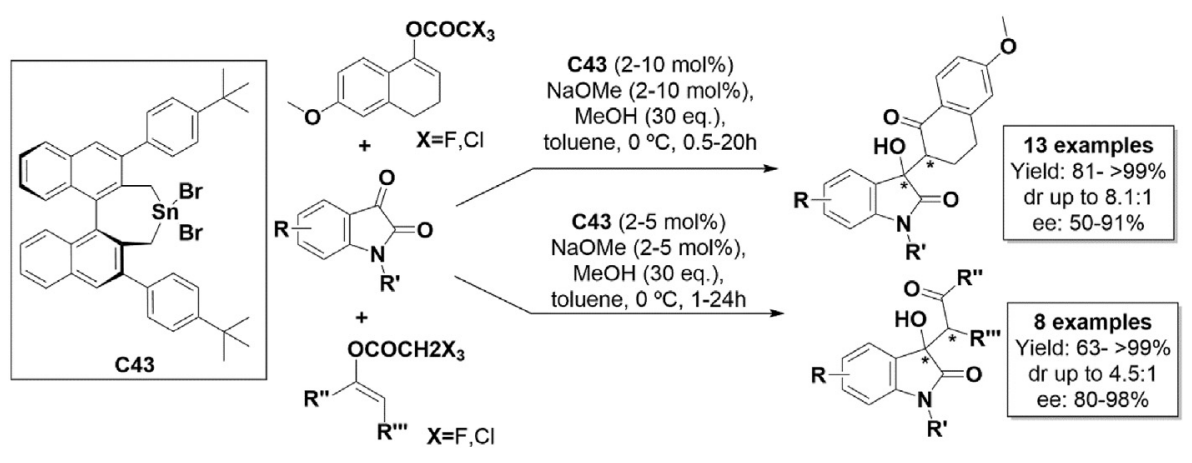

* absolute configuration not reported.

Scheme 49. Asymmetric aldol reaction using a tin chiral catalyst.

substituted and $\mathrm{N}$-unprotected isatin derivatives, with good to excellent yields and remarkable enantioselectivity (in many cases, $>99 \%$ ee was observed) (Scheme 48) [170].

A chiral (S)-BINOL-derived tin bromide C43 (Scheme 49) was used, in the presence of sodium methoxide, to promote the aldol reaction between isatin derivatives and 6-methoxy-1-tetralonederived alkenyl trichloroacetate (and trifluoroacetate) and other alkenyl esters. The 3-alkylated-3-hydroxy-oxindole derivatives were prepared in high yields and good enantioselectivities [171].

\subsubsection{Period $6-\mathrm{Yb}, \mathrm{Ir}, \mathrm{Hg}$}

Lanthanides have been widely described for their potential application in asymmetric catalysis [172-174]. Among them, ytterbium was applied in the enantioselective decarboxylative addition of $\beta$-ketoacids to isatins. The use of $N$-substituted isatins proved to be crucial for the reaction yield and enantioselectivity, in the presence of the catalytic system $\mathrm{Yb}(\mathrm{OTf})_{3} / \mathbf{L 1}$. The resulting chiral 1-benzyl-3-hydroxy-3-substituted-oxindole derivatives were obtained in very good yields (88-95\%) and moderate to excellent enantioselectivities (65-98\% ee) (Scheme 50) [175].

Iridium is a transition-metal from period 6 of the periodic table that presents a wide range of applications in synthesis [176,177]. Itoh et al. reported the first asymmetric allylations (Scheme 51 a)), crotylations (Scheme 51 b)) and prenylations (Scheme 51 c)) of $\mathrm{N}$ benzyl-isatin derivatives, using an isopropanol mediated transfer hydrogenation, in the presence of the catalyst $\left[\operatorname{Ir}(\operatorname{cod}) \mathrm{Cl}_{2}(2.5 \mathrm{~mol}\right.$ $\%)$ and the ligand cth- $(R)$-p-phos L19 $\left((R)-(+)-2,2^{\prime}, 6,6^{\prime}\right.$-tetramethoxy-4,4'-bis(diphenylphosphino)-3,3'-bipyridine - 5 mol\%), achieving moderate to good yields and good to excellent enantioselectivities (up to $96 \%$ ee) [178].

Using the same iridium source but with a lower catalyst loading (1 $\mathrm{mol} \%$ ), in the presence of the chiral phosphoramidite ligand $\mathbf{L 2 0}$ (Scheme 52), Zhuang et al. described the first iridium catalytic system for the asymmetric addition of arylboronic acids to $\mathrm{N}$-protected isatin dertivatives, achieving excellent results, in both yields and reaction stereocontrol [179].

A different approach was used by Yamamoto's group to prepare 3-hydroxy-3-substituted-oxindole derivatives with iridium. They promoted an asymmetric intramolecular direct hydroarylation of $\alpha$-ketoamides using cationic iridium $\left(\left[\operatorname{Ir}(\operatorname{cod})_{2}\right]\left(\operatorname{Bar}_{4}{ }_{4}\right)\right)$ and chiral ligand $\mathbf{L 1 0}$, affording the desired products in high to excellent yields and enantioselectivities (Scheme 53) [180]. Further studies indicated that the turnover-limiting step in the catalytic cycle was the carbonyl insertion step into the aryl-iridium bond [181].

Mercury based catalysts can also be used. However, the catalytic system that combined both $\mathrm{Hg}$ and the $(S)$-enantiomer of $\mathbf{L 1 3}$ gave the 3-hydroxy-3-substituted product with mediocre stereocontrol (up to 63\% ee) (Scheme 54) [182].

\section{3-Amino-oxindole derivatives}

\subsection{Organocatalysis}

\subsubsection{Cinchona alkaloids}

As is the case with chiral 3-hydroxyoxindole derivatives, a vast number of 3-amino-oxindoles have been prepared via asymmetric catalytic methods using cinchona alkaloids as catalysts.

Organocatalyst C16 was evaluated by two distinct research

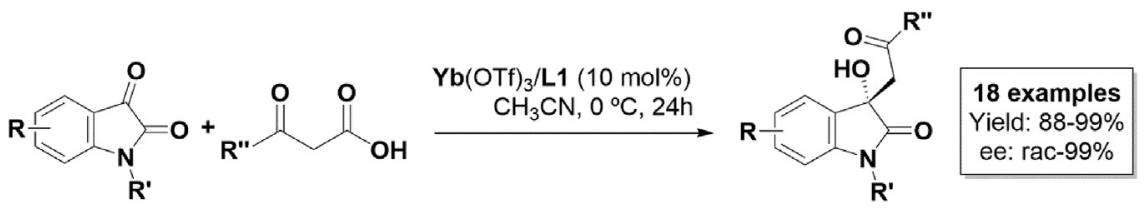

Scheme 50. Decarboxylative addition of $\beta$-ketoacids to isatin derivatives catalyzed by ytterbium. 

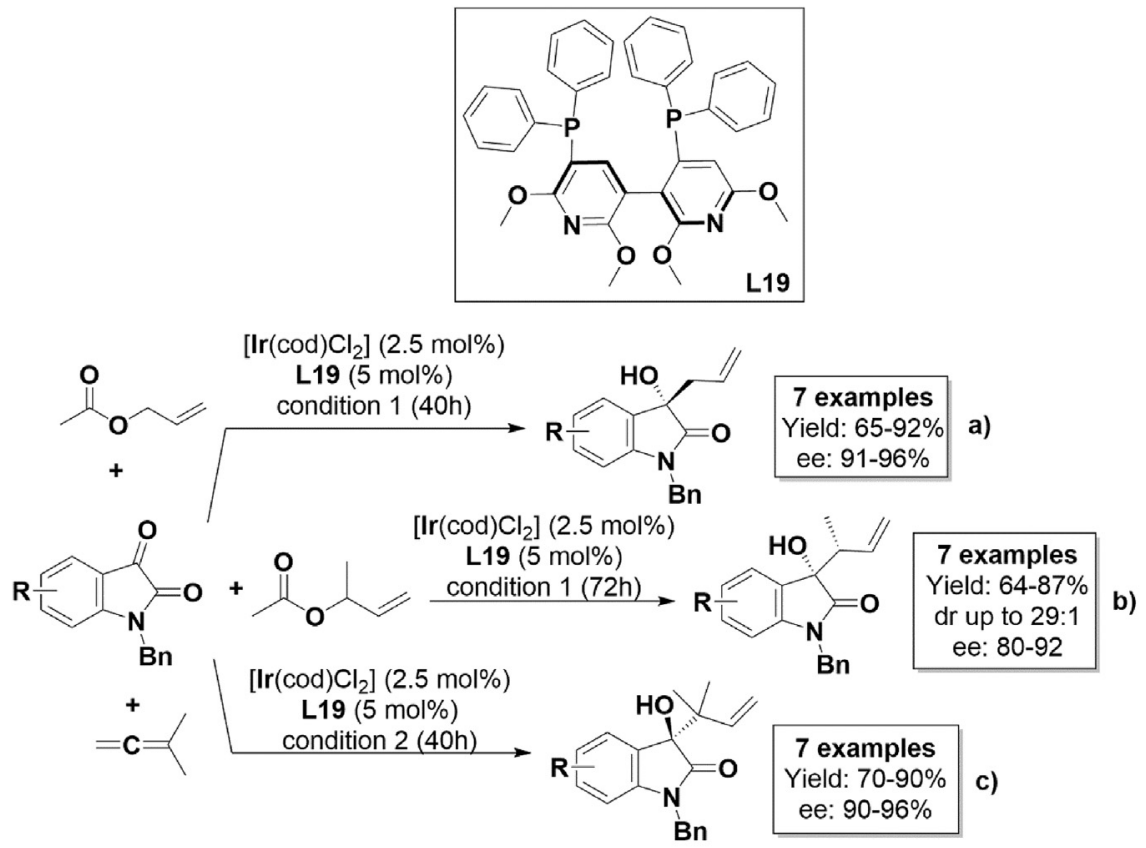

Condition 1: $\mathrm{iPrOH}(400 \mathrm{~mol} \%), \mathrm{Cs}_{2} \mathrm{CO}_{3}(20 \mathrm{~mol} \%), 4-\mathrm{CN}-3-\mathrm{NO}_{3}-\mathrm{BzOH}(10 \mathrm{~mol} \%), \mathrm{THF}, 100^{\circ} \mathrm{C}$ Condition 2: $\operatorname{iPrOH}(200 \mathrm{~mol} \%), \mathrm{Cs}_{2} \mathrm{CO}_{3}(7.5 \mathrm{~mol} \%), 3-\mathrm{NO}_{3}-\mathrm{BzOH}(7.5 \mathrm{~mol} \%)$, Toluene, $60^{\circ} \mathrm{C}$

Scheme 51. Allylation, crotylation and reverse prenylation of isatin derivatives.

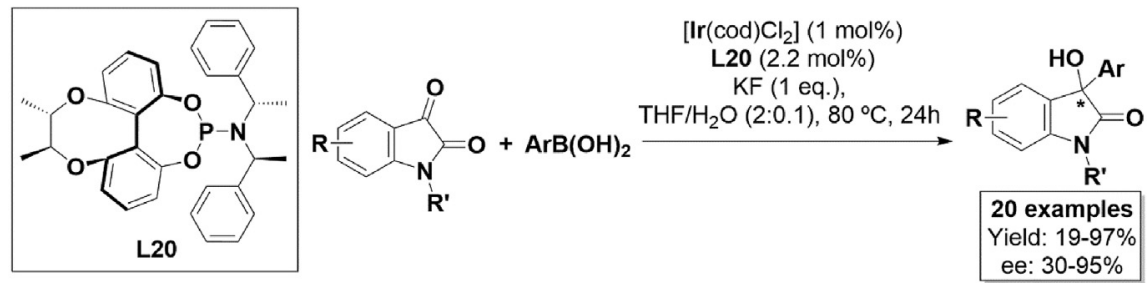

* absolute configuration not reported.

Scheme 52. Iridium-asymmetric catalytic addition of arylboronic acids to isatin derivatives.

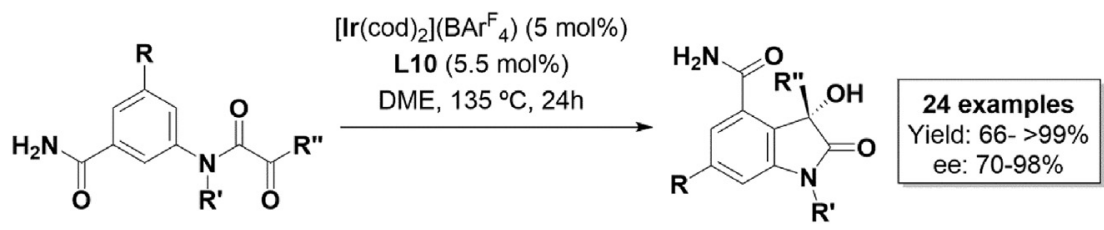

Scheme 53. Iridium-catalyzed asymmetric intramolecular direct hydroarylation of $\alpha$-keto amides.

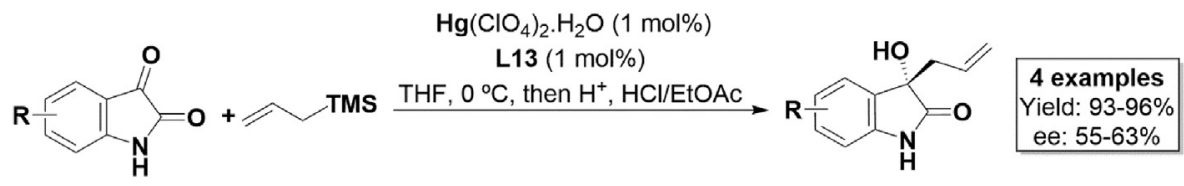

Scheme 54. Mercury-catalyzed asymmetric Sakurai-Hosomi allylation of isatin derivatives.

groups for the $\alpha$-amination of 2-oxindoles. Bui et al. used this biscinchona alkaloid (10 mol\%) in the reaction between $N$-protected oxindole derivatives and diethyl azodicarboxylate, with excellent yields and enantioselectivities (Scheme 55 a)) [183]. On the other hand, $N$-unprotected 3-amino-2-oxindole derivatives were prepared using the same catalyst loading as Cheng et al., but this time different dialkyl azodicarboxylates were evaluated, with diisopropyl azodiacarboxylate being the most promising electrophilic aminating reagent, as regards both yield and enantiomeric excess (Scheme 55 b)) [184]. 


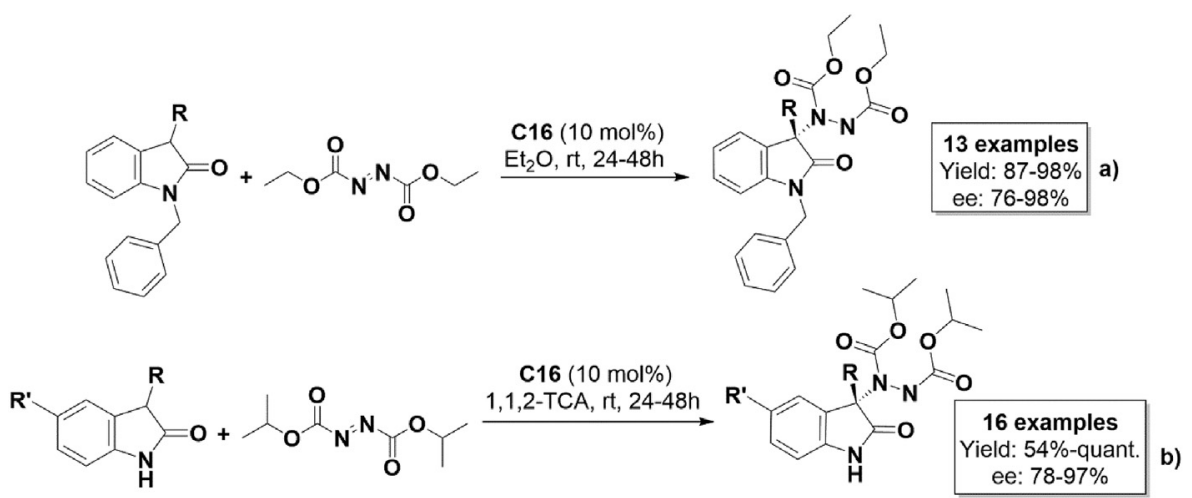

Scheme 55. Asymmetric organocatalytic $\alpha$-amination using C16.

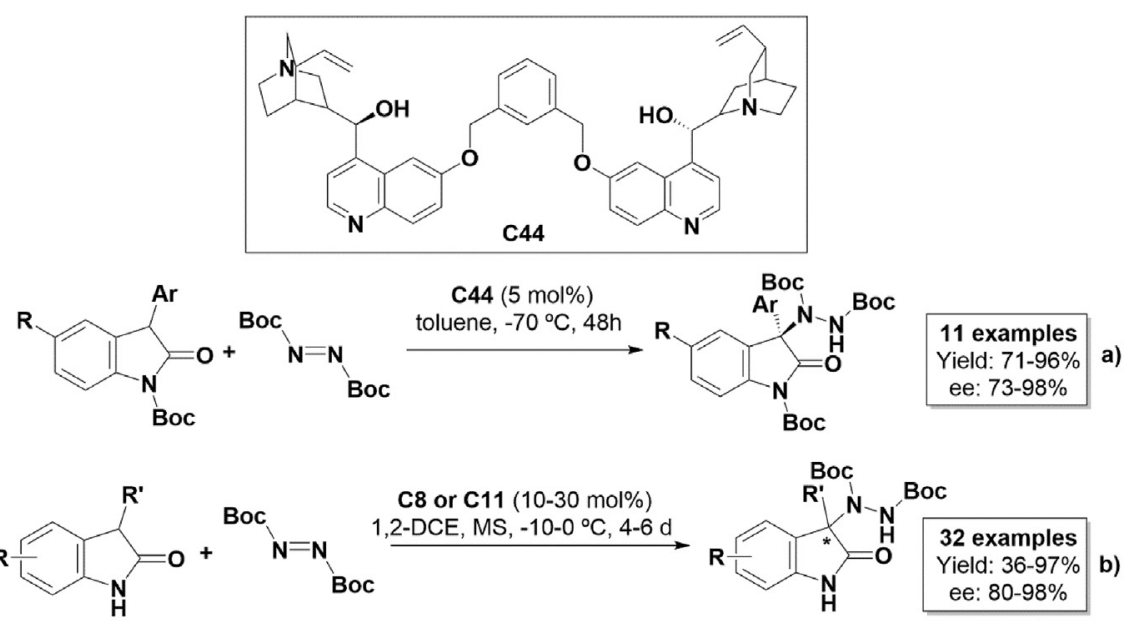

* absolute configuration reported as $(S)$ when using catalyst $\mathbf{C 8}$ and $(R)$ for $\mathbf{C} 11$.

Scheme 56. Asymmetric organocatalytic $\alpha$-amination using C44, C8 and C11.

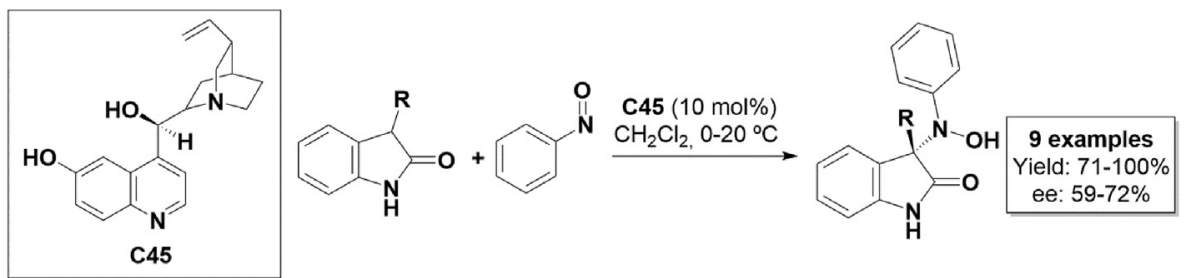

Scheme 57. Asymmetric organocatalytic $N$-nitroso-aldol reaction using $\mathbf{C 4 5}$.

The reaction was further studied applying a $\mathrm{C}_{6}$-quinidine dimer C44, which required a lower catalyst load ( $5 \mathrm{~mol} \%$ ) to prepare 3amino-3-arylsubstituted-oxindole derivatives, using di-tert-butyl azodicarboxylate (Scheme 56 a)) [185]. The same amination reagent was applied in another study, where the quinine-derived thiourea bifunctional catalyst C8 and its epimer C11 (10-30 mol $\%)$ was employed to promote the asymmetric $\alpha$-amination of unprotected 3-aryl. c11 could afford the opposite enantiomer as desired, however it was slightly less reactive and enantioselective than $\mathbf{C 8}$ (Scheme 56 b)) [186].

The cinchona catalyst $\mathbf{C 4 5}$ (10 mol\%) proved to be an efficient catalyst for the asymmetric $N$-nitroso-aldol reaction between different $N$-unprotected oxindole derivatives and nitrosobenzene (Scheme 57) [187].

A very desirable route to obtain chiral 3-amino-3-substituted oxindole derivatives is the direct nucleophilic reaction of the respective ketimines. With this goal, Hara et al. reported a decarboxylative addition of malonic acid half-thioesters to ketimines, and the best results were achieved with $N$-(8-quinolinesulfonyl)-9amino-9-deoxy-epi-cinchonidine $\mathbf{C 4 6}$ (Scheme 58 a) - 20 mol\%). This proved to be an interesting approach as a key-step for the synthesis of AG-041R (Scheme 59), a bioactive compound with gastrin/cholecyctokinin-B receptor antagonist activity, which can be applied as a cartilage defects repair agent [188-190]. Ketimines were also used in the enantioselective synthesis of 3aminooxindoles, via addition of 1,3-dicarbonyl compounds, using organocatalyst C8 (Scheme 58 b)) [191].

The catalyst $\mathbf{C 8}$ was also useful for the preparation of chiral 3amino-3-cyano-oxindole derivatives, through the nucleophilic addition of trimethylsilyl cyanide to N-Boc protected ketimines 

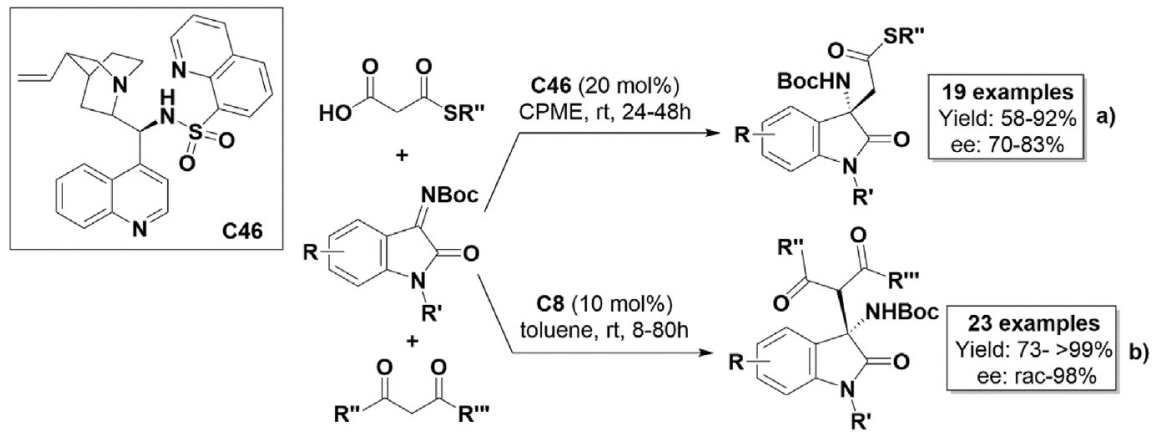

Scheme 58. Asymmetric reactions of ketimines with 1,3-dicarbonyl compounds.

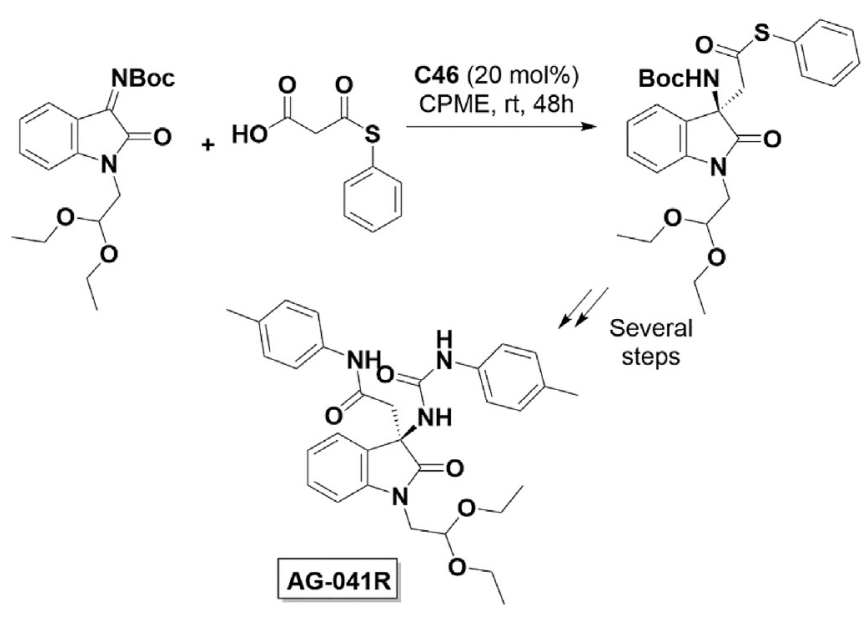

Scheme 59. Key-step for the synthesis of bioactive compound AG-041R.

(Scheme 60 a)). This was the first reported enantioselective organocatalyzed Strecker reaction using this type of substrate as electrophile and proved to be an efficient route [192]. Catalyst C5 was applied in the hydrophosphonylation of ketimines giving chiral 3amino-3-substituted-oxindoles in moderate to good yields and enantioselectivities (Scheme 60 b)) [193].

Organocatalyst C3 $(20 \mathrm{~mol} \%)$ proved to be effective in the formation of chiral 3-amino-3-nitromethyloxindole derivatives, which were formed via an aza-Henry reaction between ketimines and nitroalkanes (Scheme 61) [194].

Morita-Baylis-Hillman carbonates of isatins underwent asymmetric allylic amination with $\mathrm{N}$-silyloxycarbamates using organocatalyst $\mathbf{C 4 7}$ (10 mol\%), and afforded chiral 3-amino-3-substitutedoxindoles with good to excellent enantiomeric excesses and yields (Scheme 62) [195].

In order to access a library of chiral 3-ethylacetate-substituted3-amino-2-oxindole derivatives, Zhao et al. developed an organocatalytic Mannich/denitration reaction. Catalyst $\mathbf{C 4 8}$ proved to be the most efficient one to promote the addition of ethyl nitroacetate to different $\mathrm{N}$-Boc ketimines, affording the target compounds in moderate to good yields and very good to excellent enantioselectivity (Scheme 63 a)). This approach seems to be an interesting alternative route to obtain the already mentioned bioactive compound AG-041R [196]. Recently, new cinchona alkaloid-derived phase-transfer catalysts were developed to perform asymmetric nitro-Mannich reactions on isatin-derived $\mathrm{N}$-Boc ketimines. The quinine-urea bifunctional catalyst $\mathbf{C 4 9}$ (10 mol\%) afforded the desired chiral 3-amino-3-nitroalkyloxindole derivatives with excellent yields and very good enantiomeric excesses (Scheme 63 b)) [197].

Bao et al. reported the use of catalyst C14 to promote an asymmetric Friedel-Crafts addition/fluorination sequence to synthesize oxindole-pyrazolone hybrid compounds. The reaction between the 4-nonsubstituted pyrazolones and N-Boc ketimines derived from

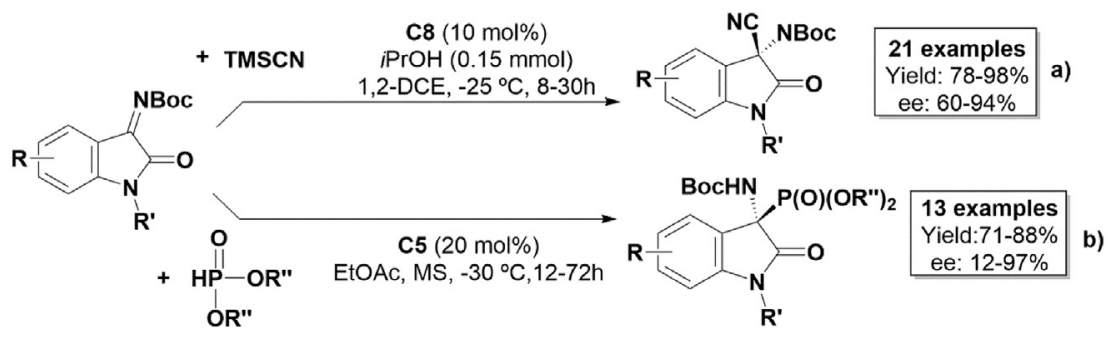

Scheme 60. Asymmetric Strecker reaction (a) and hydrophosphonylation (b) of ketimines.

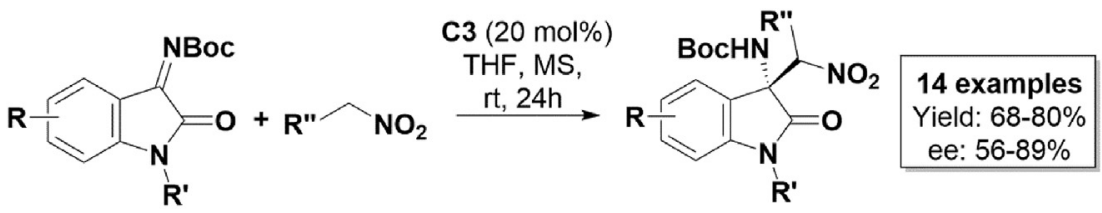

Scheme 61. Asymmetric organocatalytic aza-Henry reaction using catalyst C3. 


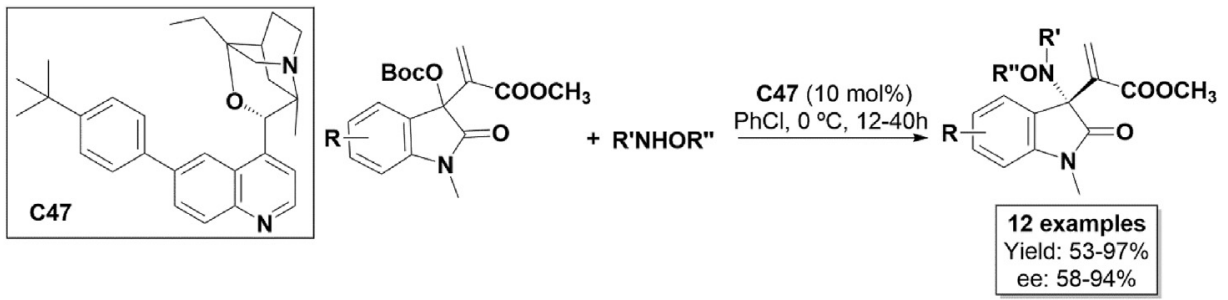

Scheme 62. Asymmetric allylic amination of Morita-Baylis-Hillman carbonates of isatins.

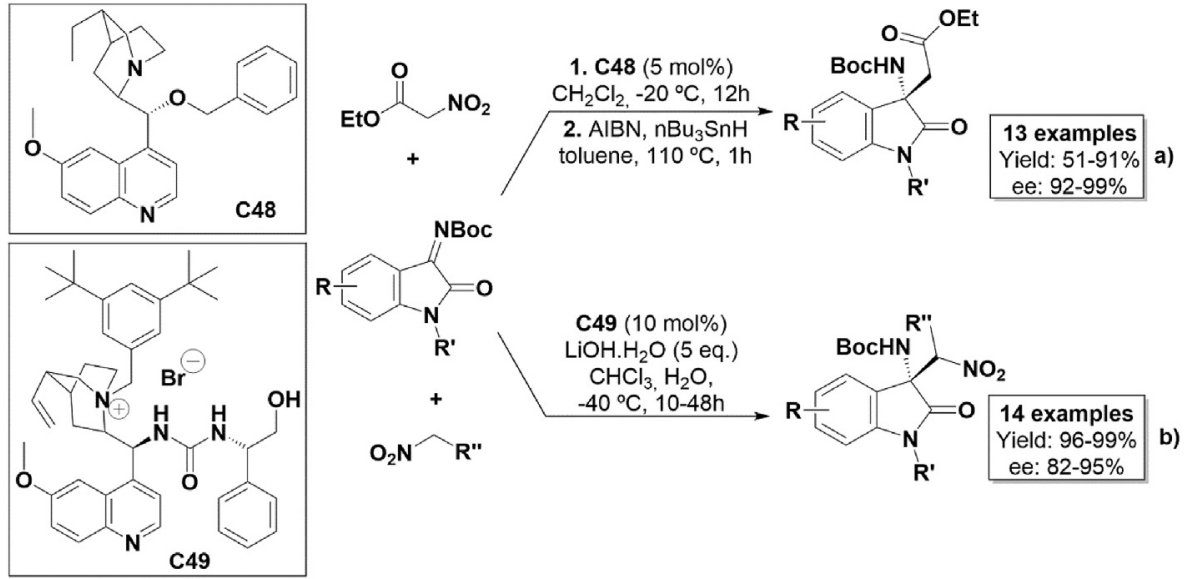

Scheme 63. Asymmetric Mannich/denitration reaction (a) and nitro-Mannich reaction (b), using isatin-derived N-Boc ketimines as starting material.

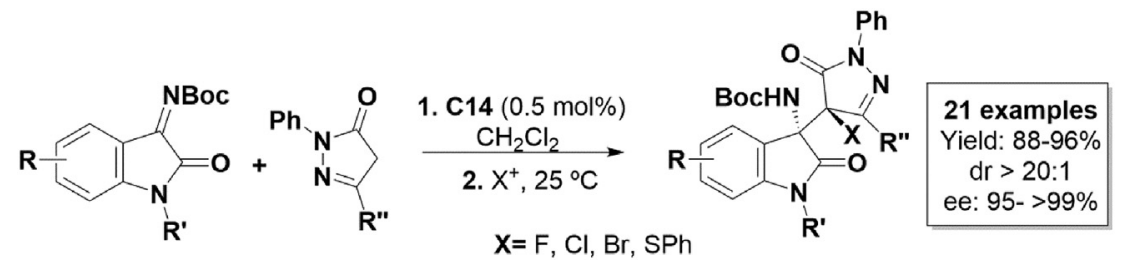

Scheme 64. Asymmetric organocatalytic synthesis of oxindole-pyrazolone hybrids.

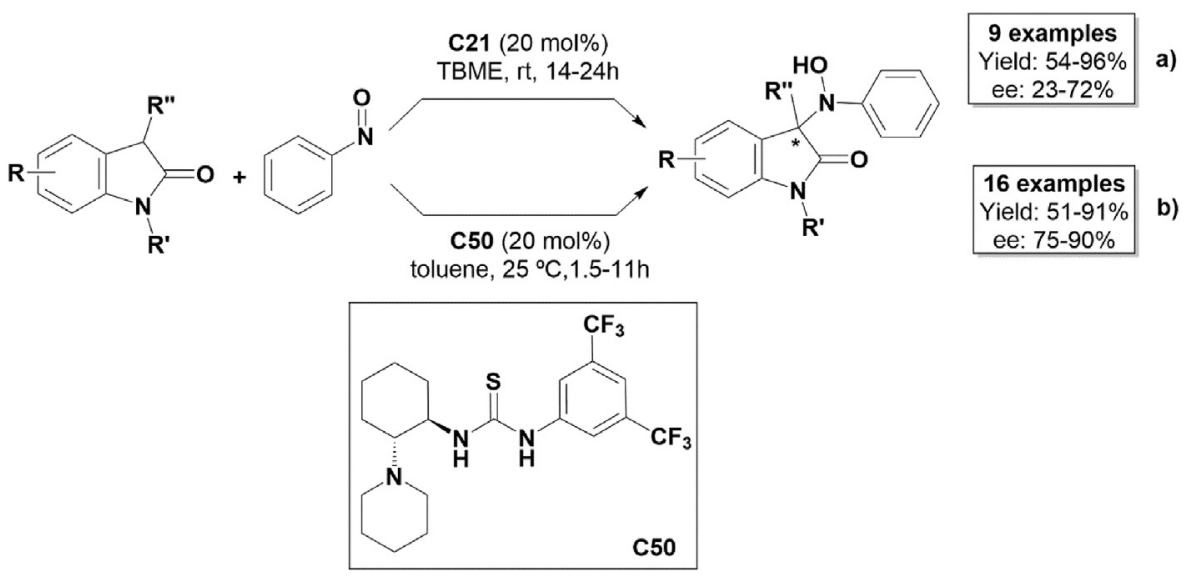

* absolute configuration reported: a) (S); b) (R).

Scheme 65. Asymmetric hydroxyamination catalyzed by chiral bifunctional tertiary amine-thiourea organocatalysts. 


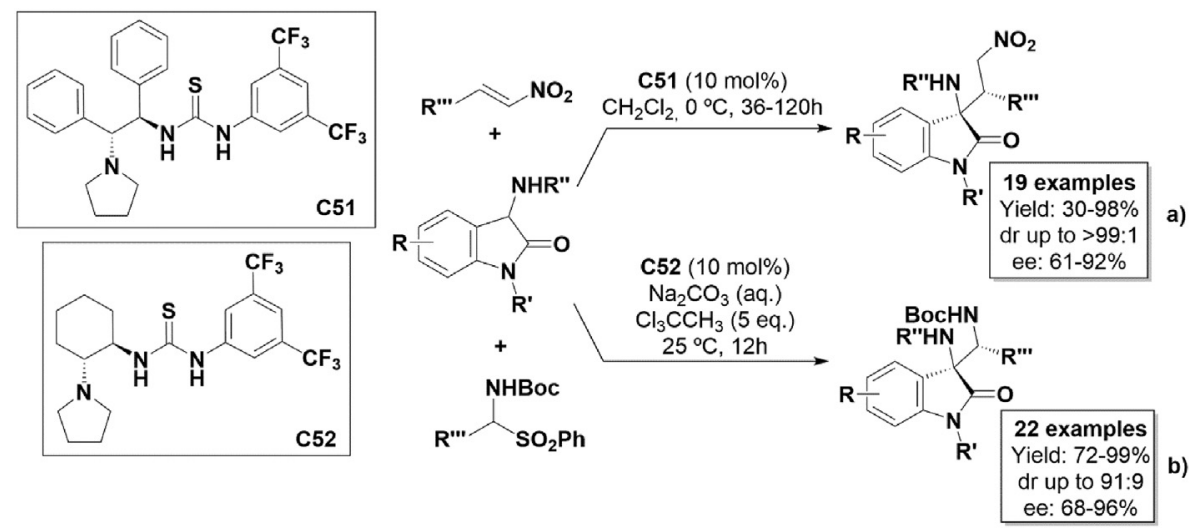

Scheme 66. Organocatalytic asymmetric Michael addition (a) and Mannich reaction (b), using bifunctional tertiary amine-thiourea organocatalysts.

isatin proceeded with excellent yields and enantioselectivities with a catalyst loading as low as $0.5 \mathrm{~mol} \%$ (Scheme 64) [198].

\subsubsection{Thiourea derivatives}

Organocatalyst C21 (20 mol\%) was effectively applied in the $\alpha$ hydroxyamination of $\mathrm{N}$-unprotected 3-substituted-2-oxindoles with nitrosobenzene. The chiral adducts generated by this nitroso-aldol reaction presented good yields and enantioselectivities (Scheme 65 a)) [199] Jia et al. reported the same type of reaction and created a library of 16 chiral 3-amino-3-substituted oxindole compounds with moderate to good yields and enantioselectivity, using 20 mol\% of catalyst C50 (Scheme 65 b)) [200].

In another example, 3-monosubstituted 3-aminooxindoles were used as starting material for an asymmetric Michael addition with nitroolefins. The quaternary 3-amino-oxindoles obtained with organocatalyst C51 (10 mol\%) contained contiguous stereocenters, and were obtained in high yields with very good levels of diastereoselectivity and enantioselectivity (Scheme 66 a)) [201].

Recently, 3-monosubstituted 3-amino-oxindole derivatives underwent asymmetric Mannich reaction with in situ generated $\mathrm{N}$ Boc-protected aldimines in the presence of catalyst $\mathbf{c 5 2}$. The compounds obtained in this library (22 examples) were obtained in high yield, diastereoselectivity and enantiomeric excess (Scheme 66 b)) [86].

\subsubsection{Squaramide and phosphine derivatives}

An asymmetric aza-Morita-Baylis-Hillman reaction was catalyzed by BINOL-phosphine-derived catalyst C53 (20 mol\%), using isatin derived ketimines and methyl vinyl ketone as substrates. The resulting chiral 3-amino-oxindole derivatives were obtained in good to excellent enantioselectivities and overall good yields. It was also noticed that the reaction required a shorter period ( $48 \mathrm{~h})$, than when compared to the $\beta$-isocupreidine organocatalysts ( $72 \mathrm{~h}$ ) (Scheme 67 a)) [202]. A similar approach was studied by Zhao et al., but using different acrylates as substrates and a phosphinesquaramide-derived organocatalyst C54. Overall good stereocontrol and good to excellent yields were achieved using this catalyst albeit with a remarkable loading of just $2 \mathrm{~mol} \%$ (Scheme 67
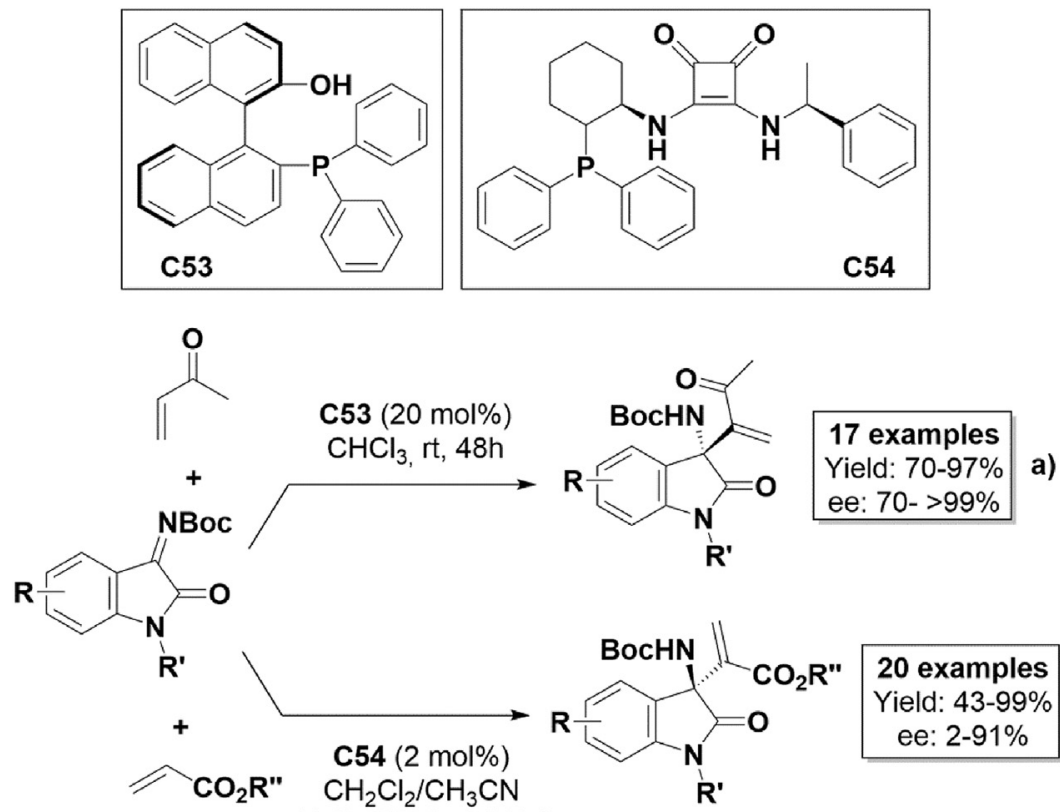

$(1: 2), 25^{\circ} \mathrm{C}, 1.5-7 \mathrm{~d}$

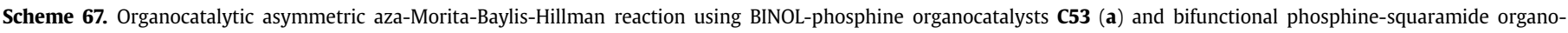
catalyst C54 (b). 

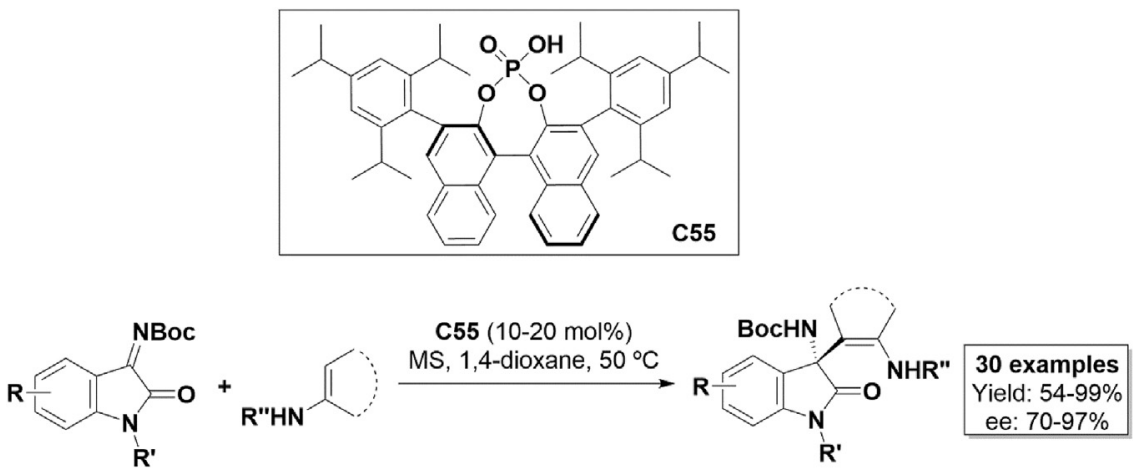

Scheme 68. Asymmetric organocatalytic synthesis of cyclic enaminone-based 3-amino-3-substituted-oxindole derivatives.

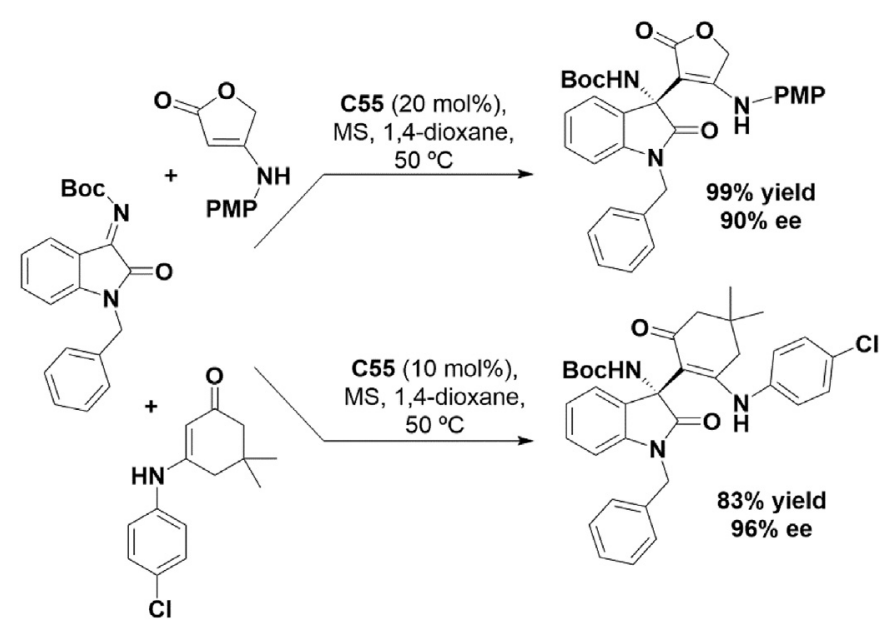

Scheme 69. Asymmetric organocatalytic synthesis of bioactive compounds using organocatalyst C55.

\section{b)) [203].}

The chiral phosphoric acid-derived catalyst $\mathbf{C 5 5}$ (10 mol\%) was successfully applied for the preparation of a library of cyclic enaminone-based 3-substituted-3-amino-oxindole derivatives, using molecular sieves ( $3 \AA$ ) as additive (Scheme 68). The researchers also demonstrated that the same system could be used in a scale-up procedure. Also, the compound's cytotoxicity was accessed. Both the racemic mixture and the isolated enantiomers were screened with four different cancer cell lines (A549 - lung cancer; 786-0 - kidney cancer; ECA109 - esophageal carcinoma; BT474 - Breast cancer). While the racemic mixtures did not present relevant activities, the single enantiomers gave better results, with the effect being dependent not only on the enantiomer, but also on the cell line in question (i.e., in some cell lines, the $(R)$-enantiomer was more active than the $(S)$-enantiomer, but in other cell lines the inverse was seen). Examples of bioactive enantiomers are presented in Scheme 69 [204]. This in fact underlines the importance of asymmetric synthesis procedures in medicinal chemistry.

\subsubsection{Triazolium salts}

Triazolium salts have become important tools in asymmetric catalysis [128,205,206]. Catalyst C56 was able to catalyze asymmetric $\alpha$-amination reactions of different hydroxylamines with $\mathrm{N}$ Boc-protected-3-phenyl-oxindole, at a catalyst loading of $5 \mathrm{~mol} \%$. The resulting $\alpha$-aminocarbonyl compounds (3-phenyl-3-aminosubstituted- oxindole derivatives - 15 examples) presented excellent enantioselectivities and moderate to very good yields
(Scheme 70) [207]. Azolium salts, as well as $N$-heterocyclic carbene compounds that originate azolium species during the catalytic cycle, have also been applied in kinetic resolution experiments to afford enantioenriched 3-hydroxy-3-substituted-oxindole derivatives [208,209].

\subsection{Transition-metal catalysis}

\subsubsection{Period $4-\mathrm{Sc}, \mathrm{Fe}, \mathrm{Ni}$}

Chiral scandium complexes have been used by Feng's group to promote asymmetric reactions with 3-substituted oxindole derivatives. In one example, they reported an $\alpha$-amination reaction using $\mathrm{Sc}(\mathrm{OTf})_{3}$ and an $N, N^{\prime}$-dioxide ligand $\mathbf{L} 21$ to catalyze the reaction between 3-substituted-oxindole derivatives and different azodicarboxylates. Depending on the substrate, they could reduce the catalyst loading to $0.5 \mathrm{~mol} \%$ of $\mathrm{Sc}(\mathrm{OTf})_{3}$ and $0.75 \mathrm{~mol} \%$ of $\mathbf{L 2 1}$, obtaining the 3-amine-3-substituted-oxindole derivatives with good to excellent yields and enantioselectivities (Scheme 71 a)) [210]. Using the same chiral scandium complex, they further expanded the scope of this catalyst to enantioselective hydroxyamination reactions of 3-substituted-oxindole derivatives with nitrosoarenes. The resulting 3-hydroxyamine-3-substituted-oxindole derivatives were obtained in high to excellent yields and enantioselectivities showing, once again, the utility and versatility of this scandium catalyst complex (Scheme 71 b)) [211].

Nickel has also been described by several groups for its ability to participate in chiral complexes and in asymmetric catalysis. A great example of the applicability of these complexes is the enantioselectivity switch induced by the presence of homobimetallic or monometallic Schiff base catalysis reported by Shibasaki's group. Using chiral ligands $\mathbf{L 2 2}$ and L23 they could prepare homobimetallic complexes and monometallic complexes, respectively. Remarkably, using $\mathrm{N}$-Boc-protected-3-substituted-oxindoles and azodicarboxylates as starting materials, they observed that the homobimetallic complex provided the $(R)$-enantiomer of the 3 amino-3-substituted-oxindole derivatives (Scheme 72 a)) and the monometallic complex resulted in the $(S)$-enantiomer (Scheme 72 b)) and, in both cases, excellent enantioselectivities and yields were achieved [212].

In another example on the use of nickel in asymmetric catalysis, Arai et al. reported the use of the complex between $\mathrm{NiCl}_{2}$ ( $5 \mathrm{~mol} \%$ ) with the chiral ligand $(S, S)$-diphenyldiamine-derived bis(imidazolidine)-pyridine $\mathbf{L 2 4}$ (5.5 mol\%) to promote a nitroMannich reaction. They verified that even under mild reaction conditions, $N$-protected isatin-derived $N$-Boc ketimines could be converted into chiral 3-amino-3-substituted-oxindole derivatives with promising results (up to 99\% yield and 95\% ee) (Scheme 73) [213]. 


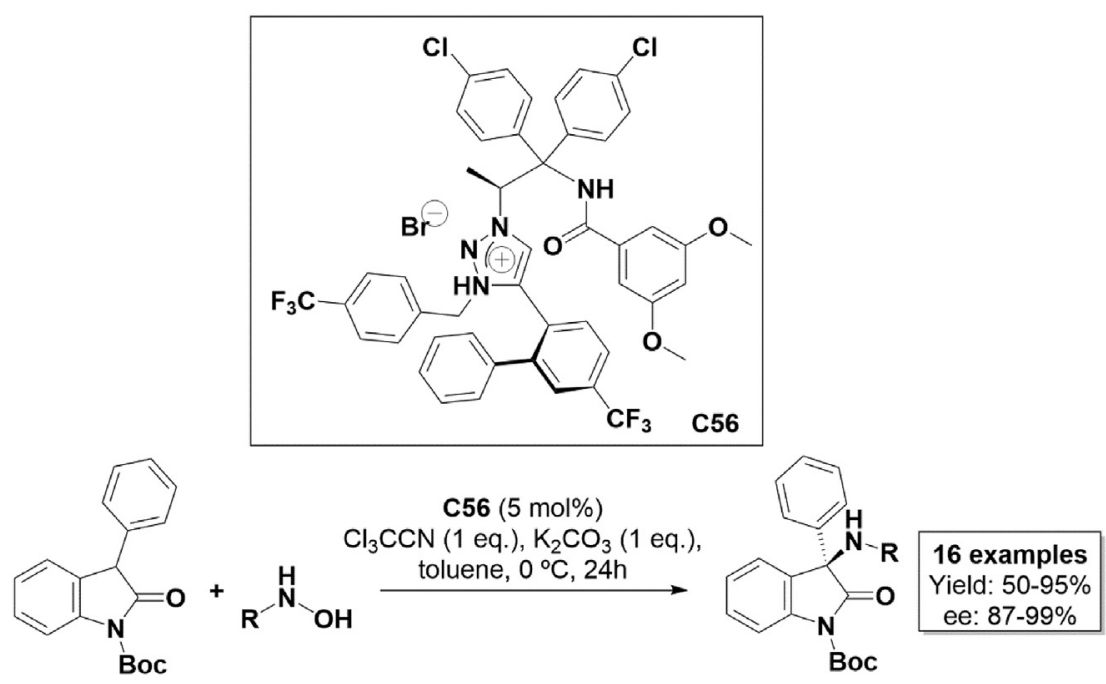

Scheme 70. Direct catalytic asymmetric $\alpha$-amination of $N$-Boc protected 3-phenyl-oxindole using triazolium salt C56.

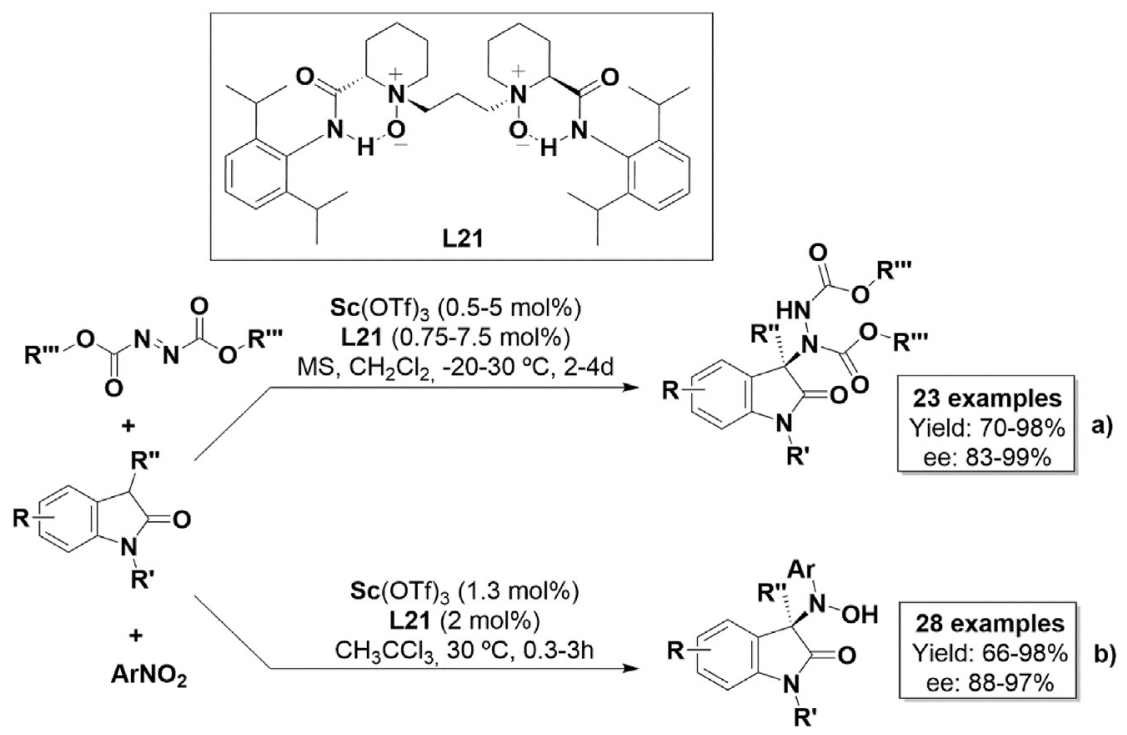

Scheme 71. Catalytic asymmetric $\alpha$-amination (a) and hydroxyamination (b) of oxindole derivatives using the scandium-L21 complex.

Recently, the synthesis of chiral 3-amino-3-substituted oxindoles was reported through the application of a chiral catalyst complex $\mathrm{Ni}(\mathrm{dppp}) \mathrm{Cl}_{2} /$ bis(oxazoline) ligand L25. In this study, the substrates consisted of 3-bromo-3-substituted-oxindole derivatives and anilines, and the final products were obtained in good yields and enantioselectivity (Scheme 74) [214].

\subsubsection{Period $5-R h$ and $P d$}

While these metals are widely applied in the preparation of chiral 3-hydroxy-oxindole derivatives, there are not many reports on the use of metals from period 5 in the preparation of chiral 3amino-oxindole derivatives.

In one example, reported by Ren et al., the catalyst complex formed between $\left[\mathrm{Rh}_{2}(\mathrm{OAc})_{4}\right]$ and compound $\mathbf{C 5 5}$, catalyzed an aldol-type three component reaction between 3-diazo oxindole derivatives, anilines and glyoxylates to obtain the chiral products in moderate to excellent yields and enantioselectivities (Scheme 75) [215].
Recently, in our group, we presented the first asymmetric catalytic arylation of isatin-derived ketimines with arylboronic acids to obtain chiral 3-amino-3-aryl-oxindole derivatives. Using the (S,S)-diene-type chiral ligand L26 [216], the best result was observed, was 30\% yield and 39\% ee (Scheme 76) [217].

Tolstoy et al. reported a new synthetic route to prepare chiral 3amino-oxindole derivatives using palladium, via asymmetric intramolecular arylation of $\alpha$-ketimino amides. The catalyst system was composed of $\left[\mathrm{Pd}\left(\mathrm{CH}_{3} \mathrm{CN}\right)_{4}\right]\left(\mathrm{BF}_{4}\right)_{2}(5 \mathrm{~mol} \%)$ and $\mathbf{L 1 4}(10 \mathrm{~mol} \%)$. The reaction's stereocontrol and yields were highly dependent on the substituent pattern, ranging from $51-96 \%$ ee and $47-95 \%$ yield (Scheme 77) [218].

\section{Final remarks}

As shown in this report, significant progress has been achieved in the asymmetric synthesis of chiral 3-hydroxy-3-substitutedoxindole derivatives and 3-amino-3-substituted-oxindole 


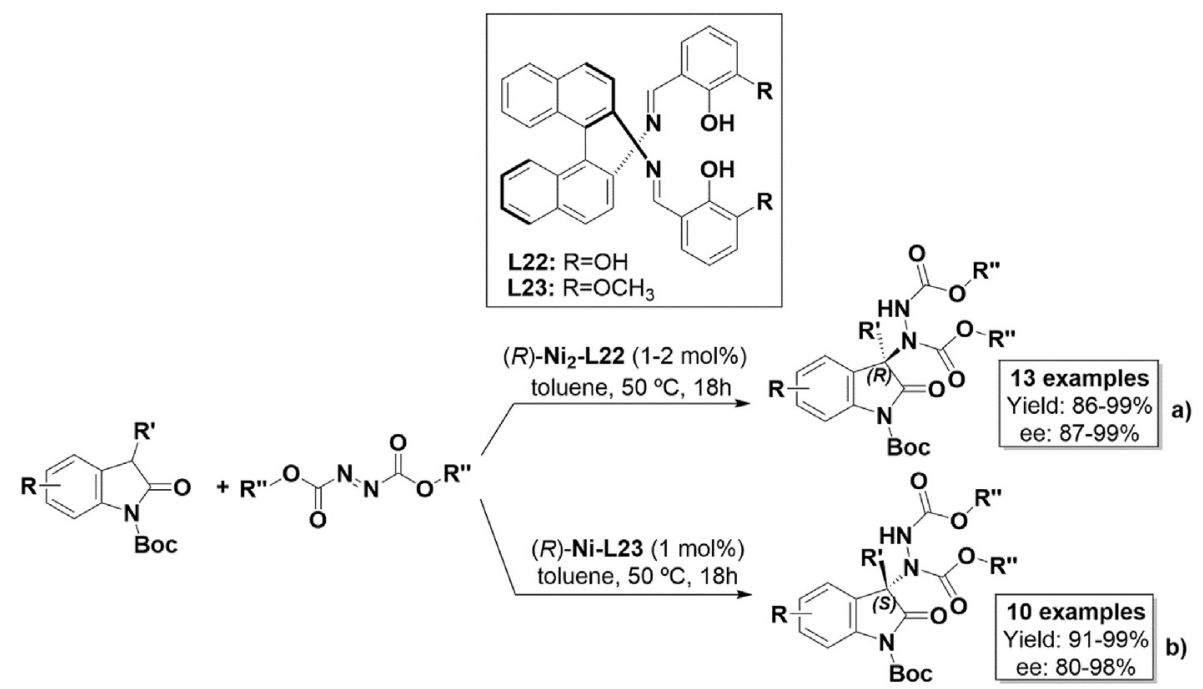

Scheme 72. Enantioselectivity switch performed by bimetallic versus monometallic nickel-chiral ligand complexes.
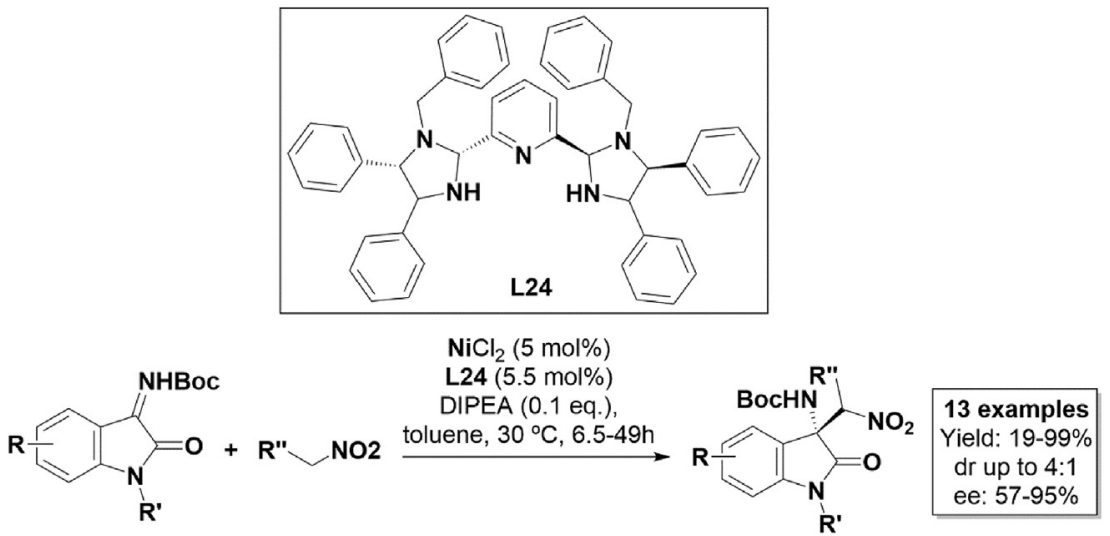

Scheme 73. Nickel-L24 complex catalyzed asymmetric nitro-Mannich reaction.
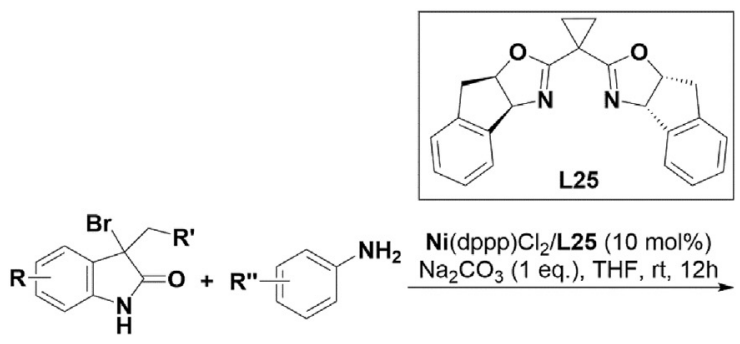

$\mathrm{NH}_{2} \quad \mathrm{Ni}(\mathrm{dppp}) \mathrm{Cl}_{2} / \mathrm{L} 25(10 \mathrm{~mol} \%)$<smiles>Cc1ccccc1</smiles>
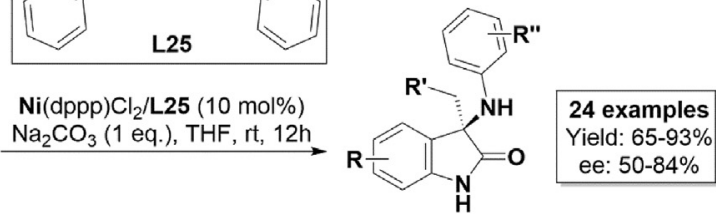

Scheme 74. Asymmetric catalytic amination reaction of 3-bromo-3-substituted-oxindole derivatives using nickel-L25.

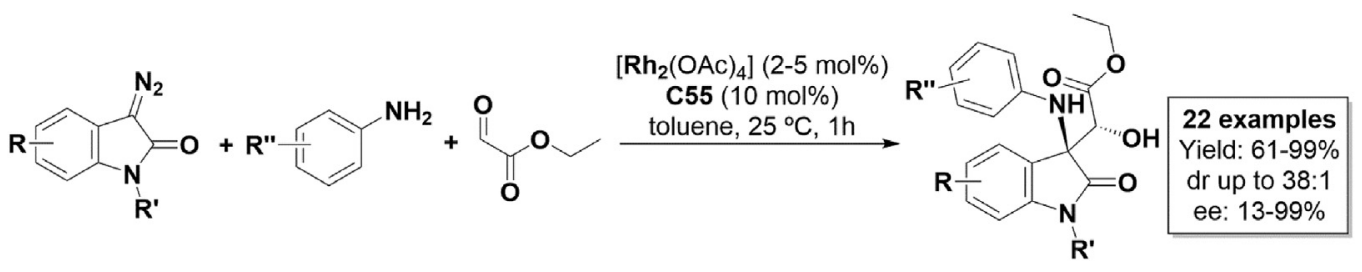

Scheme 75. Brønsted-acid C55/rhodium (II) asymmetric catalytic three-component aldol-typre reaction. 


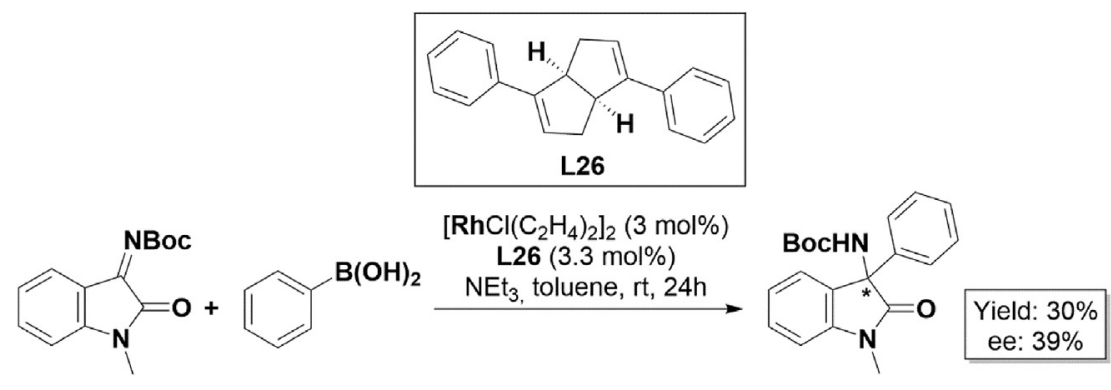

* absolute configuration not reported.

Scheme 76. $(S, S)$-diene-type chiral ligand/rhodium catalyzed asymmetric arylation of a ketamine with phenylboronic acid.

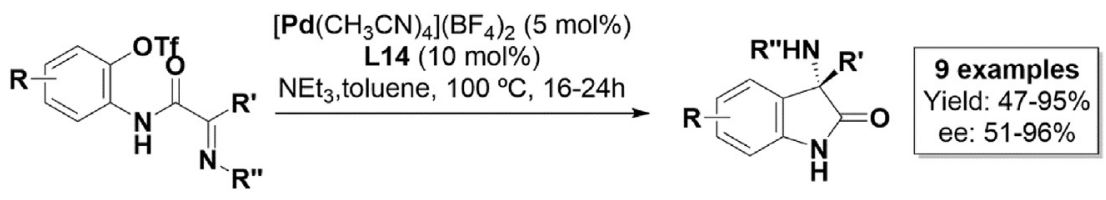

Scheme 77. Palladium/L14 asymmetric catalytic intramolecular arylation of $\alpha$-ketoimino amides.

derivatives over the past decade. While metal/chiral ligand complex catalysis still has the advantage of often requiring less catalyst loading than that for organocatalysts, the recent advances in organocatalysis have allowed researchers to decrease the required organocatalyst loading, whilst maintaining the high levels of reaction stereocontrol.

Asymmetric catalysis has proven to be an invaluable tool for the synthesis of chiral bioactive compounds, with a wide range of medicinally relevant applications. Moreover, there has been a staggering increase in the number of publications on the asymmetric catalytic synthesis of 3-hydroxy and 3-amino-oxindole derivatives that are useful new scaffolds for providing key targets with pharmacological activity.

\section{Acknowledgements}

We are grateful to the Fundação para a Ciência e Tecnologia (FCT) for funding (PB - PhD grant PD/BD/128490/2017) which is funded through the Catalysis and Sustainability doctoral program (CATSUS). We also acknowledge the FCT - Foundation for Science and Technology for funding through the strategic project UID/QUI/ 0619/2016.

\section{References}

[1] M. Kaur, M. Singh, N. Chadha, O. Silakari, Eur. J. Med. Chem. 123 (2016) $858-894$.

[2] T. Ling, F. Rivas, Tetrahedron. 72 (2016) 6729-6777.

[3] W.H. Brooks, W.C. Guida, K.G. Daniel, Curr. Top. Med. Chem. 11 (2011) $760-770$.

[4] Q. Shen, L. Wang, H. Zhou, H.-d. Jiang, L.-s. Yu, S. Zeng, Acta. Pharmacol. Sin. 34 (2013) 998.

[5] B. Kasprzyk-Hordern, Chem. Soc. Rev. 39 (2010) 4466-4503.

[6] H. Pellissier, Tetrahedron. 72 (2016) 3133-3150.

[7] V. Farina, J.T. Reeves, C.H. Senanayake, J. Song, J. Chem. Rev. 106 (2006) 2734-2793.

[8] J. Aleman, S. Cabrera, Chem. Soc. Rev. 42 (2013) 774-793.

[9] T. Yutthalekha, C. Wattanakit, V. Lapeyre, et al., Nat. Commun. 7 (2016) 12678.

[10] G. Zhan, W. Du, Y.-C. Chen, Chem. Soc. Rev. 46 (2017) 1675-1692.

[11] G. Chen, Y. Wang, S. Gao, et al., J. Heterocycl. Chem. 46 (2009) 217-220.

[12] S. Peddibhotla, Curr. Bioact. Compd. 5 (2009) 20-38.

[13] P. Sai Prathima, P. Rajesh, J. Venkateswara Rao, U. Sai Kailash, B. Sridhar,
M. Mohan Rao, Eur. J. Med. Chem. 84 (2014) 155-159.

[14] R.K.P. Tripathi, S. Krishnamurthy, S.R. Ayyannan, ChemMedChem. 11 (2016) $119-132$

[15] C. Zhang, D.-M. Zhuang, J. Li, et al., Org. Biomol. Chem. 11 (2013) 5621-5633.

[16] D. Yasuda, K. Takahashi, T. Ohe, S. Nakamura, T. Mashino, Biorg. Med. Chem. 21 (2013) 7709-7714.

[17] A. Dandia, D. Saini, D.K. Saini, M. Mathur, Eur. Chem. Bull. 3 (2014) 85-92.

[18] M.M.M. Santos, Tetrahedron. 70 (2014) 9735-9757.

[19] B. Yu, D.-Q. Yu, H.-M. Liu, Eur. J. Med. Chem. 97 (2015) 673-698.

[20] Z.-Y. Cao, Y.-H. Wang, X.-P. Zeng, J. Zhou, Tetrahedron. Lett. 55 (2014) $2571-2584$.

[21] R. Dalpozzo, G. Bartoli, G. Bencivenni, Chem. Soc. Rev, 41 (2012) 7247-7290.

[22] R. Dalpozzo, Adv. Synth. Catal. 359 (2017) 1772-1810.

[23] S. Nakamura, Org. Biomol. Chem. 12 (2014) 394-405.

[24] J.J. Badillo, N.V. Hanhan, A.K. Franz, Curr. Opin. Drug. Discov. Dev. 13 (2010) $758-776$.

[25] S. Mohammadi, R. Heiran, R.P. Herrera, E. Marqués-López, ChemCatChem. 5 (2013) 2131-2148.

[26] G. Mohammadi Ziarani, R. Moradi, N. Lashgari, Tetrahedron. Asymmetry. 26 (2015) 517-541.

[27] G. Mohammadi Ziarani, R. Moradi, N. Lashgari, Tetrahedron. 74 (2018) $1323-1353$.

[28] J.P. MacDonald, J.J. Badillo, G.E. Arevalo, A. Silva-García, A.K. Franz, ACS. Comb. Sci. 14 (2012) 285-293.

[29] X. Min, M. Ru-Zheng, J. Heterocycl. Chem. 51 (2014) 539-554.

[30] A.P. Antonchick, C. Gerding-Reimers, M. Catarinella, et al., Nat. Chem. 2 (2010) 735.

[31] N. Ye, H. Chen, E.A. Wold, P.-Y. Shi, J. Zhou, ACS. Infect. Dis. 2 (2016) 382-392.

[32] D. Cheng, Y. Ishihara, B. Tan, C.F. Barbas, ACS. Catal. 4 (2014) 743-762.

[33] B. Yu, Z. Yu, P.-P. Qi, D.-Q. Yu, H.-M. Liu, Eur. J. Med. Chem. 95 (2015) 35-40.

[34] Y. Bin, Z. Yi-Chao, S. Xiao-Jing, Q. Ping-Ping, L. Hong-Min, Anti. Canc. Agents. Med. Chem. 16 (2016) 1315-1324.

[35] T.L. Pavlovska, R.G. Redkin, V.V. Lipson, D.V. Atamanuk, Mol. Divers. 20 (2016) 299-344.

[36] Y. Yan-Tao, Z. Jun-Fang, L. Guochao, X. Hai-Jiang, Y. Bin, Curr. Med. Chem. 25 (2018) 1-12.

[37] G.-J. Mei, F. Shi, Chem. Commun. (2018), https://doi.org/10.1039/c8cc02364f advance online publication.

[38] B. Yu, H. Xing, D.-Q. Yu, H.-M. Liu, Beilstein. J. Org. Chem. 12 (2016) 1000-1039.

[39] A. Kumar, S.S. Chimni, RSC. Adv. 2 (2012) 9748-9762.

[40] P. Chauhan, S.S. Chimni, Tetrahedron. Asymmetry. 24 (2013) 343-356.

[41] J. Kaur, S.S. Chimni, S. Mahajan, A. Kumar, RSC. Adv. 5 (2015) 52481-52496.

[42] M. Groll, N. Gallastegui, X. Maréchal, et al., ChemMedChem. 5 (2010) 1701-1705.

[43] Y. Koguchi, J. Kohno, M. Nishio, et al., J. Antibiot. 53 (2000) 105-109.

[44] J.C. Menéndez, in: M.T.H. Khan (Ed.), Bioactive Heterocycles V, Springer Berlin Heidelberg, Berlin, Heidelberg, 2007, pp. 63-101.

[45] K.M. Allan, K. Kobayashi, V.H. Rawal, J. Am. Chem. Soc. 134 (2012) 1392-1395. 
[46] J.L. Wood, Nat. Chem. 4 (2012) 341-343.

[47] Y. Liu, L. Zhang, Y. Jia, Tetrahedron. Lett. 53 (2012) 684-687.

[48] G. Bergonzini, P. Melchiorre, Angew. Chem. Int. Ed. 124 (2012) 995-998.

[49] E.M.O. Yeboah, S.O. Yeboah, G.S. Singh, Tetrahedron. 67 (2011) 1725-1762.

[50] S.-K. Tian, Y. Chen, J. Hang, L. Tang, P. McDaid, L. Deng, Acc. Chem. Res. 37 (2004) 621-631.

[51] J. Duan, P. Li, Catal. Sci. Technol. 4 (2014) 311-320.

[52] Y. Yao, L. Xu, Mini-Reviews. Org. Chem. 13 (2016) 184-197.

[53] D. Sano, K. Nagata, T. Itoh, Org. Lett. 10 (2008) 1593-1595.

[54] Y.-H. Liao, Z.-J. Wu, W.-Y. Han, X.-M. Zhang, W.-C. Yuan, Chem. Eur. J. 18 (2012) 8916-8920.

[55] P. Chauhan, S.S. Chimni, Chem. Eur. J. 16 (2010) 7709-7713.

[56] J. Deng, S. Zhang, P. Ding, H. Jiang, W. Wang, J. Li, Adv. Synth. Catal. 352 (2010) 833-838.

[57] J. Kaur, A. Kumar, S.S. Chimni, RSC. Adv. 4 (2014) 62367-62374

[58] J. Kaur, A. Kumar, S.S. Chimni, Tetrahedron. Lett. 55 (2014) 2138-2141.

[59] D. Wu, X. Zhang, Y. Xu, et al., Asian. J. Org. Chem. 3 (2014) 480-486.

[60] X.-Y. Guan, Y. Wei, M. Shi, Chem. Eur. J. 16 (2010) 13617-13621.

[61] F. Zhong, G.-Y. Chen, Y. Lu, Org. Lett. 13 (2011) 82-85.

[62] Y.-L. Liu, B.-L. Wang, J.-J. Cao, et al., J. Am. Chem. Soc. 132 (2010) 15176-15178.

[63] P. Chauhan, S.S. Chimni, Asian. J. Org. Chem. 2 (2013) 586-592.

[64] Q. He, G. Zhan, W. Du, Y.-C. Chen, Beilstein. J. Org. Chem. 12 (2016) 309-313.

[65] Q. Guo, M. Bhanushali, C.-G. Zhao, Angew. Chem. Int. Ed. 49 (2010) 9460-9464.

[66] S. Allu, N. Molleti, R. Panem, V.K. Singh, Tetrahedron. Lett. 52 (2011) 4080-4083.

[67] S. Abbaraju, J.C.-G. Zhao, Adv. Synth. Catal. 356 (2014) 237-241.

[68] G.-G. Liu, H. Zhao, Y.-B. Lan, et al., Tetrahedron. 68 (2012) 3843-3850.

[69] I. Saidalimu, X. Fang, X.-P. He, J. Liang, X. Yang, F. Wu, Angew. Chem. Int. Ed. 125 (2013) 5676-5680.

[70] H. Liu, H. Wu, Z. Luo, et al., Chem. Eur. J. 18 (2012) 11899-11903.

[71] F. Zhong, W. Yao, X. Dou, Y. Lu, Org. Lett. 14 (2012) 4018-4021.

[72] A. Kumar, S.S. Chimni, Eur. J. Org. Chem. 2013 (2013) 4780-4786.

[73] N. Hara, S. Nakamura, Y. Funahashi, N. Shibata, Adv. Synth. Catal. 353 (2011) $2976-2980$.

[74] L. Peng, L.-L. Wang, J.-F. Bai, et al., Tetrahedron. Lett. 52 (2011) 1157-1160.

[75] M.-Q. Li, J.-X. Zhang, X.-F. Huang, et al., Eur. J. Org. Chem. 2011 (2011) $5237-5241$.

[76] P. Sai Prathima, K. Srinivas, K. Balaswamy, et al., Tetrahedron. Asymmetry. 22 (2011) 2099-2103.

[77] Y. Zhang, Z. Jun Li, H. Sen Xu, Y. Zhang, W. Wang, RSC. Adv. 1 (2011) 389-392.

[78] M. Ošeka, M. Kimm, S. Kaabel, I. Järving, K. Rissanen, T. Kanger, Org. Lett. 18 (2016) 1358-1361.

[79] S.J. Connon, Chem. Eur. J. 12 (2006) 5418-5427.

[80] Z. Zhang, P.R. Schreiner, Chem. Soc. Rev. 38 (2009) 1187-1198.

[81] W.-Y. Siau, J. Wang, Catal. Sci. Technol. 1 (2011) 1298-1310.

[82] O.V. Serdyuk, C.M. Heckel, S.B. Tsogoeva, Org. Biomol. Chem. 11 (2013) $7051-7071$.

[83] M. Retini, G. Bergonzini, P. Melchiorre, Chem. Commun. 48 (2012) $3336-3338$.

[84] B. Zhu, W. Zhang, R. Lee, et al., Angew. Chem. Int. Ed. 52 (2013) 6666-6670.

[85] H. Zhao, W. Meng, Z. Yang, et al., Chin. J. Chem. 32 (2014) 417-428.

[86] J. Shan, B. Cui, Y. Wang, et al., J. Org. Chem. 81 (2016) 5270-5277.

[87] Y. Chen, S. Yekta, A.K. Yudin, Chem. Rev. 103 (2003) 3155-3212.

[88] M. Shibasaki, S. Matsunaga, Chem. Soc. Rev. 35 (2006) 269-279.

[89] Z. Duan, Z. Zhang, P. Oian, J. Han, Y. Pan, RSC. Adv, 3 (2013) 10127-10130.

[90] D. Monge, A.M. Crespo-Peña, E. Martín-Zamora, E. Álvarez, R. Fernández, J.M. Lassaletta, Chem. Eur. J. 19 (2013) 8421-8425.

[91] B. List, Tetrahedron. 58 (2002) 5573-5590.

[92] C. Allemann, J.M. Um, K.N. Houk, J. Mol. Catal. Chem. 324 (2010) 31-38.

[93] S.K. Panday, Tetrahedron. Asymmetry. 22 (2011) 1817-1847.

[94] X.-Y. Chen, D. Enders, Inside. Chem. 4 (2018) 21-23.

[95] Y.-H. He, J.-F. Cao, R. Li, Y. Xiang, D.-C. Yang, Z. Guan, Tetrahedron. 71 (2015) 9299-9306.

[96] F. Xue, S. Zhang, L. Liu, W. Duan, W. Wang, Chem. Asian. J. 4 (2009) $1664-1667$.

[97] W.-B. Chen, X.-L. Du, L.-F. Cun, X.-M. Zhang, W.-C. Yuan, Tetrahedron. 66 (2010) 1441-1446.

[98] M. Raj, V.K. Singh, in: Catalytic Methods in Asymmetric Synthesis, John Wiley \& Sons, Inc., 2011, pp. 413-490.

[99] J.-R. Chen, X.-P. Liu, X.-Y. Zhu, et al., Tetrahedron. 63 (2007) 10437-10444.

[100] A.V. Malkov, M.A. Kabeshov, M. Bella, et al., Org. Lett. 9 (2007) 5473-5476.

[101] S. Nakamura, N. Hara, H. Nakashima, K. Kubo, N. Shibata, T. Toru, Chem. Eur. J. 14 (2008) 8079-8081.

[102] T.B.S. Giorno, Y.L.L. Ballard, M.S. Cordeiro, B.V. Silva, A.C. Pinto, P.D. Fernandes, Pharmacol. Biochem. Behav. 135 (2015) 13-19.

[103] G.S.M. Figueiredo, R.S. Zardo, B.V. Silva, F.A. Violante, A.C. Pinto, P.D. Fernandes, Pharmacol. Biochem. Behav. 103 (2013) 431-439.

[104] N. Hara, S. Nakamura, N. Shibata, T. Toru, Adv. Synth. Catal. 352 (2010) $1621-1624$.

[105] A.J. Pearson, S. Panda, Org. Lett. 13 (2011) 5548-5551.

[106] C. Cassani, P. Melchiorre, Org. Lett. 14 (2012) 5590-5593.

[107] A.J. Pearson, S. Panda, S.D. Bunge, J. Org. Chem. 78 (2013) 9921-9928.
[108] E.E. Manasanch, R.Z. Orlowski, Nat. Rev. Clin. Oncol. 14 (2017) 417.

[109] N. Richy, D. Sarraf, X. Maréchal, et al., Eur. J. Med. Chem. 145 (2018) 570-587.

[110] V. Pratap Reddy Gajulapalli, P. Vinayagam, V. Kesavan, Org. Biomol. Chem. 12 (2014) 4186-4191.

[111] J.P. Malerich, K. Hagihara, V.H. Rawal, J. Am. Chem. Soc. 130 (2008) $14416-14417$

[112] J. Alemán, A. Parra, H. Jiang, K.A. Jørgensen, Chem. Eur. J. 17 (2011) 6890-6899.

[113] R. Ian Storer, C. Aciro, L.H. Jones, Chem. Soc. Rev. 40 (2011) 2330-2346.

[114] P. Chauhan, S. Mahajan, U. Kaya, D. Hack, D. Enders, Adv. Synth. Catal. 357 (2015) 253-281.

[115] Y. Xiao, Z. Sun, H. Guo, O. Kwon, Beilstein. J. Org. Chem. 10 (2014) 2089-2121.

[116] Y. Xiao, H. Guo, O. Kwon, Aldrichim. Acta. 49 (2016) 3-13.

[117] D. Parmar, E. Sugiono, S. Raja, M. Rueping, Chem. Rev. 114 (2014) 9047-9153.

[118] J.-Y. Qian, C.-C. Wang, F. Sha, X.-Y. Wu, RSC. Adv. 2 (2012) 6042-6048.

[119] Z. Dong, C. Yan, Y. Gao, C. Dong, G. Qiu, H.-B. Zhou, Adv. Synth. Catal. 357 (2015) 2132-2142.

[120] C.W. Suh, C.W. Chang, K.W. Choi, Y.J. Lim, D.Y. Kim, Tetrahedron. Lett. 54 (2013) 3651-3654.

[121] M. Raj, N. Veerasamy, V.K. Singh, Tetrahedron. Lett. 51 (2010) 2157-2159.

[122] Popp, F. D.; Donigan, B. E. J Pharmacol Sci, 68, 519-520.

[123] Y. Liu, P. Gao, J. Wang, Q. Sun, Z. Ge, R. Li, Synlett. 237 (2012) 1031-1034.

[124] A. Kumar, S.S. Chimni, Tetrahedron. 69 (2013) 5197-5204.

[125] J. Agarwal, Org. Biomol. Chem. 14 (2016) 10747-10762.

[126] C. Shen, F. Shen, H. Xia, P. Zhang, X. Chen, Tetrahedron. Asymmetry. 22 (2011) 708-712.

[127] H. Dong, J. Liu, L. Ma, L. Ouyang, Catalysts. 6 (2016) 186.

[128] S. Kaneko, Y. Kumatabara, S. Shirakawa, Org. Biomol. Chem. 14 (2016) 5367-5376.

[129] Y. Yang, F. Moinodeen, W. Chin, T. Ma, Z. Jiang, C.-H. Tan, Org. Lett. 14 (2012) $4762-4765$.

[130] T. Sakai, S.-i. Hirashima, Y. Yamashita, et al., J. Org. Chem. 82 (2017) 4661-4667.

[131] H. Yang, R.G. Carter, Synlett. 2010 (2010) 2827-2838.

[132] P.G. McGarraugh, S.E. Brenner, Tetrahedron. 65 (2009) 449-455.

[133] J. Wang, Q. Liu, Q. Hao, Y. Sun, Y. Luo, H. Yang, Chirality. 27 (2015) 314-319.

[134] A.J. Burke, Tetrahedron. Lett. 57 (2016) 1197-1204.

[135] S. Handa, V. Gnanadesikan, S. Matsunaga, M. Shibasaki, J. Am. Chem. Soc. 132 (2010) 4925-4934.

[136] L. Ackermann, Chem. Rev. 111 (2011) 1315-1345.

[137] Z. Du, Z. Shao, Chem. Soc. Rev. 42 (2013) 1337-1378.

[138] H. Huo, X. Shen, C. Wang, et al., Nature. 515 (2014) 100.

[139] M.N. Hopkinson, B. Sahoo, J.-L. Li, F. Glorius, Chem. Eur. J. 20 (2014) 3874-3886.

[140] A.H. Cherney, N.T. Kadunce, S.E. Reisman, Chem. Rev. 115 (2015) 9587-9652.

[141] K. Shen, X. Liu, L. Lin, X. Feng, Chem. Sci. 3 (2012) 327-334.

[142] J.E.M.N. Klein, R.J.K. Taylor, Eur. J. Org. Chem. 2011 (2011) 6821-6841.

[143] N.V. Hanhan, A.H. Sahin, T.W. Chang, J.C. Fettinger, A.K. Franz, Angew. Chem. Int. Ed. 49 (2010) 744-747.

[144] N.V. Hanhan, Y.C. Tang, N.T. Tran, A.K. Franz, Org. Lett. 14 (2012) 2218-2221.

[145] N.V. Hanhan, N.R. Ball-Jones, N.T. Tran, A.K. Franz, Angew. Chem. Int. Ed. 124 (2012) 1013-1016.

[146] H.A. McManus, P.J. Guiry, Chem. Rev. 104 (2004) 4151-4202.

[147] H. Gao, Z. Luo, P. Ge, et al., Org. Lett. 17 (2015) 5962-5965.

[148] J. Nagamine, R. Nagata, H. Seki, et al., J. Endocrinol. 171 (2001) 481-489.

[149] D. Tomita, K. Yamatsugu, M. Kanai, M. Shibasaki, J. Am. Chem. Soc. 131 (2009) 6946-6948.

[150] R. Shintani, K. Takatsu, T. Hayashi, Chem. Commun. 46 (2010) 6822-6824.

[151] T. Deng, H. Wang, C. Cai, Eur. J. Org. Chem. 2014 (2014) 7259-7264.

[152] T. Deng, H. Wang, C. Cai, Org. Biomol. Chem. 12 (2014) 5843-5846.

[153] C. Li, F. Guo, K. Xu, et al., Org. Lett. 16 (2014) 3192-3195.

[154] Y. Naganawa, T. Aoyama, H. Nishiyama, Org. Biomol. Chem. 13 (2015) 11499-11506.

[155] N. Xu, D.-W. Gu, J. Zi, X.-Y. Wu, X.-X. Guo, Org. Lett. 18 (2016) 2439-2442.

[156] Y. Yamamoto, M. Yohda, T. Shirai, H. Ito, N. Miyaura, Chem. Asian. J. 7 (2012) 2446-2449.

[157] J. Gui, G. Chen, P. Cao, J. Liao, Tetrahedron. Asymmetry. 23 (2012) 554-563.

[158] X. Feng, Y. Nie, L. Zhang, J. Yang, H. Du, Tetrahedron. Lett. 55 (2014) 4581-4584.

[159] C.S. Marques, A.J. Burke, ChemCatChem. 8 (2016) 3518-3526.

[160] J. Totobenazara, P. Bacalhau, A.A.S. Juan, et al., J. ChemistrySelect. 1 (2016) $3580-3588$.

[161] M. Fernández-Ibañez, B. Maciá, D. Alonso, I. Pastor, Molecules. 18 (2013) 10108.

[162] N. Selander, K. Szabó, J. Chem. Rev. 111 (2011) 2048-2076.

[163] K. Ohmatsu, M. Ito, T. Kunieda, T. Ooi, Nat. Chem. 4 (2012) 473.

[164] J.W. Han, T. Hayashi, Tetrahedron. Asymmetry. 25 (2014) 479-484.

[165] L. Yin, M. Kanai, M. Shibasaki, Angew. Chem. Int. Ed. 123 (2011) 7762-7765.

[166] X.-C. Qiao, S.-F. Zhu, Q.-L. Zhou, Tetrahedron. Asymmetry. 20 (2009) $1254-1261$.

[167] K. Aikawa, S. Mimura, Y. Numata, K. Mikami, Eur. J. Org. Chem. 2011 (2011) 
62-65.

[168] Z. Liu, P. Gu, M. Shi, P. McDowell, G. Li, Org. Lett. 13 (2011) 2314-2317.

[169] S. Jayakumar, N. Kumarswamyreddy, M. Prakash, V. Kesavan, Org. Lett. 17 (2015) 1066-1069.

[170] E.G. Gutierrez, C.J. Wong, A.H. Sahin, A.K. Franz, Org. Lett. 13 (2011) 5754-5757.

[171] A. Yanagisawa, N. Kushihara, T. Sugita, K. Yoshida, Synlett. 23 (2012) 1783-1788.

[172] M. Shibasaki, N. Yoshikawa, Chem. Rev, 102 (2002) 2187-2210.

[173] J. Inanaga, H. Furuno, T. Hayano, Chem. Rev. 102 (2002) 2211-2226.

[174] K. Mikami, M. Terada, H. Matsuzawa, Angew. Chem. Int. Ed. 41 (2002) 3554-3571.

[175] Z. Duan, J. Han, P. Qian, Z. Zhang, Y. Wang, Y. Pan, Org. Biomol. Chem. 11 (2013) 6456-6459.

[176] S. Davey, Nat. Chem. (2010), https://doi.org/10.1038/nchem.669 online publication.

[177] C. Yuan, B. Liu, Org. Chem. Front. 5 (2018) 106-131.

[178] J. Itoh, S.B. Han, M. Krische, J. Angew. Chem. Int. Ed. 48 (2009) 6313-6316.

[179] Y. Zhuang, Y. He, Z. Zhou, et al., J. Org. Chem. 80 (2015) 6968-6975.

[180] T. Shirai, H. Ito, Y. Yamamoto, Angew. Chem. Int. Ed. 53 (2014) 2658-2661.

[181] T. Shirai, Y. Yamamoto, Organometallics. 34 (2015) 3459-3463.

[182] Z.-Y. Cao, Y. Zhang, C.-B. Ji, J. Zhou, Org. Lett. 13 (2011) 6398-6401.

[183] T. Bui, M. Borregan, C.F. Barbas, J. Org. Chem. 74 (2009) 8935-8938.

[184] L. Cheng, L. Liu, D. Wang, Y.-J. Chen, Org. Lett. 11 (2009) 3874-3877.

[185] T. Bui, G. Hernández-Torres, C. Milite, C.F. Barbas, Org. Lett. 12 (2010) 5696-5699.

[186] F. Zhou, M. Ding, Y.-L. Liu, et al., Adv. Synth. Catal. 353 (2011) 2945-2952.

[187] T. Zhang, L. Cheng, L. Liu, D. Wang, Y.-J. Chen, Tetrahedron. Asymmetry. 21 (2010) 2800-2806.

[188] N. Hara, S. Nakamura, M. Sano, R. Tamura, Y. Funahashi, N. Shibata, Chem. Eur. J. 18 (2012) 9276-9280.

[189] H. Kitamura, M. Okazaki, Osteoarthr. Cartil. 13 (2005) 287-296.

[190] M. Ochi, K. Kawasaki, H. Kataoka, Y. Uchio, H. Nishi, Biochem. Biophys. Res. Commun. 283 (2001) 1118-1123.

[191] W. Yan, D. Wang, J. Feng, P. Li, D. Zhao, R. Wang, Org. Lett. 14 (2012) 2512-2515.

[192] D. Wang, J. Liang, J. Feng, et al., Adv. Synth. Catal. 355 (2013) 548-558.

[193] A. Kumar, V. Sharma, J. Kaur, et al., Tetrahedron. 70 (2014) 7044-7049.
[194] A. Kumar, J. Kaur, S.S. Chimni, A.K. Jassal, RSC. Adv. 4 (2014) 24816-24819.

[195] H. Zhang, S.-J. Zhang, Q.-Q. Zhou, L. Dong, Y.-C. Chen, Beilstein. J. Org. Chem. 8 (2012) $1241-1245$.

[196] K. Zhao, T. Shu, J. Jia, G. Raabe, D. Enders, Chem. Eur. J. 21 (2015) 3933-3936.

[197] Y. Liu, Y. Liu, J. Wang, et al., Tetrahedron. Lett. 58 (2017) 2400-2403.

[198] X. Bao, B. Wang, L. Cui, et al., Org. Lett. 17 (2015) 5168-5171.

[199] X. Companyo, G. Valero, O. Pineda, et al., Org. Biomol. Chem. 10 (2012) $431-439$.

[200] L.-N. Jia, J. Huang, L. Peng, et al., Org. Biomol. Chem. 10 (2012) 236-239.

[201] B.-D. Cui, W.-Y. Han, Z.-J. Wu, X.-M. Zhang, W.-C. Yuan, J. Org. Chem. 78 (2013) 8833-8839.

[202] F.-L. Hu, Y. Wei, M. Shi, S. Pindi, G. Li, Org. Biomol. Chem. 11 (2013) $1921-1924$.

[203] X. Zhao, T.-Z. Li, J.-Y. Qian, F. Sha, X.-Y. Wu, Org. Biomol. Chem. 12 (2014) 8072-8078.

[204] L.-J. Zhou, Y.-C. Zhang, F. Jiang, et al., Adv. Synth. Catal. 358 (2016) 3069-3083.

[205] K. Ohmatsu, M. Kiyokawa, T. Ooi, J. Am. Chem. Soc. 133 (2011) 1307-1309.

[206] N. Ríos-Lombardía, R. Porcar, E. Busto, et al., ChemCatChem. 3 (2011) $1921-1928$.

[207] K. Ohmatsu, Y. Ando, T. Nakashima, T. Ooi, Inside. Chem. 1 (2016) 802-810.

[208] S. Lu, S.B. Poh, W.-Y. Siau, Y. Zhao, Angew. Chem. Int. Ed. 52 (2013) $1731-1734$.

[209] S. Lu, S.B. Poh, W.-Y. Siau, Y. Zhao, Synlett. 24 (2013) 1165-1169.

[210] Z. Yang, Z. Wang, S. Bai, et al., Chem. Eur. J. 16 (2010) 6632-6637.

[211] K. Shen, X. Liu, G. Wang, L. Lin, X. Feng, Angew. Chem. Int. Ed. 123 (2011) 4780-4784.

[212] S. Mouri, Z. Chen, H. Mitsunuma, M. Furutachi, S. Matsunaga, M. Shibasaki, J. Am. Chem. Soc. 132 (2010) 1255-1257.

[213] T. Arai, E. Matsumura, H. Masu, Org. Lett. 16 (2014) 2768-2771.

[214] M. Zhao, N.-K. Li, Y.-F. Zhang, F.-F. Pan, X.-W. Wang, Tetrahedron. 72 (2016) $1406-1414$.

[215] L. Ren, X.-L. Lian, L.-Z. Gong, Chem. Eur. J. 19 (2013) 3315-3318.

[216] Z.-Q. Wang, C.-G. Feng, M.-H. Xu, G.-Q. Lin, J. Am. Chem. Soc. 129 (2007) $5336-5337$.

[217] C.S. Marques, A. Burke, J. Eur. J. Org. Chem. 2016 (2016) 806-812.

[218] P. Tolstoy, S.X.Y. Lee, C. Sparr, S.V. Ley, Org. Lett. 14 (2012) 4810-4813. 